\title{
AN INVESTIGATION INTO LOW VELOCITY IMPACT OF 3D PRINTED THERMOPLASTIC PLATES
}

by

Guneet Kaur Mankoo

Bachelor of Engineering, PEC University Of Technology, Chandigarh, India (2018)

\author{
A project \\ presented to Ryerson University \\ in partial fulfilment of the \\ requirements for the degree of \\ Master of Engineering \\ in the program of \\ Aerospace Engineering
}

Toronto, Ontario, Canada, 2020

(C)Guneet Kaur Mankoo, 2020 


\section{AUTHOR'S DECLARATION FOR ELECTRONIC SUBMISSION OF A PROJECT}

I hereby declare that I am the sole author of this project. This is a true copy of the project, including any required final revisions.

I authorize Ryerson University to lend this project to other institutions or individuals for scholarly research.

I further authorize Ryerson University to reproduce this project by photocopying or by other means, in total or in part, at the request of other institutions or individuals for the purpose of scholarly research.

I understand that my project may be made electronically available to the public. 


\title{
AN INVESTIGATION INTO LOW VELOCITY IMPACT OF 3D PRINTED THERMOPLASTIC PLATES
}

\author{
Guneet Kaur Mankoo \\ Master of Engineering, Aerospace Engineering, Ryerson University, Toronto
} (2020)

\section{ABSTRACT}

PolyLactic Acid (PLA) is the most widely used material for 3D printing, especially in industrial applications. PLA is an environment-friendly material as it is biodegradable and has high stiffness and low cost. But PLA shows brittle nature when subjected to out-of-plane loading, i.e. impact. Hence, in this paper, a pendulum impact test apparatus was used to perform impact tests and understand the impact damage characteristics of 3D printed PLA coupons. A high-speed and an infra-red camera were used to investigate the impact damage characteristics of the coupons and understand the failure mechanisms. 24 coupons were printed on a Prusa i3 MK2S 3D printer with a $0^{\circ}$ raster angle and different layer thickness. The layer thickness was varied from $0.10 \mathrm{~mm}$ to $0.18 \mathrm{~mm}$ and the coupons were impacted with 3 $\mathrm{J}$ impact energy at two different impact locations, which were, at the center and near the upper clamped edge. For impact at the center of the specimen, the absorbed energy first increased and then decreased and the coupons with higher absorbed energy showed more damage. The absorbed energy was always higher for the coupons impacted at the second location, i.e. near the clamped edge with an only exception in the case of $0.16 \mathrm{~mm}$ layer thickness. Coupons with $0.16 \mathrm{~mm}$ layer thickness had the highest absorbed energy percentage for the impact to the plate center, however for the impact near the clamped edge, $0.12 \mathrm{~mm}$ layer thickness had the highest absorbed energy percentage. Specimens with cracks in the direction perpendicular to the orientation absorb more energy than the specimens with cracks in the direction of extrudates. And specimens with only horizontal or vertical cracks absorb less energy than the coupons with cracks in multiple directions. 


\section{ACKNOWLEDGMENT}

First, I would like to thank my supervisors Dr. Zouheir Fawaz and Dr. Kazem Fayazbakhsh of the Department of Aerospace Engineering at Ryerson University. Their valued guidance and support helped me advance my knowledge and understanding in the field of 3D printing, thermoplastics, and testing standards. Their continuous feedback has been very significant in steering my project work in the right direction.

Likewise, I would like to express my gratitude to Dr. Kazem Fayazbakhsh for his contribution during the manufacturing and testing phases of my project.

Finally, I would like to thank my family for their understanding, support, and encouragement throughout the course of this project. 


\section{TABLE OF CONTENTS}

$\begin{array}{ll}\text { ABSTRACT } & \text { iii }\end{array}$

ACKNOWLEDGMENT

LIST OF TABLES $\quad$ vi

LIST OF FIGURES $\quad$ vii

1 Introduction 1

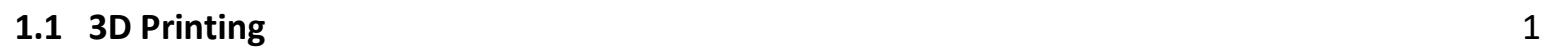

1.2 Fused Filament Fabrication (FFF) 1

$\begin{array}{ll}1.3 \text { Various Process Parameters } & 2\end{array}$

2 Literature Review $\quad 3$

2.1 Effect of Layer Thickness and Raster Width 4

2.2 Effect of Raster Angle 9

2.3 Effect of Infill Pattern, Orientation and Infill Percentage 11

2.4 Effect of Impact Energy and Layer Thickness on Low Velocity Impact Properties 16

$\begin{array}{lll}2.5 & 23 \\ \end{array}$

3 Methodology 25

\begin{tabular}{ll}
3.1 & Testing Apparatus \\
\hline
\end{tabular}

$\begin{array}{ll}3.2 & \text { Test Plan } \\ \end{array}$

3.3 Specimen Manufacturing $\quad 32$

$\begin{array}{ll}3.4 & 34\end{array}$

4 Results and Discussion $\quad 38$

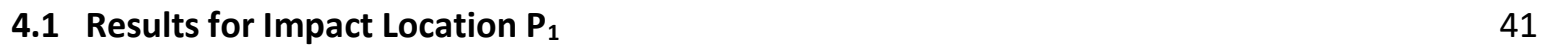

$\begin{array}{lll}4.2 & \text { Results for Impact Location } P_{2} & 47\end{array}$

5 Conclusions and Future Work 56

$\begin{array}{ll}\text { APPENDIX } & 58\end{array}$

$\begin{array}{lr}\text { REFERENCES } & 70\end{array}$ 


\section{LIST OF TABLES}

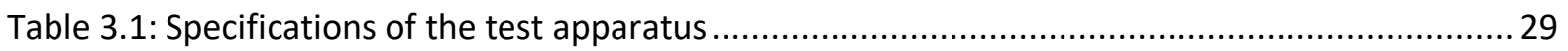

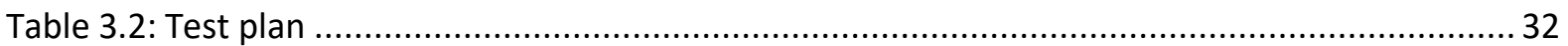

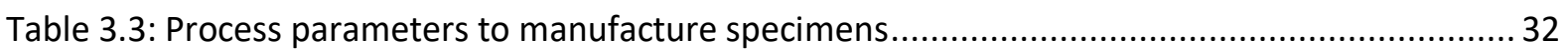

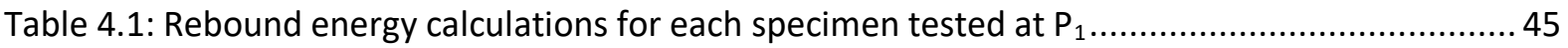

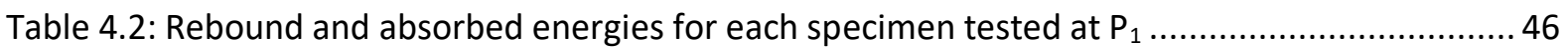

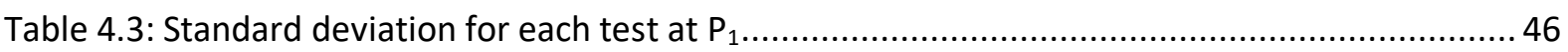

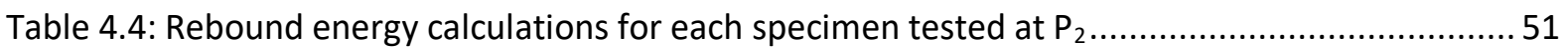

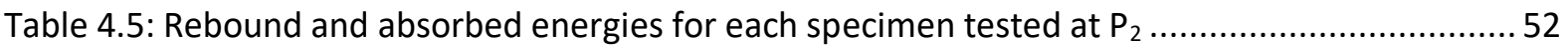

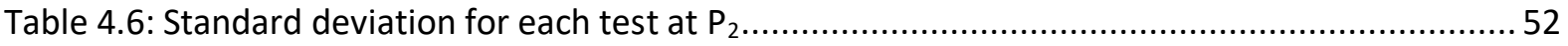

Table 4.7: Comparison of Absorbed energy percentages between $P_{1}$ and $P_{2}$ impact locations.......... 54 


\section{LIST OF FIGURES}

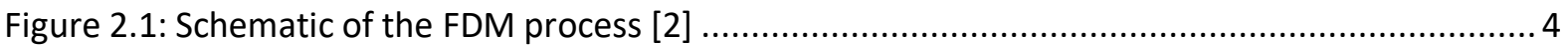

Figure 2.2: Representation of raster width and layer thickness/height [2]...................................... 5

Figure 2.3: Different built orientations used in this study [4].................................................. 7

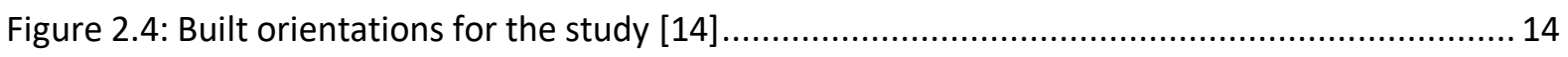

Figure 3.1: The Standard mechanism of Charpy and Izod Impact tests [32] ................................... 25

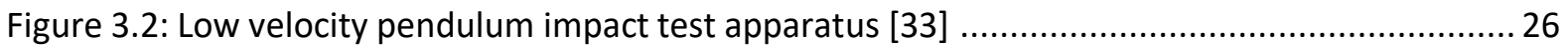

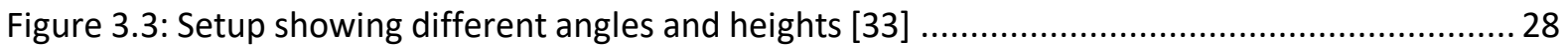

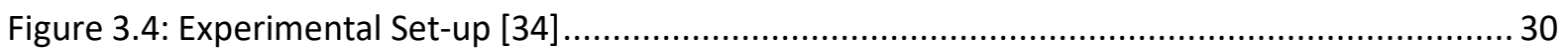

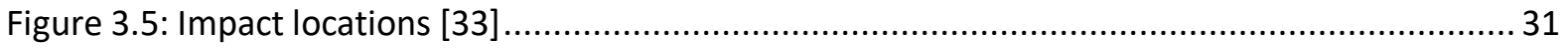

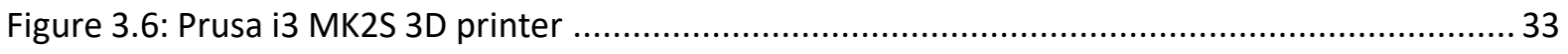

Figure 3.7: 3D Printed PLA plate before testing: (a) for location P1 (b) for location P2 .................... 34

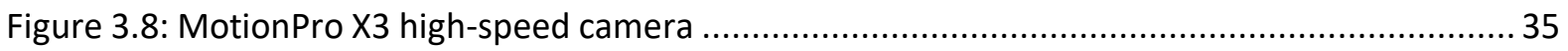

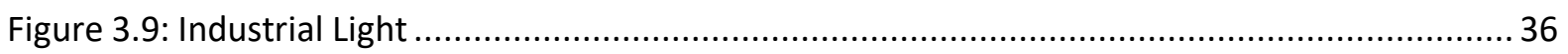

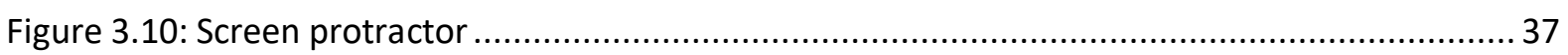

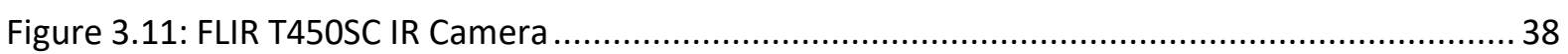

Figure 4.1: Specimens for location $\mathrm{P}_{1}$ with 25 layers: (a) specimen after testing; (b) thermal imaging

Figure 4.2: Specimens for location $\mathrm{P}_{1}$ with 21 layers: (a) specimen after testing; (b) thermal imaging

Figure 4.3: Specimens for location $\mathrm{P}_{1}$ with 16 layers: (a) specimen after testing; (b) thermal imaging

Figure 4.4: Specimens for location $\mathrm{P}_{1}$ with 14 layers: (a) specimen after testing; (b) thermal image 44

Figure 4.5: Specimens for location $\mathrm{P}_{1}$ with 14 layers: (a) specimen after testing; (b) thermal imaging

Figure 4.6: Absorbed energy percentage versus layer thickness at $\mathrm{P}_{1}$ location

Figure 4.7: Specimens for location $\mathrm{P}_{2}$ with 25 layers: (a) specimen after testing; (b) thermal imaging

Figure 4.8: Specimens for location $P_{2}$ with 21 layers: (a) specimen after testing; (b) thermal image 49 Figure 4.9: Specimens for location $\mathrm{P}_{2}$ with 21 layers: (a) specimen after testing; (b) thermal imaging 
Figure 4.10: Specimens for location $\mathrm{P}_{2}$ with 16 layers: (a) specimen after testing; (b) thermal imaging

Figure 4.11: Specimens for location $\mathrm{P}_{2}$ with 14 layers: (a) specimen after testing; (b) thermal imaging 51

Figure 4.12: Absorbed energy percentage versus layer thickness at $\mathrm{P}_{2}$ location 53

Figure 7.1: $1^{\text {st }}$ specimen for case ID 1a: (a) specimen after testing; (b) thermal image...................... 58

Figure 7.2: $2^{\text {nd }}$ specimen for case ID 1a: (a) specimen after testing; (b) thermal image ......................58

Figure 7.3: $3^{\text {rd }}$ specimen for case ID 1a: (a) specimen after testing; (b) thermal image ..................... 59

Figure 7.4: $1^{\text {st }}$ specimen for case ID 1b: (a) specimen after testing; (b) thermal image...................... 59

Figure 7.5: $2^{\text {nd }}$ specimen for case ID 1b: (a) specimen after testing; (b) thermal image ..................... 60

Figure 7.6: $3^{\text {rd }}$ specimen for case ID 1b: (a) specimen after testing; (b) thermal image ..................... 60

Figure 7.7: $1^{\text {st }}$ specimen for case ID 1c: (a) specimen after testing; (b) thermal image ...................... 61

Figure 7.8: $2^{\text {nd }}$ specimen for case ID 1c: (a) specimen after testing; (b) thermal image ..................... 61

Figure 7.9: $3^{\text {rd }}$ specimen for case ID 1c: (a) specimen after testing; (b) thermal image......................62

Figure 7.10: $1^{\text {st }}$ specimen for case ID 1d: (a) specimen after testing; (b) thermal image.................... 62

Figure 7.11: $2^{\text {nd }}$ specimen for case ID 1d: (a) specimen after testing; (b) thermal image .................... 63

Figure 7.12: $3^{\text {rd }}$ specimen for case ID 1d: (a) specimen after testing; (b) thermal image ...................63

Figure 7.13: $1^{\text {st }}$ specimen for case ID 2a: (a) specimen after testing; (b) thermal image .................... 64

Figure 7.14: $2^{\text {nd }}$ specimen for case ID 2a: (a) specimen after testing; (b) thermal image .................... 64

Figure 7.15: $3^{\text {rd }}$ specimen for case ID 2a: (a) specimen after testing; (b) thermal image ................... 65

Figure 7.16: $1^{\text {st }}$ specimen for case ID 2b: (a) specimen after testing; (b) thermal image.....................65

Figure 7.17: $2^{\text {nd }}$ specimen for case ID $2 \mathrm{~b}$ : (a) specimen after testing; (b) thermal image ....................66 66

Figure 7.18: $3^{\text {rd }}$ specimen for case ID 2b: (a) specimen after testing; (b) thermal image ....................66

Figure 7.19: $1^{\text {st }}$ specimen for case ID 2c: (a) specimen after testing; (b) thermal image .................... 67

Figure 7.20: $2^{\text {nd }}$ specimen for case ID 2c: (a) specimen after testing; (b) thermal image ...................67

Figure 7.21: $3^{\text {rd }}$ specimen for case ID 2c: (a) specimen after testing; (b) thermal image..................... 68

Figure 7.22: $1^{\text {st }}$ specimen for case ID 2d: (a) specimen after testing; (b) thermal image.....................68

Figure 7.23: $2^{\text {nd }}$ specimen for case ID 2d: (a) specimen after testing; (b) thermal image ...................69

Figure 7.24: $3^{\text {rd }}$ specimen for case ID 2d: (a) specimen after testing; (b) thermal image ...................69 


\section{Introduction}

\subsection{D Printing}

3D printing also known as Additive Manufacturing (AM) or Rapid Prototyping (RP) is a technique to develop structures and parts using three-dimensional model data. Using this technique, parts can be developed with complex shapes and geometries. The threedimensional model is built layer by layer and the shape, angle, infill percentage are defined for each layer. The technique of 3D printing for fabricating parts was introduced in 1980s and ever since then extensive research has been going on this topic and with the on-going research and improving technology, 3D printing is used in aerospace, mechanical, civil and biomedical industries. Initially, this technology was only used to print plastics but now it can print metal, alloys, nanomaterials, composites, etc. Although 3D printing can be used to fabricate complex geometries with low cost and waste, one of the major drawbacks is that it is really difficult to print large structures as it becomes expensive and complex due to the size. 3D printing consists of various different methods some of which develop parts with mechanical properties comparable to injection molding parts. Various types of techniques included in 3D printing are fused filament fabrication (FFF), selective laser sintering (SLS), stereolithography (SLA), inkjet 3D printing (3DP), direct energy deposition (DED). Out of all these techniques, FFF will be discussed in detail below [1,2].

\subsection{Fused Filament Fabrication (FFF)}

Fused Filament Fabrication (FFF) also known as Fused Deposition Modelling (FDM) is one of the most popular additive manufacturing technology. In this technique, parts can be printed using a range of materials including fiber reinforced composites with less cost and waste. In this process, the material is fed to the printer in the form of a spool and the material from this spool goes into the liquefier head and the material is heated to get to a semi-liquid stage. The extrusion nozzle lays the material onto the printing bed in the desired shape, angle and 
pattern. The shape along with other process parameters such as layer thickness, number of layers, raster angle, raster width, infill percentage, orientation, etc. are fixed at an earlier stage. Choosing the correct value of these properties is important as the mechanical properties of the final printed part will depend on these properties. The nozzle and the bed temperatures are fixed and maintained at a constant value throughout the printing process, and usually, the bed temperature is lower than the nozzle temperature. To print a three dimensional part, the nozzle moves in a 2-D plane and the bed moves in the third direction. One of the major drawbacks of using FFF as an additive manufacturing technology is that only materials having low glass transition temperature and high viscosity can be used to print parts and the final printed parts are anisotropic in nature $[3,4]$.

\subsection{Various Process Parameters}

As mentioned before, process parameters are important when 3D printing coupons. Hence some of the process parameters are defined below.

- Layer Thickness - The thickness of the layer deposited by the nozzle tip. The layer thickness depends on the nozzle type $[5,6]$.

- Raster Angle - The inclination of the raster relative to the $\mathrm{x}$-axis of the built table $[5,6,7]$.

- Raster Width - Width of the raster pattern or the material bead to fill the interior region of the layer $[5,6,7]$.

- Orientation - The angle of the part on the build platform with respect to the $X, Y, Z$ axis. The orientation can be horizontal, vertical or perpendicular [6,7].

- Air Gap - This is usually defined for two ratsers as the gap between two adjacent rasters in the same layer $[6,7]$. 


\section{Literature Review}

Dizon et. al. [8] gave an overview of the various Additive Manufacturing (AM) techniques to produce high print qualities. Recently there have been many advancements in the AM technologies. Hence in this paper, various AM technologies such as Fused Deposition Modelling (FDM), Stereolithography (SLA), Digital Light Processing (DLI), Selective Layer Sintering (SLS), Three-Dimensional Printing (3DP), Laminated Object Manufacturing (LOM) were studied and following that the ASTM and ISO mechanical test standards were explained. The mechanical tests include tensile, bending, compression, fatigue and impact tests.

Out of all the additive manufacturing techniques mentioned above, Fused Filament Fabrication (FFF) is the most widely used technique for manufacturing thermoplastics. In FFF, 3D parts are manufactured by pushing the semi-solid material through a nozzle onto a bed. The nozzle moves in $X-Y$ direction and the bed moves in $Z$ direction or in some cases, the nozzle moves in $X-Z$ direction and the bed moves in the $Y$ direction to produce a threedimensional part [5]. A schematic of the FDM process is shown below: 


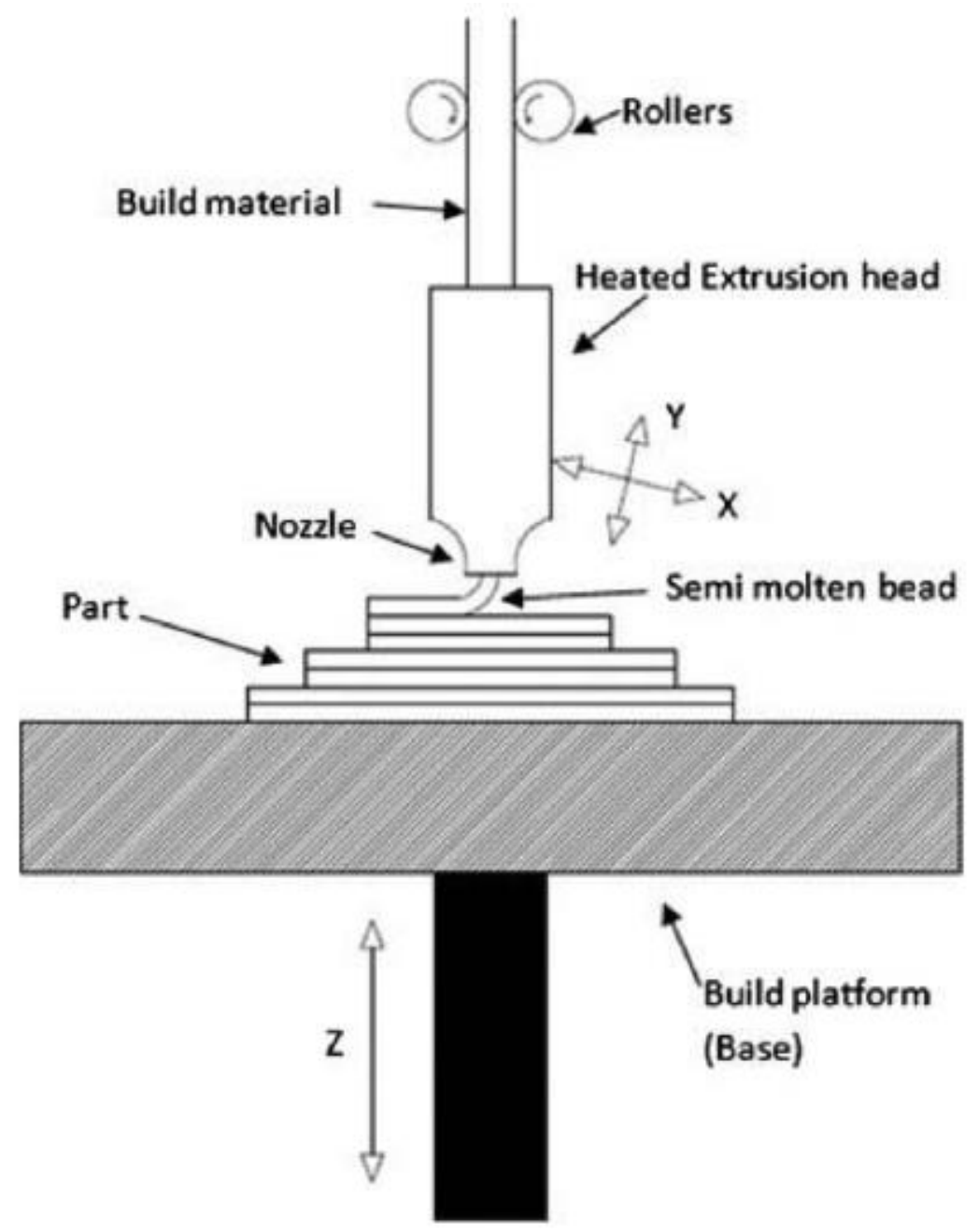

Figure 2.1: Schematic of the FDM process [2]

\subsection{Effect of Layer Thickness and Raster Width}

The mechanical properties of various FFF printed parts have been widely studied along with the effect of different process parameters such as layer thickness, raster angle, and raster width on tensile, fatigue and impact strength. 


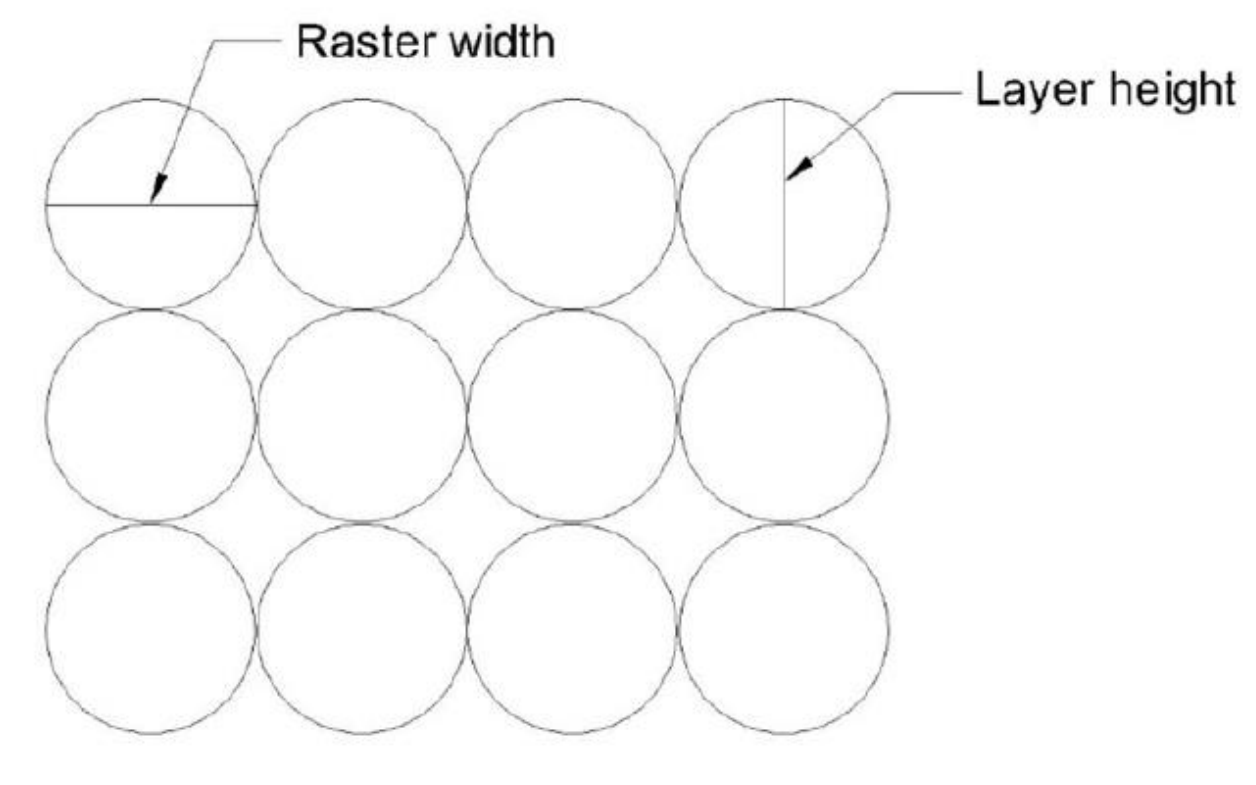

Figure 2.2: Representation of raster width and layer thickness/height [2]

Rajpurohit et. al. [5] studied the variation of tensile strength with layer thickness, raster angle, and raster width for PLA parts printed using the FFF technique. The authors performed 100 different experiments with five variations in raster angle and layer thickness and four variations in raster width. The specimens were produced, and tests were performed according to the ASTM D638 standard. It was observed that there was a decrease in the tensile strength with an increase in raster angle for every value of raster width. This is expected since in the case of low raster angle the load is divided between each raster as all rasters are almost parallel to the loading direction. Also, the highest value of tensile strength was at the lowest value of layer thickness due to strong bonding between layers and the absence of voids at lower layer thicknesses. Finally, they found that the tensile strength first increases with raster width due to high bond strength, but then decreases due to the voids between two adjacent rasters caused by large width.

Ning et. al. [9] mentioned that along with pure thermoplastics, FFF is one of the best techniques to manufacture Carbon Fiber Reinforced Plastic (CFRP) parts as well. CFRP's are superior composites with high strength to weight ratio, good resistance to corrosion, wear and fatigue and they are light weighted as well. CFRP composites were manufactured by various open-mold and close-mold processes, but these procedures have a long cycle time 
and high production cost, which make it difficult to meet the increasing demand in the industry. Acrylonitrile-butadiene-styrene (ABS) was chosen for CFRPs. The authors conducted tensile tests to study the tensile behavior of the manufactured parts and fracture interfaces were observed under a field emission scanning electron microscope (FE-SEM). For this experiment, the material was manufactured with $5 \mathrm{wt} \%$ carbon fiber due to high tensile properties at this weight percentage. The tests were performed according to ASTM D638 standards to study the effect of layer thickness, raster angle, infill speed and nozzle temperature on tensile properties. To make the experiment more cost-effective, the specimens were scaled down to $50 \%$ as the tensile properties are not affected by the scale of the specimen. They investigated tensile strength, Young's modulus, yield strength, toughness, and ductility. From the experiments it was concluded that the $[0,90]$ raster angle showed higher values of tensile strength, young's modulus and yield strength due to a strong bond between the fiber and matrix, while for $[-45,45]$ the fibers were pulled out of the matrix due to poor interfacial adhesion. Even with this, the latter showed high values of toughness and ductility. With an increase in the infill speed, the tensile properties showed varying trends as the yield strength first increased then decreased, but all other properties first decreased then increased. All the properties had the highest values at $25 \mathrm{~m} / \mathrm{s}$ as at this speed the void formation was minimum and the rasters had a more compact interaction with each other. All the tensile properties exhibited highest values at a middle nozzle temperature value of 220 degrees since at a temperature less than this value, the inter-bonding between rasters was very weak and at a temperature higher than this value the void formation increased. Also, tensile strength, Young's modulus, and yield strength decreased with an increase in the layer thickness. However, toughness and ductility first increased then decreased. It was suggested that the above-mentioned trend, i.e. the decrease of Young's modulus, tensile strength, and yield strength is because of the large inter-bonding strength at small layer thicknesses and also the fact that deformations caused at these values fill up the voids reducing porosity.

ABS is also a commonly used material for FFF processes due to its excellent mechanical response, chemical resistance, and good processing characteristics [4]. In a study done by Vidakis et. al. [10] tensile strength of parts manufactured by FFF using ABS material was analyzed and compared to the bulk ABS filament. After the experiments, the fracture surfaces were studied under a SEM microscope to understand failure modes. In the experiment, the 
coupons were produced using two different machines with two different materials in three build orientations (shown in figure 2.3 ) and two-layer thicknesses $(0.1778 \mathrm{~mm}, 0.2540 \mathrm{~mm}$ for $A B S$ and $0.2540 \mathrm{~mm}, 0.3302 \mathrm{~mm}$ for ABS plus) for each machine/material.

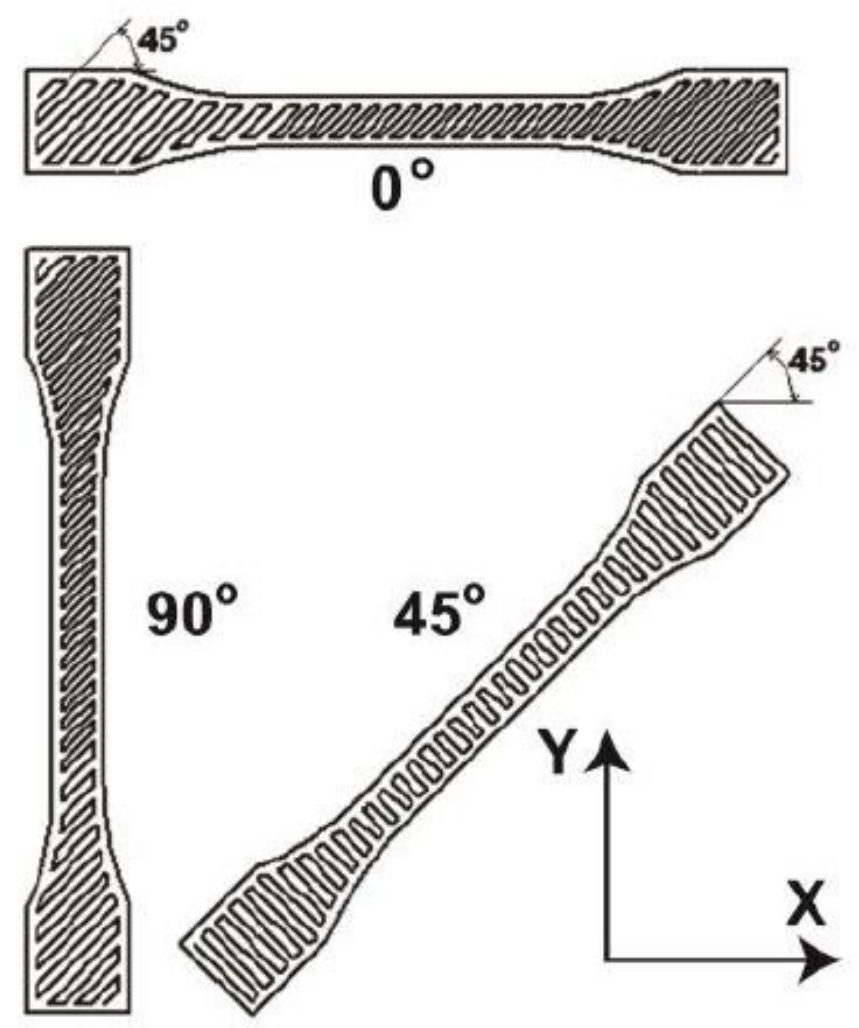

Figure 2.3: Different built orientations used in this study [4]

One machine used ABS material, while the other used ABS plus material which has improved mechanical properties compared to ABS. The authors kept the raster angle constant for each specimen; however, the build orientations were changed to understand the anisotropic behavior of FFF manufactured parts. The results showed that all the ABS material specimens showed similar values of properties, but the coupon at 90-degree orientation and $0.25 \mathrm{~mm}$ layer thickness had the lowest values of tensile strength. In general, the ABS plus material displayed higher values of tensile strength compared with ABS material coupons with the lowest values at 45-degree orientation in both cases. The authors argued that the variation of the properties was due to the bond between the adjacent rasters and the anisotropic behavior of the parts. This might be the reason that as the thickness increases the strength of the $A B S$ material coupons decreases, but for the ABS plus material coupons the strength increases. The Young's modulus and the strain values are almost the same in all the cases with 
one variation at 0 -degree orientation. At this orientation, the strain values were significantly higher showing ductility. The SEM images show that the fracture for ABS material at a 45degree raster angle is brittle; however, at 0 and 90 degrees the failure was ductile in nature. It was concluded that the mechanical properties depend heavily on the build orientation of the part and in general, 3D printed parts showed less strength than nominal filaments with the strength values for $A B S$ material reaching closer to the nominal value than $A B S$ plus material.

Along with the experiments, some researchers also worked on the finite element analysis of FFF printed parts under tensile loading. Garg et. al. [11] analyzed the variation of tensile strength with layer thickness and raster angle with generating a realistic Finite Element (FE) model to study the elastoplastic behavior of each raster. In addition, optical microscopic and SEM images were used to study the failure modes. ABS feedstock was used to manufacture parts by the FFF technique. To generate the FE model, first microscopic measurements were taken of the specimen to create a model and then the model was trimmed according to the layer thickness and raster angle. For building the FE model, a tetrahedron mesh was chosen to mesh all the rasters properly without increasing the computational time by making a very fine mesh. In the FE model, one end of the part was kept fixed, while the load was applied to the other end. The authors observed that an increase in layer thickness resulted in an increase in inter-layer and intra-layer necking. The results showed that the tensile strength first decreases with increasing layer thickness, but then increases. For the 90-degree raster angle, the main reason for failure was the separation of layers from the adjacent bonds and delamination, which further concluded that the failure for specimens with a 90-degree raster angle does not depend on the layer thickness. And for the 0-degree angle, the failure was brittle in nature. All these FE results were validated by experimental data and fractographic images as well.

In a study by Sood et. al. [6], the effect of layer thickness, orientation, raster angle, raster width, and air gap on the tensile, flexural, and impact strength of FFF printed parts using ABS material was investigated. The authors attempted to obtain an empirical relation between the processing parameters and mechanical properties using response surface methodology. To derive the empirical model, the tests were conducted based on Central Composite Design 
(CCD). For determination of tensile properties, ISO R527:1996 standards were used and ISO R178:1975 standard was used for flexural properties. In the three-point bending test, the specimen was fixed at two ends and load was applied in the middle till the specimen failed. For the impact testing, ISO R179:1982 standard was used to perform tests on a pendulum test machine. The specimens were impacted at $3.8 \mathrm{~m} / \mathrm{s}$ impact speed and toughness was calculated based on the absorbed energy. Three different variations for all the processes parameters were chosen and three tests were performed for each case. The experimental results were analyzed with the help of MINITAB R14 software and it was concluded that a quadratic model satisfies all the tensile, flexural and impact strength values. In the model, it was found that the tensile strength is affected by all the terms in the quadratic model, whereas the flexural strength does not depend on the square terms and the interaction terms do not affect the impact strength of the part. The model was concluded to be fairly accurate as only $6 \%, 3 \%$, and $2 \%$ error was calculated between the model and experimental values for tensile, flexural, and impact strength, respectively. The effect of various process parameters was examined, and it was observed that the number of layers depends on the layer thickness and part orientation and as the number of layers increase, the strength improves due to more diffusion between rasters as a result of the high-temperature gradient at the bottom part. Small raster angle and high raster width result in improved strength since small-angle rasters are almost aligned with the loading direction and the stress accumulation along the width for thick rasters improves diffusion. The authors also concluded that the air gap has an effect on the strength, where zero air gap results in improved diffusion between the adjacent rasters.

\subsection{Effect of Raster Angle}

Carneiro et. al. [12] performed experiments on FFF printed polypropylene (PP) to study the effect of the raster angle. For the experiments. two grades of PP were used: a glass fiber reinforced (GRPP) and a neat polypropylene (PP). PP has a lot of industrial applications, e.g. in textile, medical devices, automotive, aeronautics, etc. In the aeronautics industry, the glass-reinforced PP finds more use than the neat polypropylene due to better thermal and mechanical properties of the glass-reinforced grades. For a better understanding of the FFF technique, the parts manufactured by FFF were compared to the parts fabricated using 
compression molding for their tensile strength. Due to a lack of literature on polypropylene, to determine the optimal printing conditions for GRPP and PP, several print runs were conducted, where the bed temperature was fixed to room temperature and the nozzle temperature was chosen to be $165^{\circ} \mathrm{C}$ for PP and $185^{\circ} \mathrm{C}$ for GRPP. To manufacture the parts and study the tensile properties, five different variations in the raster angle were chosen along with three variations in the infill degree and two for the layer thicknesses. Parts were manufactured according to the DIN 53504-S3a standard using FFF and compression molding techniques. From the tensile tests, it was concluded that the strength is more for lower raster angles. In addition, the parts manufactured by compression molding exhibited better mechanical properties as comparted to the 3D printed ones due to the presence of voids in the latter ones. The results also showed that the properties of GRPP printed samples were very close to the PP compression-molded ones showing the effect of glass fiber reinforcements on pure PP.

Another study done by Afrose et. al. [13] was also focused on the effect of the raster angle on the tensile properties of parts processed by FFF. They 3D printed parts in three different raster angles (0,90 and 45 degrees) out of PLA filaments using a small 3D printer (Cube-2). Dog-bone shaped specimens were printed according to ASTM D638 standards with a constant layer thickness of $0.20 \mathrm{~mm}$ and tensile tests were performed on the specimens. It was concluded that the specimens with rasters aligned in the direction of loading showed higher values of tensile strength and modulus. In addition, failure for 0 and 90-degree specimens occurred at the neck region, but for 45-degree one's failure was near the middle part.

Some authors attempted to use the Genetic Algorithm (GA) and Response Surface Model (RSM) to develop the regression equation to determine the optimal input parameters so as to maximize tensile strength and density [7]. To obtain the regression equation, three different levels of raster angle, raster width, and air gap were chosen, and parts were printed using $A B S$ material. The values obtained with the help of the model for the tensile strength and density only showed $1.87 \%$ and $0.75 \%$ deviation from the experimental values, respectively. Thus, it can be concluded that RSM is a helpful tool to determine the optimum values of process parameters prior to manufacturing. It can also be seen that as the raster angle decreases, and the raster width and the air gap increase, the tensile strength of the 
parts also increase due to better heat transfer and less stress accumulation. Similar to the trend exhibited by the tensile strength, the density has a maximum at the lowest chosen value of raster angle and highest chosen value of raster width. Furthermore, the tensile strength has its maximum value when the build orientation is flat, but density is maximum for vertical orientation.

The work of Dawoud et al. [14] was focused on determining the impact of the build parameters, like the raster angle and air gap on the mechanical properties of 3D printed parts and comparing these properties to the injection molding specimens. They evaluated the following properties: density, impact strength, flexural strength, impact strength, and dimensional accuracy. In their experiments, the authors chose crisscross meshing systems, in which even layers had a positive raster angle and odd layers had a negative raster angle. From the experiments, it can be found that at positive air gaps the strength depends highly on the raster angle, where rasters aligned in the direction of stress carry the maximum amount of load and provide strength. It was also shown that negative air gaps provided enhanced mechanical properties and high density in a 3D printed part. Furthermore, for the parts printed with +/- 45-degree raster angle and a negative air gap the mechanical properties were high enough to be compared to the injection-molded specimens. Finally, the printed parts showed acceptable dimensional accuracy and it was found that the dimensional accuracy was independent of the raster angle and the air gap.

\subsection{Effect of Infill Pattern, Orientation and Infill Percentage}

Efforts were made to relate the change in infill pattern, infill percentage and build orientation to the tensile and fatigue strength. Work done by Gomez-Gras et. a. [15] focuses on the fatigue strength of FFF printed PLA specimens. The authors studied the effect of build orientation and infill strategy on fatigue strength by subjecting the specimens to dynamic loading. The infill strategy consists of both the infill pattern and the infill percentage. Along with the two process parameters discussed above, the effects of nozzle diameter, layer height, and printing velocity were also considered. The two infill patterns considered in this study were a rectilinear pattern and a honeycomb pattern. The rectilinear is the most widely 
used pattern but the honeycomb pattern shows good mechanical properties. Four different levels of infill density, nozzle diameter, and printing velocity were chosen. In total, to account for all the process parameters, 54 specimens were printed. From the tests, it was concluded that the fatigue strength was influenced the most by infill density and then the nozzle diameter and lastly by the layer thickness. The specimens with honeycomb infill patterns show a longer lifespan and higher strength to withstand alternating loads when compared to the rectilinear infill pattern. The results also showed that there should always be a difference between the value of nozzle dimeter and layer thickness where the former should be at least 1.5 times the latter. The reason for this is that this arrangement shows proper cohesion and enhanced part integrity. Finally, the highest fatigue life was for $75 \%$ infill density, $0.3 \mathrm{~mm}$ layer thickness and $0.5 \mathrm{~mm}$ nozzle diameter.

Beniak et. al. [16] argued that ABS is the most commonly used material for FFF. But at the same time materials like PLA, PolyCarbonate and other composites are also gaining importance, especially PLA due to its environmental friendliness. Hence in their study to investigate the effect of infill percentage, infill shape, orientation and layer thickness on the tensile strength, the authors choose PLA biodegradable thermoplastic. For the tensile test, the specimens were manufactured at two different levels for each chosen parameter. The infill percentages were $90 \%$ and $50 \%$ with perimeter line and honeycomb infill shape and orientations were 0 degrees and 45 degrees. The tensile tests revealed that the infill percentage had a significant effect on the tensile properties, and this was reasoned as there will be more plastic fibers in the cross-section with an increase in the infill percentage. Also similar to the results mentioned in the above study the honeycomb infill pattern showed higher values of tensile strength as well however, there was no significant effect of build orientation on the tensile properties.

As mentioned before there are various materials used for FFF. Along with some of the materials mentioned above, Ultem 1010 and Ultem 9085 are also used. Hence in a publication by Fischer et. al. [17] they took into consideration the effect of three different build orientations on the tensile and fatigue strength of FFF printed parts using Ultem 9085. Ultem 
9085 is used in aviation as this material has fire smoke toxicity evaluation and a high strengthto-weight ratio. Post-treatment of FFF printed parts in necessary as they often have a rough and wavy surface. For Ultem 9085 chloroform gas is used for chemical treatment of the material as the gas dissolves the surface leaving a smooth outer layer. Chemical smoothing is chosen over other post-processing techniques due to its ability to reach difficult and inaccessible areas of the part and the reason that after chemical treatment the surface hardness remains the same. Three different build orientations chosen for this experiment were $\mathrm{X}, \mathrm{Y}$ and $\mathrm{Z}$ build directions. The test specimens were manufactured according to ASTM D638 standards for static and dynamic tests and post-processing was done for 2 hours at room temperature by submerging the specimens in a glass vessel filled with chloroform. The results showed that for static testing, there was no significant difference between the specimens which were chemically treated and the normal specimens for $\mathrm{X}$ and $\mathrm{Y}$ orientations but for $\mathrm{Z}$ orientation, the treated specimens showed higher values of tensile strength. Overall, the tensile properties were highest for parts printed in $\mathrm{X}$ build orientation then followed by specimens in $\mathrm{Y}$ and lastly $\mathrm{Z}$ orientation. For dynamic loading, there was a significant reduction in the lifespan of parts in all three orientations after $10^{4}$ cycles however, $\mathrm{X}$ orientation specimens had the longest lifespan. Observing the specimens also showed that the fatigue properties for $\mathrm{X}, \mathrm{Y}$ and $\mathrm{Z}$ orientations converged at around $10^{6}$ cycles with $\mathrm{X}$ and $\mathrm{Y}$ converging first at $10^{5}$ cycles. Also concluding that at very high values of repeating loads the effect of build orientations becomes insignificant and the reason behind this might be the failure of all specimens at this value. After testing the chemically treated specimens it was observed that the treated and untreated specimens showed no difference in the case of fatigue properties. This shows that there is no significant effect of chemical treatment as a technique of postprocessing on the lifespan of the Ultem 9085 parts.

Following the work of the authors above, Zalvivar et. al. [18] also worked on the 3D printed ULTEM 9085 material. Tests were performed to understand the mechanical and thermal behavior of the material. The authors in their publication mentioned that for AM parts manufactured with different materials such as ABS, PLA, etc. the tensile strength, compression strength, hardness, elastic modulus, and the thermal profile varies with the build orientation. Since the FFF printed parts inherently have low mechanical properties, the 
process parameters can be varied to improve these properties. Hence in their study, the authors tested different specimens with six different build orientations and studied the effect of build orientation on the tensile strength, strain, poisons ratio and thermal expansion coefficient. To understand the failure mechanisms better, CAT scans and image analysis were performed. The specimens were manufactured according to ASTM D638-03 standards and different build orientations considered were, flat in $\mathrm{x}$-direction (A), flat in y-direction (B), on edge $x$-direction (C), upright z-direction (D), flat in 45 degrees (E) and on edge in 45 degrees (F), explained in figure 2.4 below.

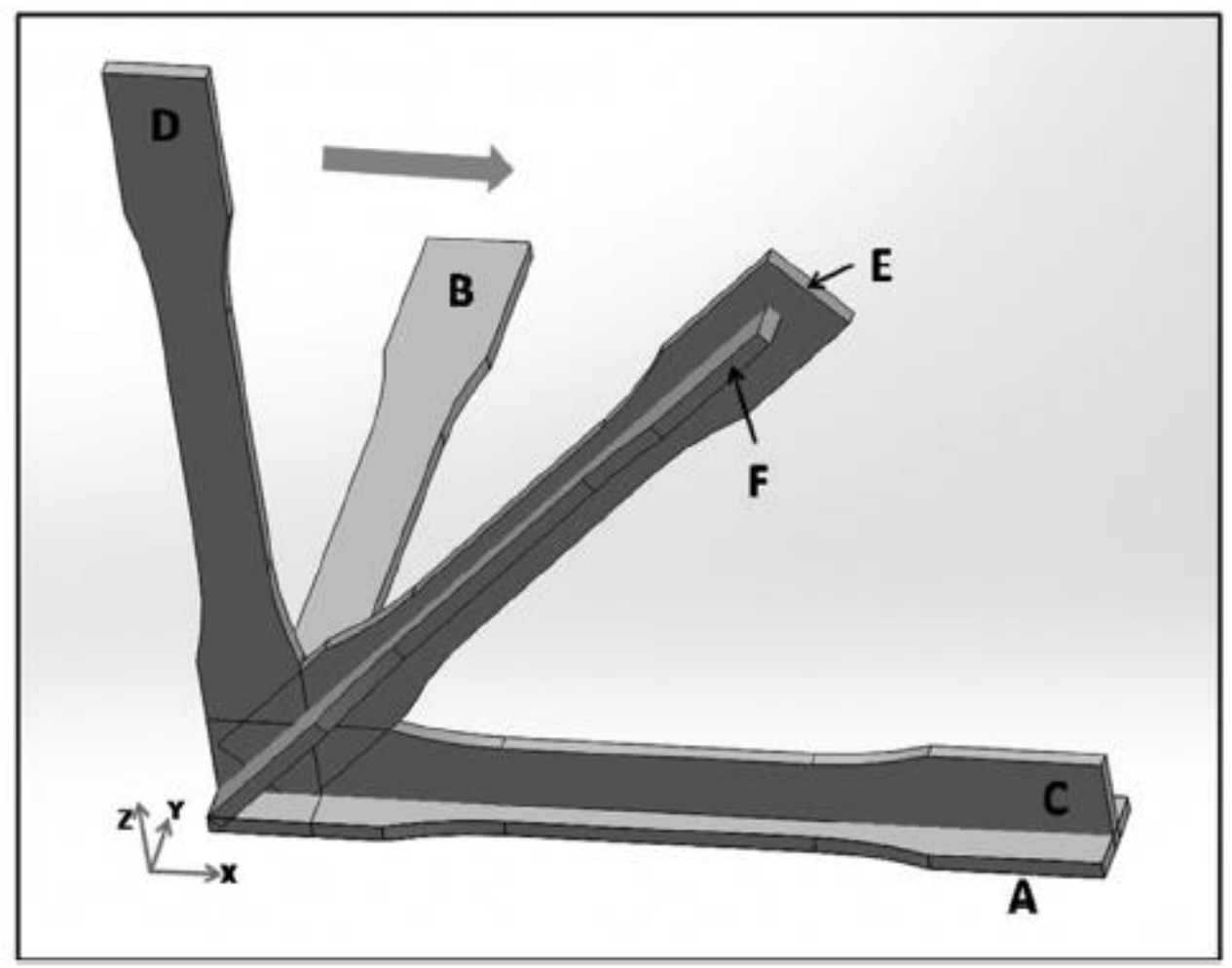

Figure 2.4: Built orientations for the study [14]

The loading direction was axial i.e. $x$-direction. From the tests, it was concluded that the build orientation significantly effects the mechanical properties of ULTEM 9085 parts and the specimens with more extruded polymeric fibers along the direction of the loading have higher strength and mechanical properties. The results showed that the strength of 3D printed parts was about 46 to 85 percent of the strength of injection molding parts. The post-processing of the specimens is used to assess the microstructures and the void formation in the parts and 
the studies reveal that the poisons ratio and the coefficient of thermal expansion depend on the microstructure. And the strength is low for the specimens with a high angle from the build platform because the microstructures, in this case, reduce the volume fraction of extruded fiber material in the loading direction.

Further expanding on the work done on the effects of build orientation is a study by Uddin et. al. [19]. As mentioned above the properties of FFF manufactured parts using ABS material depend on the selected process parameters. Hence the Authors analyzed the effect of the printing orientation, printing plane and layer thickness on the mechanical properties of $A B S$ material with the help of tensile and compression tests. The mechanical properties analyzed were young's modulus, yield strength, failure strength and strain for every case of the process parameter. ASTM D638 standards were followed to manufacture 27 different parts in horizontal, vertical, diagonal orientations, XY, YZ, ZX printing planes and $0.09 \mathrm{~mm}, 0.19 \mathrm{~mm}$, $0.39 \mathrm{~mm}$ layer thicknesses and results were compared to conventional injection molding parts. Also, while printing the parts, on the perimeter a shell feature is used with the infill being 100 percent. Some of the major inferences form the tests were that the highest young's modulus was for specimens with YZ-H plane and orientation respectively and lowest layer thickness whereas, the yield strength was maximum for YZ-H and YZ-D specimens and lowest layer thickness as well. The parts manufactured in YZ-V orientation and $0.19 \mathrm{~mm}$ layer thickness had the highest value of failure strength which was almost double than that for the injection molded part. And on the contrary, the young's modulus and yield strength were more for the parts manufactured by injected molding. Looking into the results of compression tests it was concluded that the highest yield strength and stiffness were for $\mathrm{XY}-\mathrm{H}$ and $\mathrm{XY}-\mathrm{D}$ specimens, but the orientation had no influence on the failure strength and compressive properties.

Lastly, on the topic of orientation, infill pattern and infill percentage, Giovanni et. al. [20] performed fatigue tests on 3D printed PLA parts. For the tests, two different infill patterns were chosen namely, rectilinear and honeycomb with different infill densities and varying layer thickness, nozzle diameter, and print velocity. In total 27 specimens were printed for 
each above-mentioned print patterns. In order to focus on the print parameters which actually effect the fatigue properties and to reduce the number of runs, Taguchi Experimental Design was formed. Comparing the results showed that the infill pattern and infill density had a huge impact on the fatigue properties of the parts where honeycomb infill pattern and high infill density results in high fatigue life. This high fatigue life is due to the reason that at high infill percentages the specimens show a ductile behavior and a low shear fracture. Whereas there was a negligible effect of the print velocity. The best fatigue properties were for the specimen with $75 \%$ infill density, $0.5 \mathrm{~mm}$ nozzle diameter, $0.3 \mathrm{~mm}$ layer height and a honeycomb infill pattern.

\subsection{Effect of Impact Energy and Layer Thickness on Low Velocity Impact Properties}

Composites are sensitive to low-velocity impact damage hence it is really important to study the impact properties of 3D printed composites. For that, Caminero et. al. in their papers $[21,22]$ provide an overview of low-velocity impact damage characteristics of composites and the challenges and importance of these tests. According to the authors, one of the major limitations in the effective use of composites in the aerospace industry is their sensitivity to low-velocity impact damage. When composites are impacted at low velocity, internal damage is caused which is barely visible at the outer surface. This barely visible damage leads to delamination and matrix cracking hence reducing the material strength and causing catastrophic failures. Hence, it is really important to analyze the low-velocity impact characteristics using NDT techniques. NDT techniques are an effective way to analyze defects in 3D printed composite structures. Thermography and Ultrasonic are one of the most widely used NDT techniques. But in this study [21], the authors focused on the phased array ultrasonic NDT technique to analyze internal damage in carbon fiber reinforced epoxy laminates. For the study, the carbon fiber reinforced epoxy laminates were embedded with various artificial inclusions of different shapes and sizes. Further to assess this NDT technique, impact tests on 3D printed composite laminates were carried and the specimens were analyzed using phased array ultrasonic C- scanning technique. Drop tests were performed on the printed specimens with just enough impact energy to cause barely visible impact damage. 
The values of impact energy chosen were $20 \mathrm{~J}$ and $30 \mathrm{~J}$. From the tests, it was concluded that phased array ultrasonic technique is an effective way to analyze and understand the internal damage in a composite structure however there were some variations in results due to the manufacturing process of the carbon fiber reinforced epoxy laminates. The phased array ultrasonic technique also showed that, for 3D printed composite laminates, there was more delamination caused by higher values of impact energy and at higher layer thickness values.

Due to the increasing significance of continuous fiber-reinforced thermoplastic composites (CFRTPC) in the industrial applications, in another study by the same authors [22] low-velocity impact damage resistance of CFRTPS's was analyzed. For this study, build orientation, layer thickness and fiber volume content of CFRTPSs were changed and their effect on three different types of reinforcements namely, carbon, glass, and Kevlar were studied. Charpy tests according to ASTM D6110 standards were carried out and following the impact tests, SEM images were examined to understand the failure mechanism of the fractured surface. For a better understanding of the impact properties, in addition to the comparison between nylon composites reinforced with different fibers, a comparison with unreinforced nylon specimens was also done. Two different build orientations were used - flat and on-edge, three different layer thicknesses for unreinforced specimens were $0.1 \mathrm{~mm}, 0.125 \mathrm{~mm}, 0.2$ $\mathrm{mm}$ and for carbon fiber the layer thickness used to print the specimens was $0.125 \mathrm{~mm}$ and for glass and kevlar the thickness was $0.1 \mathrm{~mm}$. And finally, partially and fully reinforced fiber volume content was considered. From the tests, the following observations were made, due to the ductile nature of the parts at higher values of layer thickness for flat samples, the impact strength was high and opposite to that, due to the brittle nature of the specimens for lower layer thickness and on-edge orientation, the impact strength values were low. It was also observed that generally, flat orientation parts showed higher values of impact strength compared to the on-edge samples and the impact strength showed an increasing trend with the increase in the fiber volume. Finally, the reinforcement of glass fibers resulted in enhanced impact properties while the specimens with carbon and kevlar reinforcements showed lower performance when compared to glass fiber reinforcements. 
Mizera et. al. [23] studied and compared the impact properties of 3D printed ABS and HIPS specimens in $\mathrm{XY}$ orientation. To study the impact behavior three different layer thicknesses for ABS $-0.09 \mathrm{~mm}, 0.19 \mathrm{~mm}$ and $0.29 \mathrm{~mm}$ and two-layer thicknesses for HIPS $-0.19 \mathrm{~mm}$ and $0.29 \mathrm{~mm}$ were used. The specimens were impacted with an impact pendulum having $15 \mathrm{~J}$ potential energy. Three parameters namely, maximum impact force, consumed impact work and impact strength were analyzed. And from the results, it was concluded that there was a general decrease in the maximum impact force as the layer thickness is increased for both the materials. However, there was no significant effect of the layer thickness on the consumed impact work as the value remained constant in both cases but the value for HIPS was less than that for ABS specimens. Similar to the maximum impact force, the impact strength also decreases with an increase in the layer thickness with values for HIPS material less than the value for ABS material. To understand the failure mechanism, fracture surface evaluation was done, and it revealed that the layers with $0.09 \mathrm{~mm}$ layer thickness are more compact and hence might be the reason for greater impact strength. Finally, it can be concluded from the above study that, if needed for impact applications, parts with lower layer thickness are more suitable.

Studies have proved that sandwich composites and carbon fiber reinforced polymers show improvement in mechanical properties when compared to composites with an unfilled core, but still they are sensitive to impact damage. Hence, Kao et. al. [24] performed experiments to study the impact properties of bi-material structures (BMS) when subjected to low-velocity impact. The scientists used three different kinds of polyurethane (PU) foams for a Ply Lactide (PLA) lattice structure. The different kinds of foams were, one rigid (Foam-it 8, FI-8) and two flexibles (FlexFoam-it 17, FF-17 and FlexFoam-it 25. FF-25). FI-8 is brittle, light and porous whereas, FF-17 and FF-25 foams are dense. Tension tests according to ASTM D3574 standards with an impact energy of $3.14 \mathrm{~J}$ were performed to calculate the maximum acceleration, energy absorption, maximum displacement and rate of change of acceleration (jerk). Jerk is calculated from the attenuation of the impact shock, the local and global deformation combine to form the maximum displacement, the complete energy absorbed during the impact is called energy absorption and the material strength defines the maximum acceleration. The results show that impregnating a flexible foam, decreases the jerk however 
a rigid foam, increases the jerk the percentages being $9 \%$ and $7 \%$ respectively. The maximum displacement for flexible foams is increased by $17 \%$ due to the ductility of the material and for rigid foams, the value is decreased by $5 \%$ caused by the high stiffness of the foam. Similar to the above, the energy absorption is increased by flexible foams and decreased by rigid foams. And finally, the maximum acceleration shows no significant effect when the foam reinforcement is changed. Since the maximum acceleration depends on the material strength, it can be concluded that the PLA frame dominates this impact property.

Tsouknidas et. al. [25] with the help of their study tried to enhance the impact absorption capacity of PLA parts manufactured by FFF by changing the process parameters such as layer thickness, infill pattern and density while keeping the same dimensional characteristics. For the experiments, rectilinear, octagonal, concentric infill patterns; $0.1 \mathrm{~mm}, 0.2 \mathrm{~mm}, 0.3 \mathrm{~mm}$ layer thicknesses and $25 \%$ and $50 \%$ infill densities were used to produce 27 cylindrical PLA specimens. Further, the tests were performed according to ASTM:D638 standards. It was concluded that the specimen with $0.3 \mathrm{~mm}$ layer thickness, $25 \%$ infill density and concentric infill pattern exhibited the highest value of impact strength. While generally, the concentric infill pattern and $25 \%$ infill density specimens performed better than the specimens with other values of process parameters.

Adding to the research on the impact strength of FFF printed parts is the work of Alavrez et. al. [26]. Their study was focused on the tensile and impact strength of ABS parts with varying infill percentages. The infill percentage can be any value between $0 \%$ and $100 \%$ where specimens with $0 \%$ infill percentage will just have an external surface and a $100 \%$ infill percentage will result in a solid specimen. If any value between $0 \%$ and $100 \%$ is chosen, the material will be laid in a specified geometrical pattern depending on the manufacturer. However, for this study, a hexagonal infill pattern was chosen. Tensile tests according to ASTM D638-10 and Charpy Impact Resistance tests according to ASTM D6110-10 were performed and the values of maximum tensile force, maximum impact force and effective printing time were analyzed. The effective printing time is calculated by subtracting the time taken by the nozzle and print bed to heat from the total time displayed on the printer at the 
end of the printing process. From the tests, the following inferences were drawn, the maximum tensile force and the impact resistance vary linearly with the infill percentage and show an increasing trend as the infill percentage is increased. However, the effective printing time showed an unexpected trend as it increased with increasing infill percentage till $95 \%$ but there was a sudden decrease after this value till $100 \%$ such that the effective time at $100 \%$ corresponded to the effective time at $45 \%$ infill percentage. The authors argued that the reason for this unexpected trend might be the different manufacturing processes for different infill percentages. As for $100 \%$, the nozzle just moves in the $X-Y$ direction however for a smaller infill percentage the nozzle moves in a specified geometrical pattern hence increasing the total printing time.

Sugun et. al. [27] performed experiments to characterize the low-velocity impact properties when an epoxy matrix is reinforced with different kinds of fibers using Resin Ingression Technique (RIT). Three different kinds of fibers used in this particular study were glass, kevlar, and carbon. Since most of the previous literature was focused on the assessment of single drop impact properties, the authors decided to impact the composites repeatedly at low velocity with energy varying from $3.5 \mathrm{~J}$ to $15 \mathrm{~J}$. To analyze the failure mechanism in case of glass and Kevlar epoxy composites, delamination area maps were obtained. After the drop tests, peak load versus the number of impacts to failure and total energy versus the number of impacts to failure plots were plotted. And from the plots, it was concluded that as the number of impacts increased, the peak load decreased whereas the total energy increased. Some authors also worked on the low-velocity impact characterization of natural fiber composites such as Kenaf [28]. Ismail et. al. [28] manufactured pure kevlar composites, pure kenaf composites, and hybrid kenaf-kevlar composites to compare the impact properties. To manufacture hybrid composites a ratio of 3:1:3 of Kevlar, kenaf, and Kevlar was chosen. The specimens were impacted with three different impact energies $10 \mathrm{~J}, 20 \mathrm{~J}, 30 \mathrm{~J}$, and $40 \mathrm{~J}$ and impact energies were varied by changing the height of the striker. The results showed that all the specimens failed at $40 \mathrm{~J}$ impact energy however the Kevlar composites showed the best results. The tests also concluded that the hybrid laminates showed mechanical strength almost similar to the Kevlar laminates but surpassed the quality performance of kenaf composites. Buang et. al. [29] attempted to use numerical simulations to understand the 
behavior of composites under the low-velocity impact. The authors developed a numerical model based on the results of previous works. The composites were made of epoxy laminates reinforced with carbon fiber and the orientation was $\left[-45^{\circ} / 0^{\circ} / 45^{\circ} / 90^{\circ}\right]_{3 \mathrm{~s}}$. The impact velocity of $6.5 \mathrm{~m} / \mathrm{s}$ was chosen, and the energy was transferred to the laminates by a hemispherical striker having a mass of $1.85 \mathrm{kgs}$ and a diameter of $25.4 \mathrm{~mm}$. The authors concluded that LSDYNA is a reliable finite element software to carry out numerical simulations and gave acceptable results to understand the low-velocity impact properties.

When the composites have suffered a low-velocity impact, the fatigue properties of the composites are also affected. This was studied by Freeman et. al. [30] when they conducted experiments on the fatigue life of sandwich composites after they were impacted at low velocity. Carbon fiber epoxy sandwich composites with foam-filled honeycomb were impacted at $10 \mathrm{~J}, 20 \mathrm{~J}$ and $30 \mathrm{~J}$. After the impact tests, ultrasonic NDT techniques were used to analyze the fracture surface and finally fatigue tests were conducted to understand the fatigue properties after impact. Two- and four-layer sandwich composites were manufactured where two different densities were used for two-layer sandwich composites $\left(0.164 \mathrm{~g} / \mathrm{cm}^{3}\right.$ and $\left.0.106 \mathrm{~g} / \mathrm{cm}^{3}\right)$ and one density for four-layer sandwich composites $(0.106$ $\mathrm{g} / \mathrm{cm}^{3}$ ). The major conclusions from the tests were, the impact tests showed that for the composites with four layers, $30 \mathrm{~J}$ impact energy caused penetration while the $20 \mathrm{~J}$ impact energy caused delamination. For the composites with two layers, there was no penetration to the back surface of the composites for $10 \mathrm{~J}$ impact energy however for $20 \mathrm{~J}$ and $30 \mathrm{~J}$ the damage penetrated to the back surface as well. In the end, the fatigue tests showed that for two later samples there was no significant effect of different impact energies on fatigue life however due to the low-velocity impacts, the fatigue failure mode changed from shear to bending at the point of contact of the test fixture. However, for four-layer samples, lowvelocity impacts had no effect on the fatigue life of the composites.

Lastly, Es-said et. al. [31] focused their work on the impact properties of ABS parts printed using FFF technique in different layer orientations. Five coupons were printed in five different orientations; $0^{\circ}, 45 /-45^{\circ}, 45^{\circ}, 90^{\circ}$, and $45 / 0^{\circ}$ and following this Izod tests were performed 
using an impact pendulum. From the data collected by the impact tests, it was evident that the absorbed energy was highest for samples with $0^{\circ}$ orientation and lowest for samples with $90^{\circ}$ orientation. In addition to this, the absorbed energy had similar values for all other orientations which were $45 /-45^{\circ}, 45^{\circ}$, and $45 / 0^{\circ}$. Analyzing the fracture surface of all the samples it was concluded that for $0^{\circ}$ orientation, the fracture was across the layers however for $90^{\circ}$, the fracture was at a perpendicular angle to the length along the layers. 


\subsection{OBJECTIVE}

The sections 2.1, 2.2, 2.3, 2.4 gave an overview on the research carried out and work done on the thermoplastics and composites manufactured by additive manufacturing techniques such as FFF. In the previous section it was seen that 3D printing is a very complex process and the final mechanical, tensile, flexural and impact properties of the printed parts depend on the various process parameters such as the layer thickness, raster angle, raster width, infill percentage, orientation, nozzle temperature etc. [21,22]. From previous studies it was evident that composites manufactured by FFF are very sensitive to low-velocity impact damage. This sensitivity is due to the barely visible impact damage cause when impacted at a low velocity which results in the degradation of the mechanical properties and structural integrity. The damage caused by the low-velocity impact may not be visible by the naked eye, but it causes delamination, fiber breakage and crack propagation which can lead to a catastrophic failure [21,22].

There is not enough research done on the low-velocity impact resistance of FFF printed composites and thermoplastics hence in the present study following mentioned accomplishments were achieved:

- Low-velocity impact tests were conducted on 3D printed PLA plates

- Coupons were printed in four different layer thicknesses and number of layers keeping the laminate thickness constant

- The specimens were tested on a pendulum impact test apparatus for two different impact locations

- The post-processing was done by calculating the energy absorbed by each specimen after impact with the help of the high-speed camera

- Thermography was performed using an infra-red camera to understand the failure mechanism in each case

In this project, the coupons were printed using PLA (PolyLactic Acid) as the material is biodegradable and hence environment friendly, it is cost effective and has high stiffness. PLA is often chosen for 3D printing due to its ease in printing as it shows no warping. Currently, 
thermoplastics parts have found application in the aerospace industry, where ULTEM 9085, a pure polymer is used by Stratasys in the secondary structures of the aircraft. Also, fibres can be reinforced in pure polymers to enhance their utilization in the industry. However, since PLA as such is not used in the industry but due to its properties such as efficiency in printing and testing, this material was used in the project to understand the behaviour of thermoplastics under the low-velocity impact. The results from this experiment can be used to validate a finite element model that simulates low velocity impact. The validated FE model can be used for other high performance and high temperature polymers like ULTEM 9085 and PEEK.

In the following sections, a brief description of the test apparatus, test plan, specimen manufacturing, and testing procedure is given followed by the results and discussions and conclusions from the tests. Finally, the scope for future work is also presented. 


\section{Methodology}

In Section 2, an introduction to the FFF technique was given and the effects of various process parameters on the tensile, impact, and flexural strength were discussed. In this section, the testing apparatus, test plan, specimen manufacturing, and testing procedure of the lowvelocity impact tests performed on 3D printed PLA parts with varying layer thickness are discussed in detail.

\subsection{Testing Apparatus}

A low velocity impact test was conducted according to the principles of the Charpy and Izod impact tests. In a Charpy test, a specimen with a V-shaped notch is placed in the test apparatus and an impact load is applied at the center of the specimen, which causes specimen failure. In the Izod test, a similar specimen with a V-shaped notch is used; however, the force is applied at the free end of the specimen. The Charpy and Izod tests are explained in figure 3.1. In both tests, the absorbed energy is calculated by recording the angle of the hammer before the impact and the rebound angle after the impact [32]. The same principle is used to calculate the absorbed energy in the low velocity pendulum impact tests used in this current study.
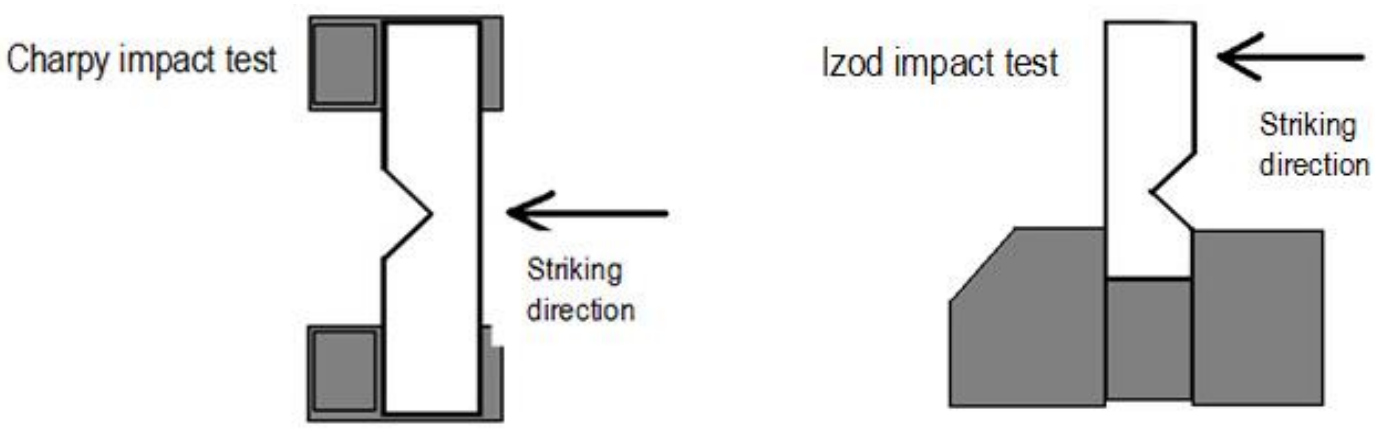

Figure 3.1: The Standard mechanism of Charpy and Izod Impact tests [32] 
Following the principle of Charpy and Izod tests, an in-house low velocity pendulum impact testing apparatus was fabricated to perform these tests [33]. A detailed design of the apparatus is shown below.

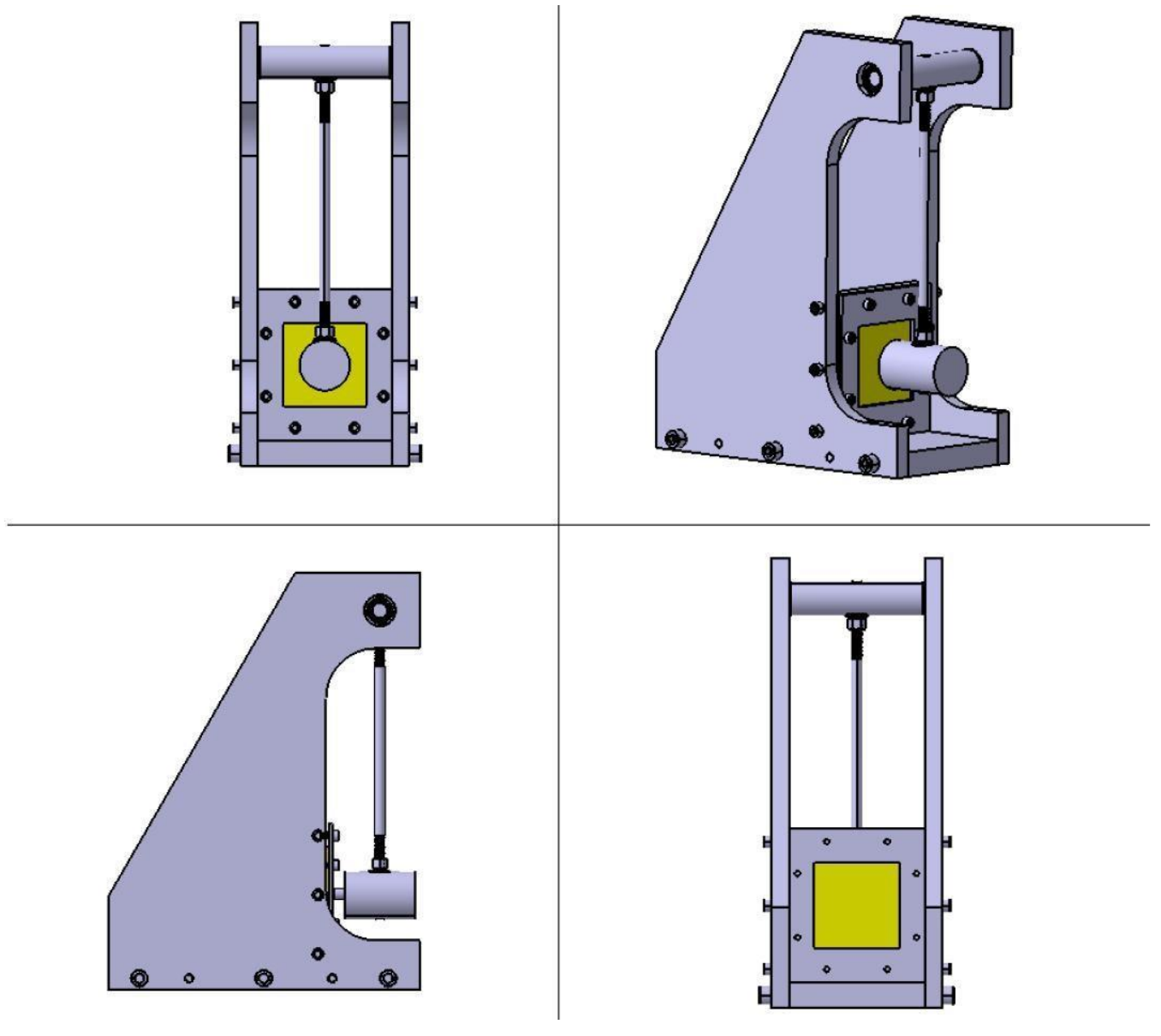

Figure 3.2: Low velocity pendulum impact test apparatus [33]

The apparatus follows the principle of energy conservation of the pendulum, where the specimen was impacted with a mass released from a certain height according to the initial impact energy. To calculate the absorbed energy, the height of the pendulum before the impact and the rebound height after the impact is recorded and absorbed energy is calculated according to the principle of conservation of energy.

The impact energy (E) to the specimens is chosen so that the energy level is high enough to cause barely visible impact damage while preventing any catastrophic failure. The height of the pendulum can be calculated from the selected impact energy value. Figure 3.3 gives a detailed description of all the terms used in the equations. 


$$
E=m g H_{1}
$$

Hence,

$$
H_{1}=\frac{E}{m g}
$$

Knowing the release height, $\mathrm{H}_{1}$, the release angle can be calculated as follows:

$$
\alpha=\left[1-\frac{H_{1}}{L}\right]
$$

The value of the rebound angle $(\theta)$ is recorded and used to calculate the rebound height (Eq. 3.4)

$$
H_{2}=L(1-\cos \theta)
$$

At the end, the rebound energy can be calculated as follows

$$
E_{R}=m g H_{2}
$$

Following the principle of energy conservation, the absorbed energy can be calculated (Eq. 3.6). However, to avoid the complexity, various assumptions were made to calculate the absorbed energy value. For the energy conservation equation (Eq. 3.6) it was assumed that the other forms of energies have negligible value when compared to Absorbed, Impact and Rebound energy. And hence all other energy forms can be categorised as energy loss during testing and are neglected from the energy conservation equation.

$$
\begin{gathered}
\text { Absorbed energy }=\text { Impact energy }- \text { Rebound energy } \\
\qquad \boldsymbol{E}_{\boldsymbol{a} \boldsymbol{b}}=\boldsymbol{E}-\boldsymbol{E}_{\boldsymbol{R}}
\end{gathered}
$$

In Equations 3.1 to 3.6, the following parameters are used 
$m$ - Mass of the pendulum

$\mathrm{L}$ - length of the pendulum arm from the center of the pivot to the center of the mass of the pendulum

$\mathrm{H}_{1}$ - Initial height of the pendulum before impact

$\mathrm{H}_{2}$ - Rebound height of the pendulum after Impact

$\alpha-$ Release angle

$\theta-$ Rebound angle

E - Impact energy

$E_{R}-$ Rebound energy

$E_{a b}-$ Absorbed energy

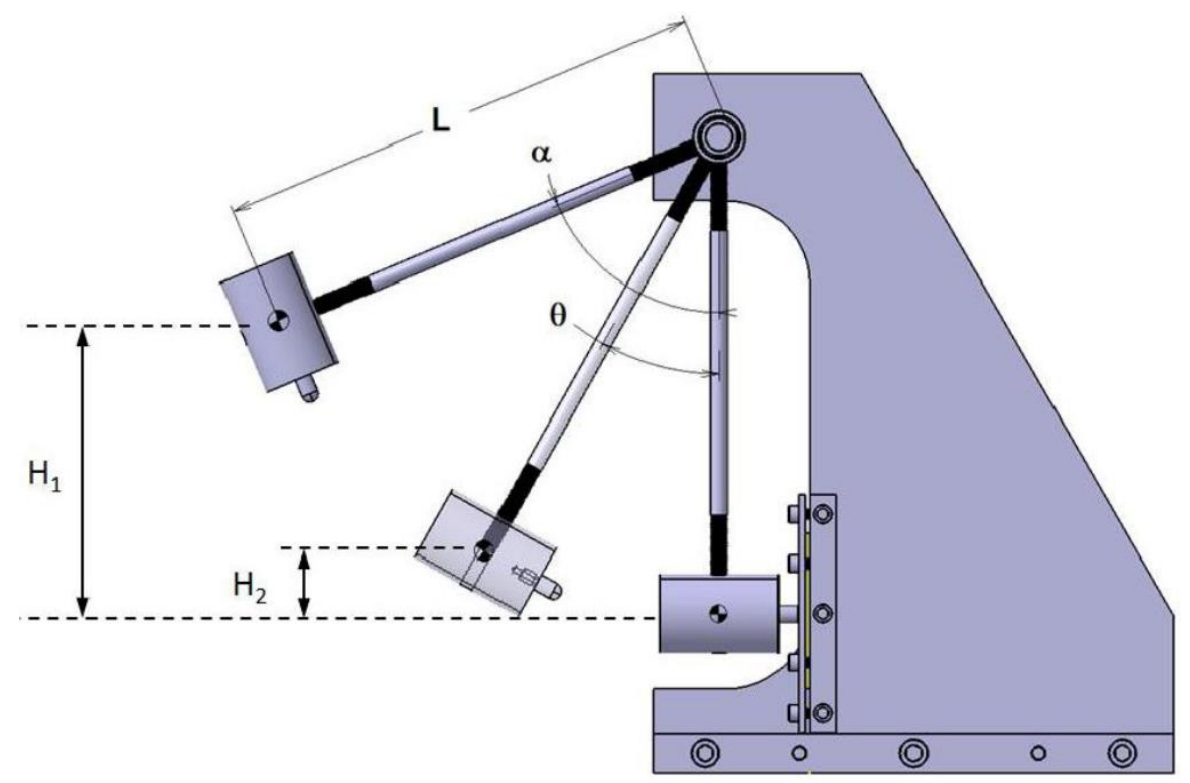

Figure 3.3: Setup showing different angles and heights [33]

The specimen was mounted between two plates called the support plate and the clamping plate. The test aperture has a square shape and is $4.5 \times 4.5$ inches in dimensions. The pendulum is made of steel and is cylindrical in shape with a mass of $4.4 \mathrm{~kg}$. The energy is transferred to the specimen with a hemispherical tip attached to the pendulum having a 
diameter of $16 \mathrm{~mm}$. The pendulum arm can be adjustable to change the impact location based on the test plan. Some of the specifications of the test apparatus are mentioned in table 3.1.

Table 3.1: Specifications of the test apparatus

\begin{tabular}{|l|l|}
\hline Mass of the pendulum & $4.4 \mathrm{~kg}$ \\
\hline Impactor tip diameter & 0.63 inches (16 mm) \\
\hline Specimen dimensions & 4.5 by 4.5 inches \\
\hline Distance from pivot to centerline of impactor & 18 inches (457 mm) \\
\hline Distance from pivot to center of the mass of pendulum & 17.85 inches $(453 \mathrm{~mm})$ \\
\hline Cut out window size & 3.5 by 3.5 inches \\
\hline Maximum pendulum drop angle & 179 degrees \\
\hline Acceleration due to gravity (g) & $9.81 \mathrm{~ms}^{-2}$ \\
\hline Length of pendulum arm for position $\mathrm{P}_{1}$ & $0.457 \mathrm{~m}$ \\
\hline Length of pendulum arm for position $\mathrm{P}_{2}$ & $0.428 \mathrm{~m}^{2}$ \\
\hline Impact energy & $3 \mathrm{~J}$ \\
\hline
\end{tabular}

In the experimental setup, along with the apparatus shown in Figure X, a MotionPro X3 highspeed camera is placed right in the line of sight of the pendulum to record the rebound angle. The frequency of the camera is $1000 \mathrm{~Hz}$ and the camera use 100 nanoseconds interframe time. In addition to the high-speed camera, a Flir t400 Infra-Red (IR) camera is also utilized to perform thermography to analyze the fracture mechanism in the specimens post-impact. The IR camera has a resolution of $320 \times 240$ pixels and a temperature sensitivity of less than 45 mK. This camera has an integrated 3.1 Mpixels digital camera. In order to capture better image for the high-speed camera, high intensity lights were used. The IR camera was placed opposite to the specimen on the other side of the pendulum and the high-speed camera was 
placed perpendicular to the test apparatus. Figure 3.4 shows the experimental test set-up including the pendulum impact test apparatus, the IR camera, and the high-speed camera.

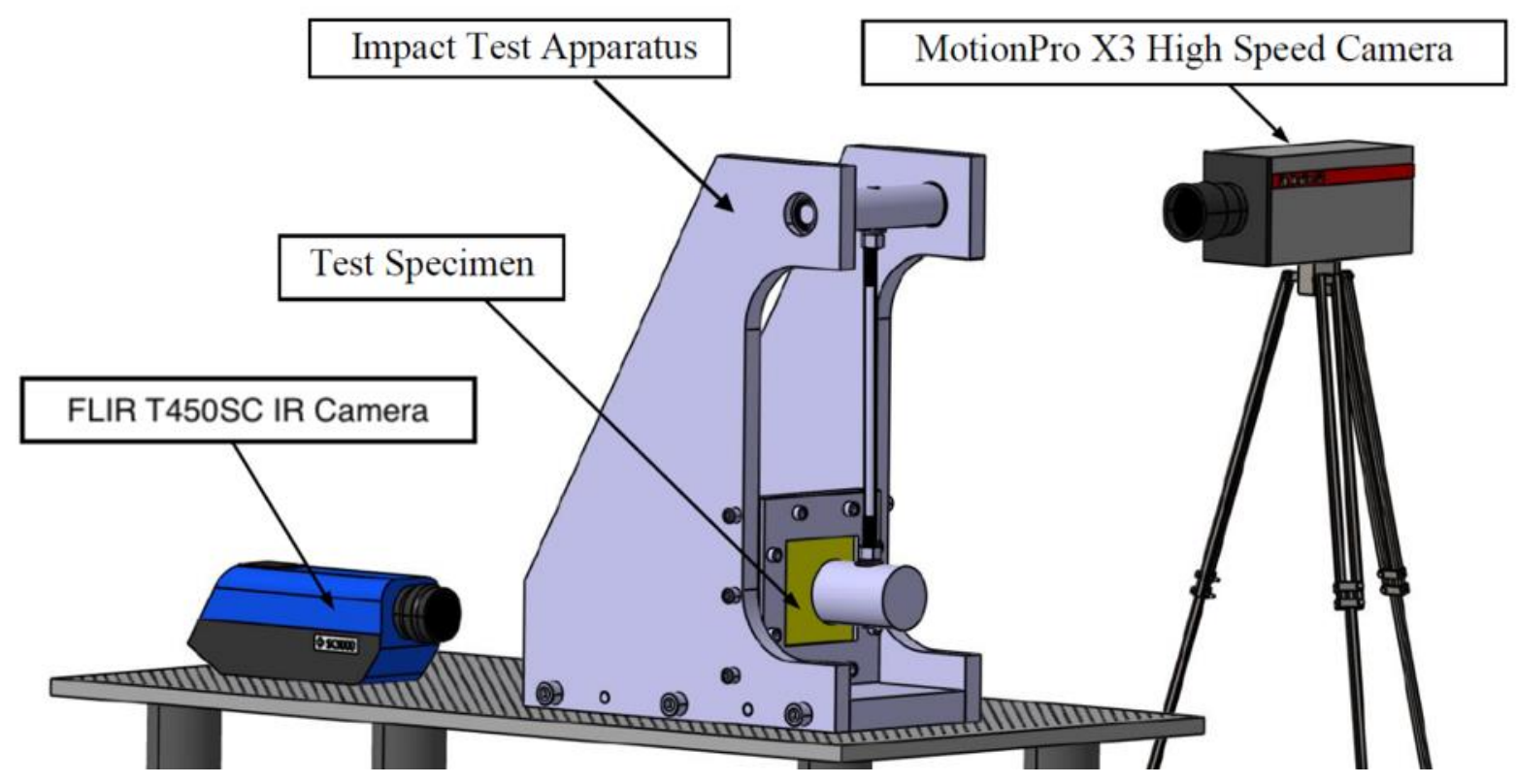

Figure 3.4: Experimental Set-up [34]

\subsection{Test Plan}

To perform the low velocity impact tests, $4.5 \times 4.5$ inches specimens were manufactured out of PLA material using FFF 3D printing technology. Since the pendulum arm can be changed, it was possible to impact the specimens at two different impact locations. The specimen was impacted at two different locations $P_{1}$ and $P_{2}$ where, $P_{1}$ is the center position of the specimen and $\mathrm{P}_{2}$ is the center position between the center of the specimen and the top edge as shown in figure 3.5 . 


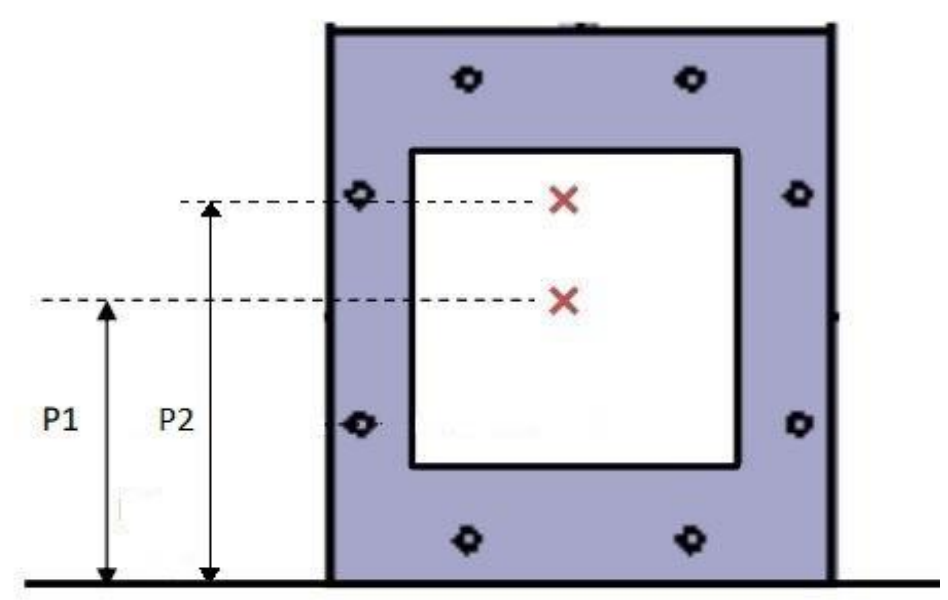

Figure 3.5: Impact locations [33]

After the impact, both the high-speed camera and infra-red camera recordings were saved for further analysis.

To perform the experiments, the specimen was clamped at all four edges between the two plates. In this study, the effect of layer thickness and impact location were studied, hence the specimens were manufactured with varying layer thicknesses, but the overall thickness of the specimen was kept constant at approximately $2.54 \mathrm{~mm}$ (0.1 in). To obtain constant laminate thickness, the number of layers and the layer thickness was changed accordingly for every coupon. And to cause substantial damage without specimen catastrophic failure, $3 \mathrm{~J} \mathrm{impact}$ energy was chosen. The height of the pendulum was calculated to impact the specimen with the exact $3 \mathrm{~J}$ impact energy. Four different layer thicknesses were chosen as follows: 0.10 $\mathrm{mm}, 0.12 \mathrm{~mm}, 0.16 \mathrm{~mm}$, and 0.18 , corresponding to $25,21,16$ and 14 layers, respectively, to keep the specimen thickness constant. Three coupons were manufactured for each layer thickness and two impact locations, hence in total 24 coupons were 3D printed. For better understanding, each test case was defined with a unique name according to the layer thickness and the impact position. Test plan is summarized in Table 3.2. 
Table 3.2: Test plan

\begin{tabular}{|c|c|c|c|}
\hline Test Case ID & $\begin{array}{c}\text { Layer thickness } \mathrm{mm} \\
\text { (number of layers) }\end{array}$ & $\begin{array}{c}\text { Laminate thickness } \\
(\mathrm{mm})\end{array}$ & Impact location \\
\hline $1 \mathrm{a}$ & $0.10(25)$ & 2.50 & $\mathrm{P}_{1}$ \\
\hline $1 \mathrm{~b}$ & $0.12(21)$ & 2.52 & $\mathrm{P}_{1}$ \\
\hline $1 c$ & $0.16(16)$ & 2.56 & $\mathrm{P}_{1}$ \\
\hline $1 \mathrm{~d}$ & $0.18(14)$ & 2.52 & $\mathrm{P}_{1}$ \\
\hline $2 \mathrm{a}$ & $0.10(25)$ & 2.50 & $\mathrm{P}_{2}$ \\
\hline $2 \mathrm{~b}$ & $0.12(21)$ & 2.52 & $\mathrm{P}_{2}$ \\
\hline $2 \mathrm{c}$ & $0.16(16)$ & 2.56 & $\mathrm{P}_{2}$ \\
\hline $2 \mathrm{~d}$ & $0.18(14)$ & 2.52 & $\mathrm{P}_{2}$ \\
\hline & & & \\
\hline
\end{tabular}

\subsection{Specimen Manufacturing}

The aim of the study was to analyze the effect of layer thickness and impact location on the low velocity impact strength of PLA printed parts. Since printing process parameters affect the properties of the final 3D printed part, all the other parameters except layer thickness were kept constant. Table $Y$ summarizes the selected process parameters to 3D print PLA specimens.

Table 3.3: Process parameters to manufacture specimens

\begin{tabular}{|l|c|l|c|}
\hline Material & PLA & Bed temperature & $60^{\circ} \mathrm{C}$ \\
\hline Print direction & $\mathrm{XYZ}$ & Layer height & $0.14 \mathrm{~mm}$ \\
\hline Raster angle & $0^{\circ}$ & Printing speed & $2400 \mathrm{~mm} / \mathrm{min}$ \\
\hline Filament diameter & $1.75 \mathrm{~mm}$ & Cooling & No fan cooling \\
\hline Nozzle diameter & $0.4 \mathrm{~mm}$ & Infill & $100 \%$ \\
\hline
\end{tabular}


A Prusa i3 MK2S 3D printer (Figure 3.6) was used to print all the 24 specimens in the Facility for Research on Aerospace Materials and Engineered Structures (FRAMES) lab at Ryerson University.

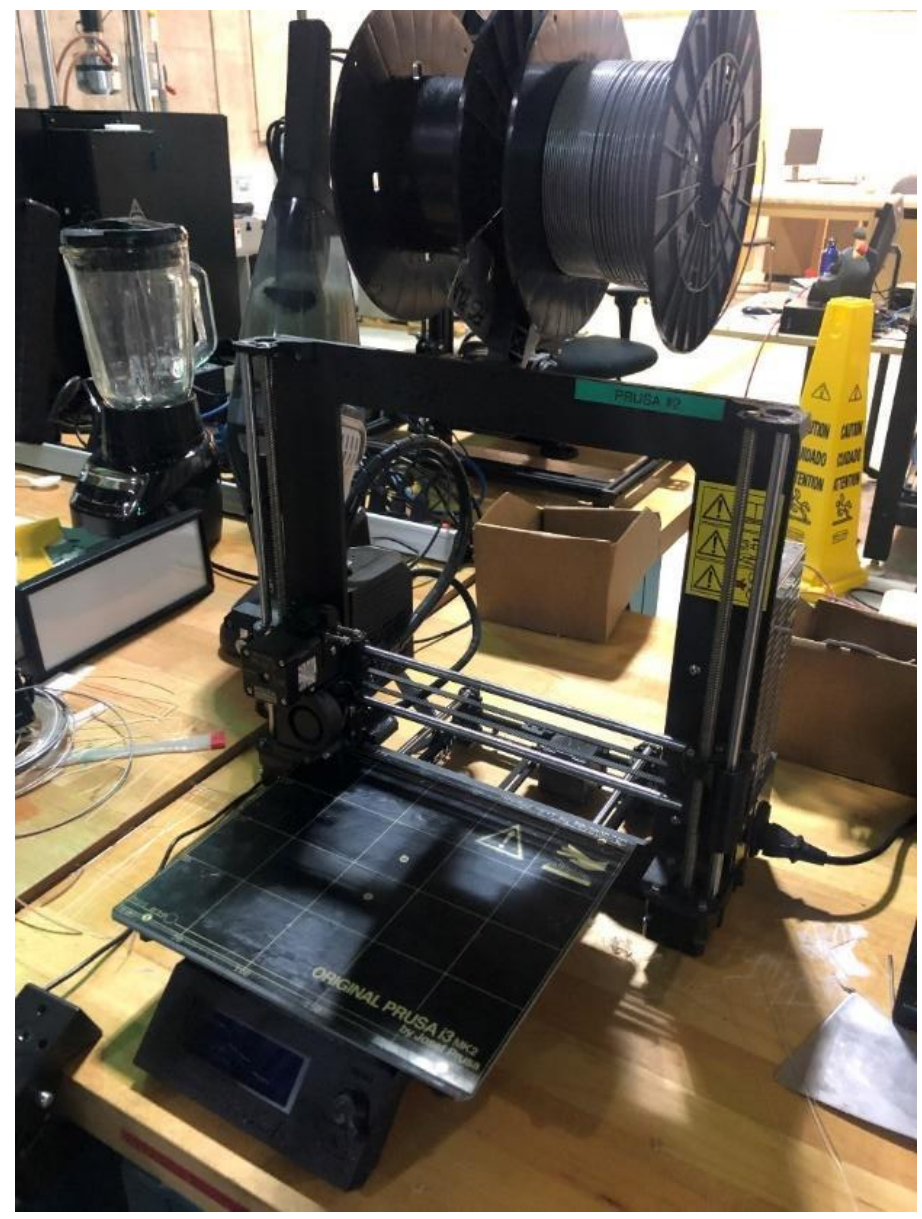

Figure 3.6: Prusa i3 MK2S 3D printer 
The specimens were 3D printed out of a grey PLA filament with a diameter of $1.75 \mathrm{~mm}$. CATIA V5 software was used to make the CAD model of the specimen that was later converted to an STL file which was sliced in Simplify 3D software. After slicing, a GCODE file was used to command the 3D printer extruder. In total 24 specimens were printed, and each specimen took an average of 3 to 5 hours to print. Figures $3.7 \mathrm{a}$ and $3.7 \mathrm{~b}$ show the final printed coupons and two different impact locations are marked on the coupons.

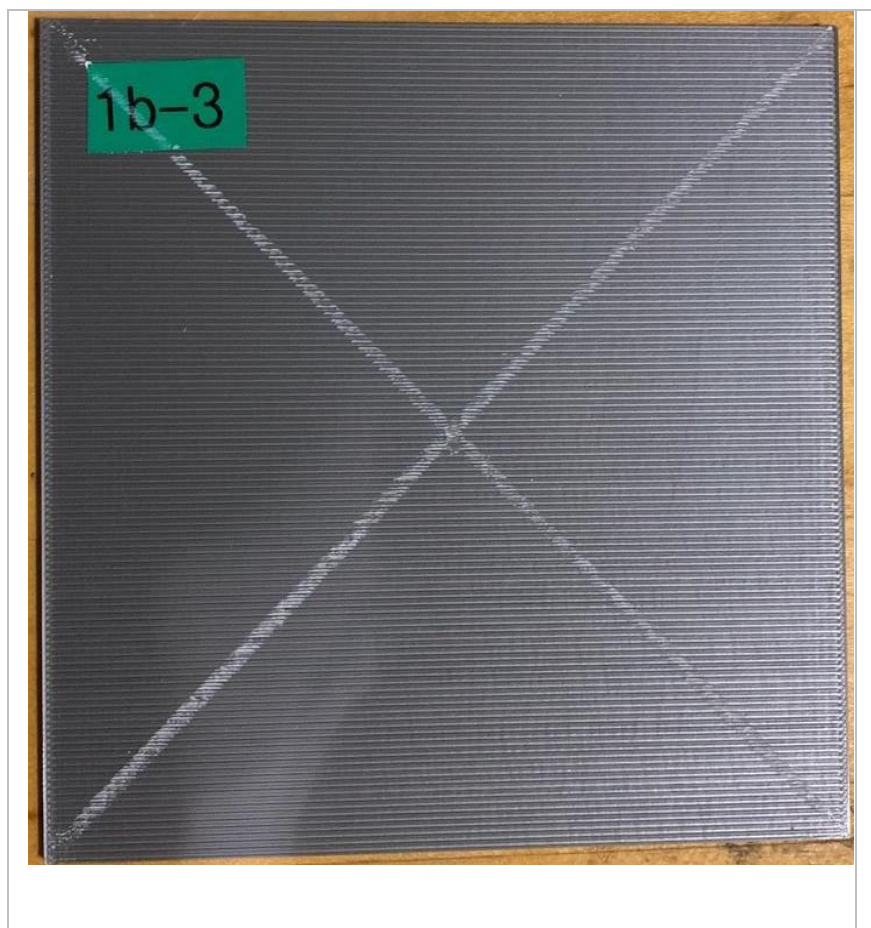

(a)

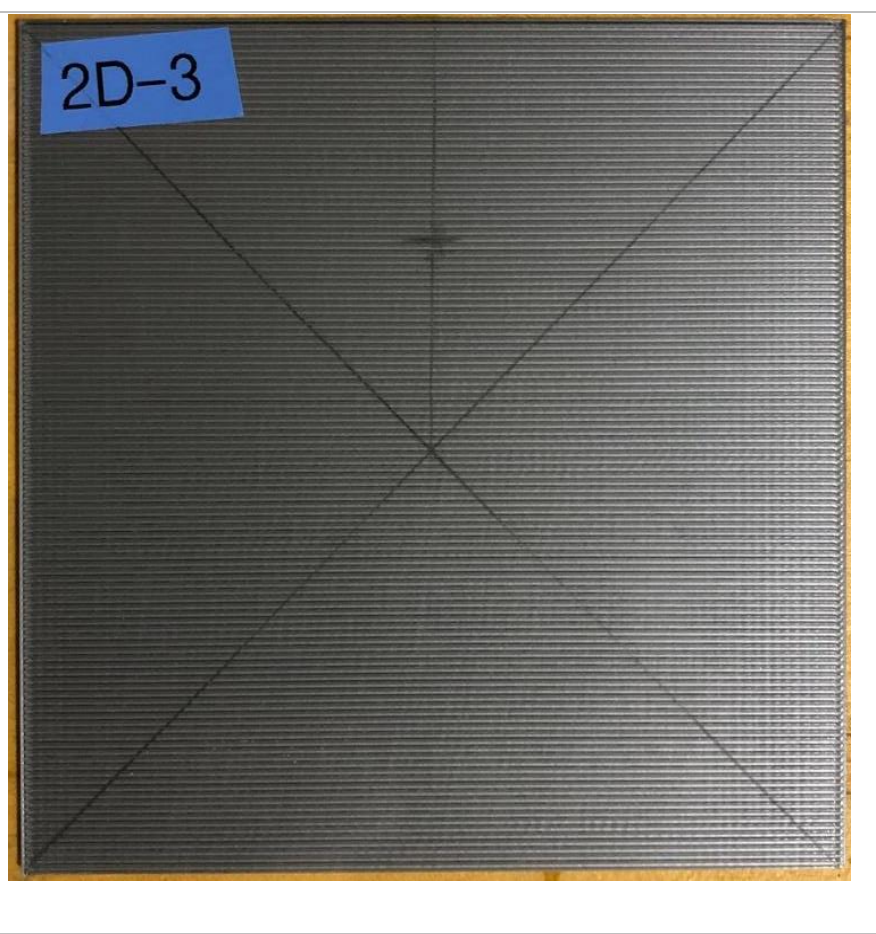

(b)

Figure 3.7: 3D Printed PLA plate before testing: (a) for location P1 (b) for location P2

\subsection{Testing Procedure}

After the specimens were 3D printed, they were stored at room temperature before testing.

During the testing procedure, a MotionPro X3 high speed camera (Figure 3.8) was used to calculate the rebound angle and hence determine the rebound and absorbed energy. The absorbed energy by the specimen post-impact was used to determine the effect of layer 
thickness on the low velocity impact strength. As seen in Figure 3.8, the high-speed camera is placed at the side of the apparatus in the line of sight of the pendulum to get a clear video of the pendulum and the pendulum arm. The high-speed camera can record a video up to a frequency of $1040 \mathrm{~Hz}$.

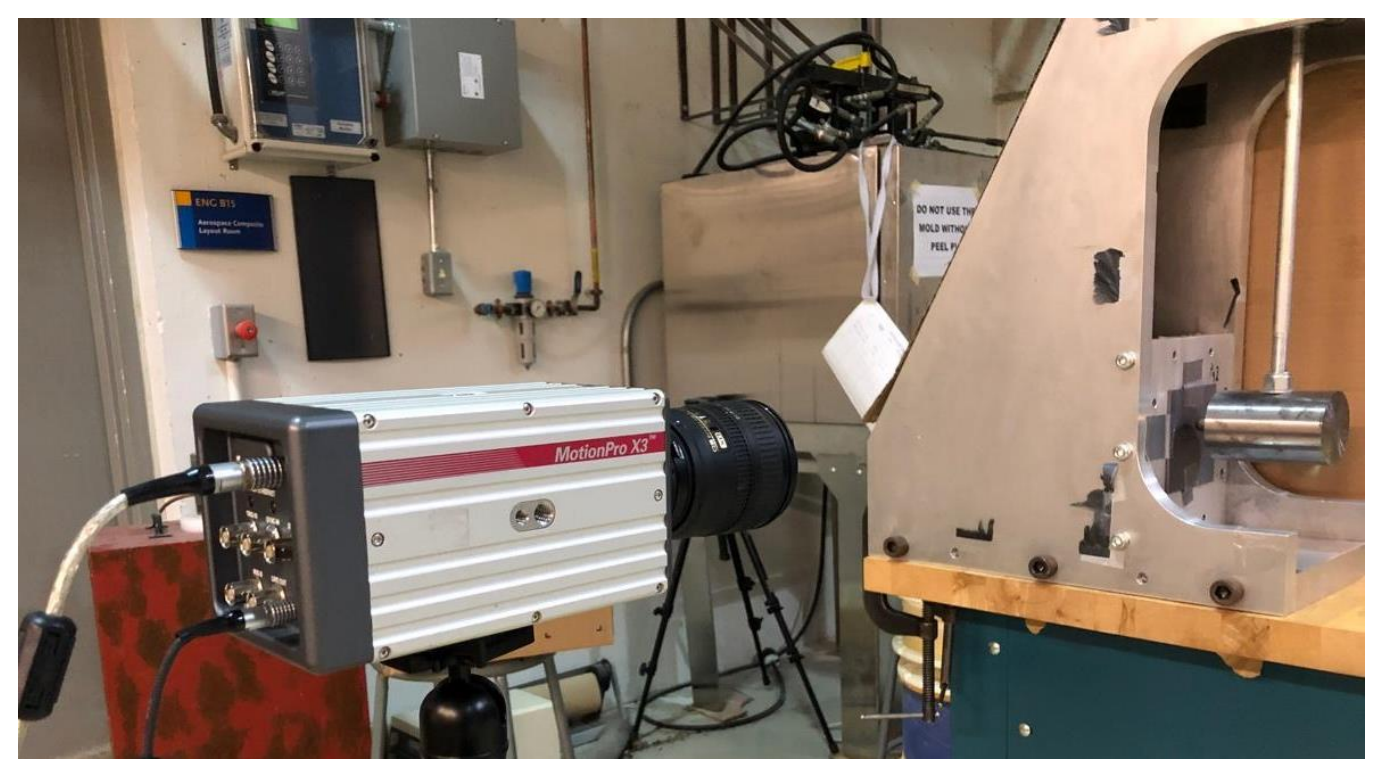

Figure 3.8: MotionPro X3 high-speed camera

Due to the lighting conditions at the laboratory, a video was recorded at $300 \mathrm{~Hz}$ frequency. Further to enhance the video and get a better view of the pendulum arm, high-intensity industrial lights were used during the testing (Figure 3.9) 


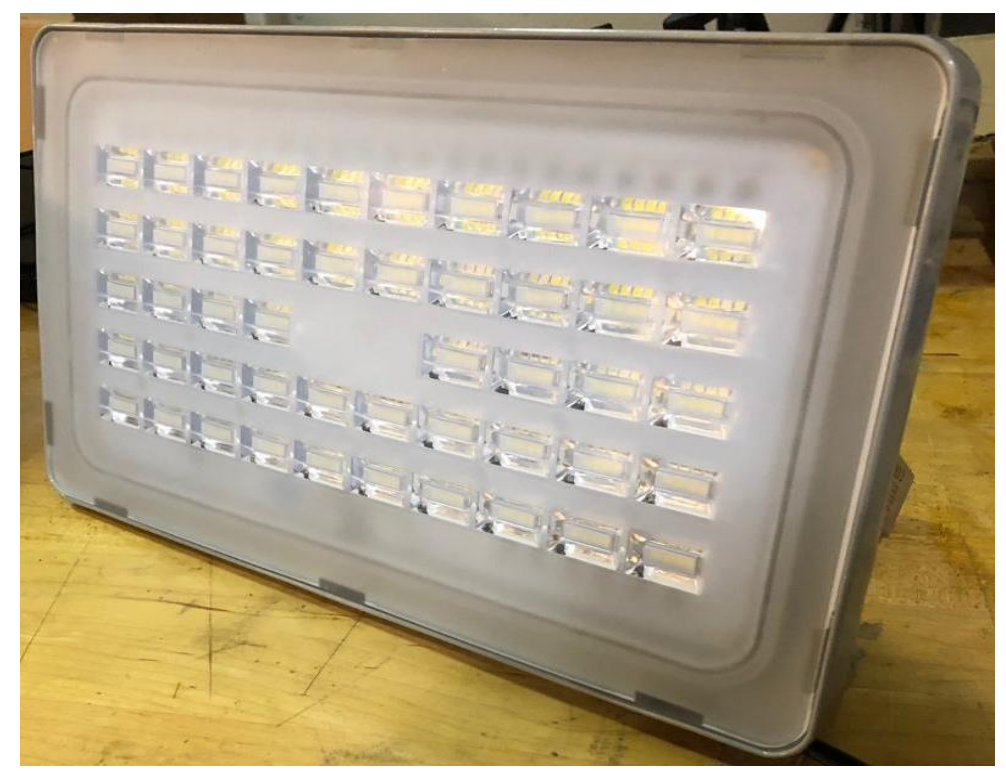

Figure 3.9: Industrial Light

An IDT MotionPro x64 software was used to record video of the impact event and perform post-processing on the recorded video. To help with the calculation of the rebound angle, an Iconico screen protractor software was used. After the impact, the pendulum moves backwards due to the rebound energy in the pendulum. The pendulum arm swings to a maximum angle where the rebound angle is maximum, after this point, the pendulum starts to move back towards the specimen. At this point the video is paused, and the rebound angle is calculated with the help of the screen protractor. The screen protractor is shown in Figure 3.10. The figure shows two arms of the protractor, one arm (red color) is kept vertical and other arm (blue color) is aligned with the pendulum arm where the video is paused to determine the rebound angle. 


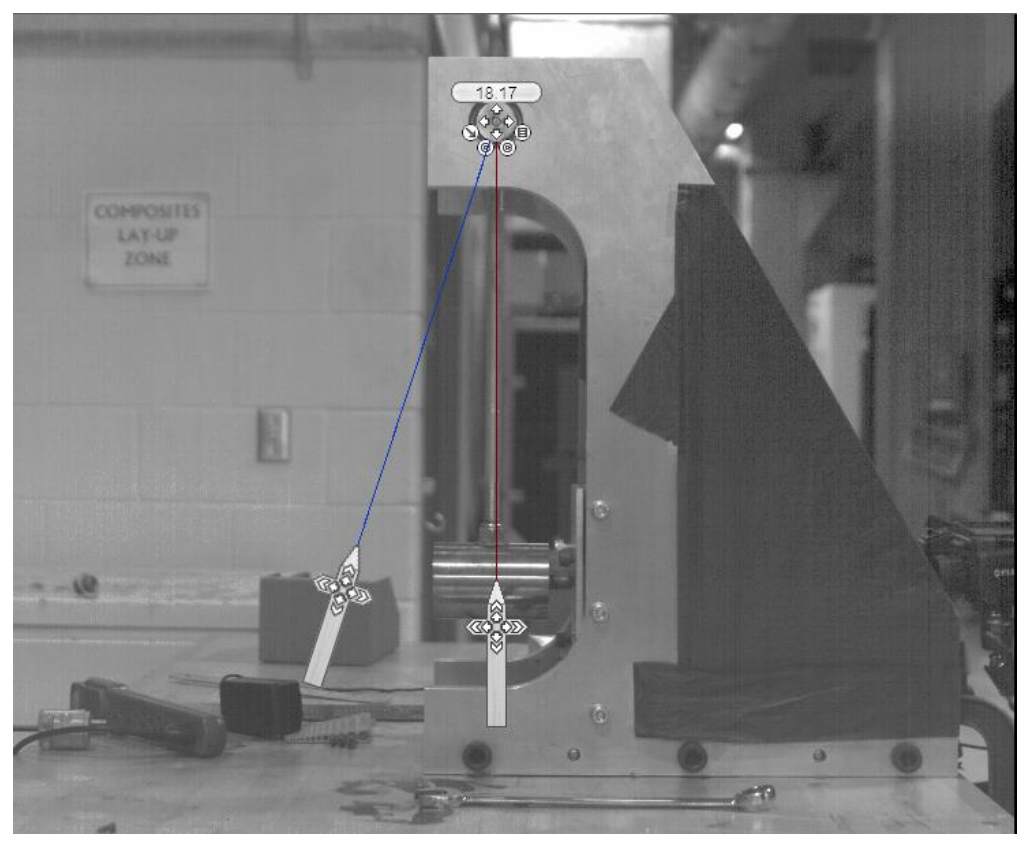

Figure 3.10: Screen protractor

Thermography is an emerging Non-Destructive Testing (NDT) technique to detect damages in 3D printed parts. Hence in this study, thermography was performed for better understanding of the failure mechanisms of different tested specimens. With the help of the thermal images, the damage pattern and its extent were evaluated. In addition, specimen with highest absorbed impact energy were identified since they experienced more damage and cracking. Some of the damages were not visible to the naked eye, but these barely visible damages due to the low velocity impact can be seen in the thermal images.

The video was recorded and saved with the help of the Altair software which supports the FLIR IR cameras. The IR camera used in this study is shown in Figure 3.11. 


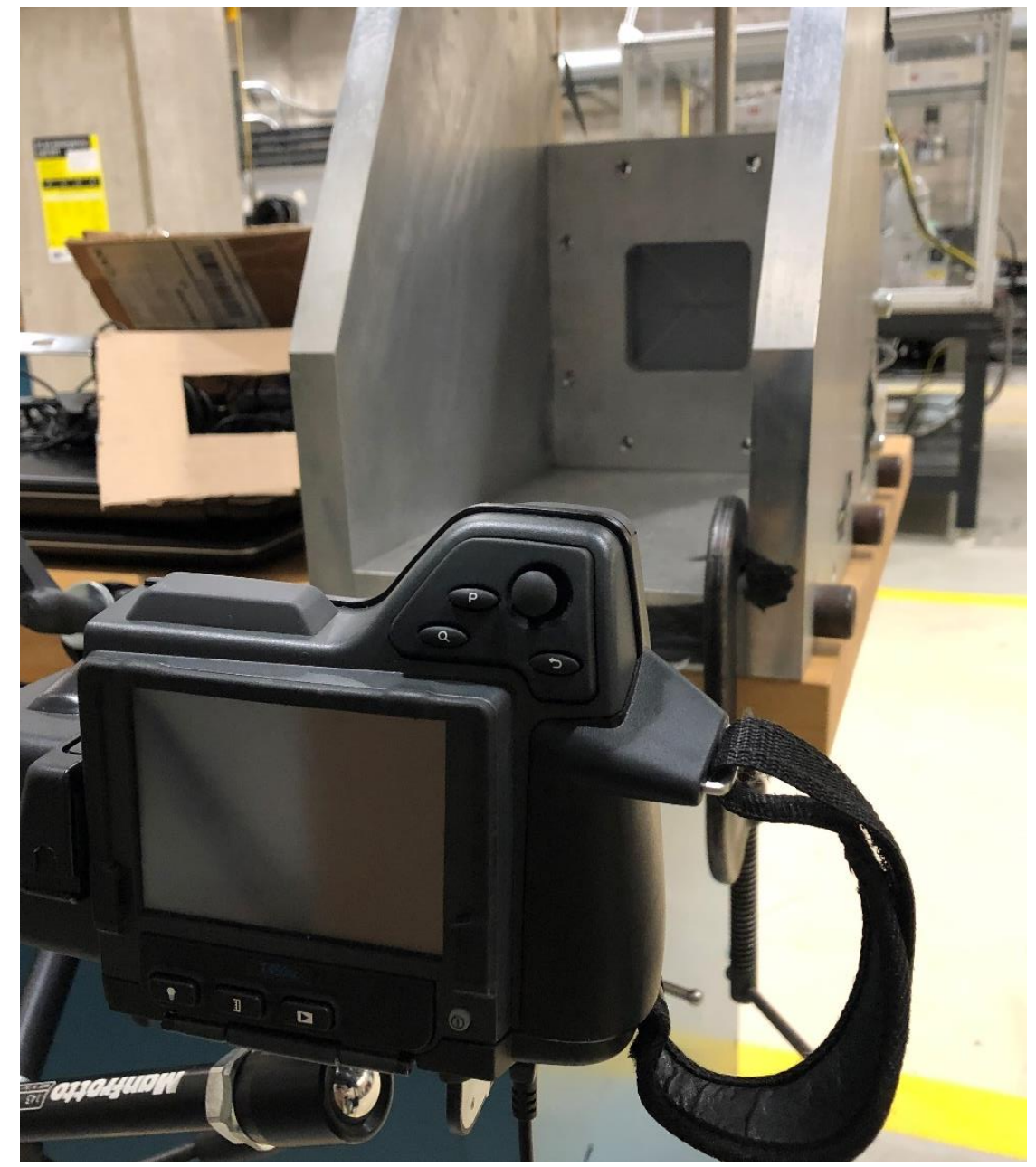

Figure 3.11: FLIR T450SC IR Camera

In this study, to analyze the low velocity impact damage characteristics of PLA plates, 3D printed specimens were subjected to low velocity impact on an in-house manufactured pendulum impact apparatus. Different coupons were printed with varying layer thicknesses and were impacted at two different impact locations. Post impact, NDT technique of thermography was used to understand the fracture mechanisms and analyze the fracture surfaces. In section 4, the results are presented with an explanation of the fracture mechanisms for different test cases.

\section{Results and Discussion}

Section 3 provided a detailed description of the testing apparatus, the test plan, specimen manufacturing and the testing procedure. Tests were performed on 3D printed PLA plates 
with varying layer thicknesses keeping the laminate thickness constant i.e. $2.54 \mathrm{~mm}$. To keep the laminate thickness constant along with the layer thickness, the number of layers for each coupon were changed. The coupons were impacted with $3 \mathrm{~J}$ energy which was transferred to the coupon by a pendulum impactor. For every case, three samples were manufactured and tested for two different impact locations. In this section, the results and the conclusions are briefly discussed from the tests to understand the low velocity impact damage characteristics of PLA parts. In addition to the camera pictures for each sample, infra-red pictures are presented alongside for better understanding of the damage. Since three samples were tested for each case, the rebound energy values are recorded for each sample to calculate the absorbed energy, but to calculate absorbed energy percentage, the average of all three absorbed and rebound energy values was taken. In the following section, the camera and infra-red pictures are presented for only one sample but all the results are shown in the appendices (section 7).

In this low velocity impact testing, when the coupons are impacted with $3 \mathrm{~J}$ energy by the impactor, some of the energy of the impactor is transferred to the test specimens. If the entire energy is absorbed by the specimen, it will shatter the test part; however, depending on the conditions, the specimen may also transfer some of the momentum to the impactor causing a rebound. As a result, the impact energy is divided into the absorbed energy by the specimen and the rebound energy. The absorbed energy can be calculated with the help of equation 3.6 presented in the section 3 ,

$$
E_{a b}=E-E_{R}
$$

Using this formula, the absorbed energy is calculated for all the samples however for understanding purposes, a detailed calculation example is shown below for case ID 1a, that is, sample with 25 layers and impact location $P_{1}$. The calculations explain how the release angle $(\alpha)$ and rebound angle $(\theta)$ can be used to get the absorbed energy value.

For Case ID 1a1:

Impact Energy $(E)=3 \mathrm{~J}$

Mass of Impactor $(M)=4.4 \mathrm{Kg}$ 
Acceleration due to gravity $(\mathrm{g})=9.807 \mathrm{~ms}^{-2}$

Length of the pendulum arm (L) for impact location $P_{1}=0.457 \mathrm{~m}$

The rebound angle as calculated by high-speed camera readings and the screen protractor software $(\theta)=22.20^{\circ}$

Using equation 3.1 from section 3,

$$
\begin{gathered}
E=m g H_{1} \\
3=4.4 \times 9.807 \times H_{1} \\
H_{1}=0.0695 \mathrm{~m}
\end{gathered}
$$

With the help of $\mathrm{H}_{1}$, the value of the impact angle can be calculated using the equation 3.3,

$$
\begin{gathered}
\alpha=\left[1-\frac{H_{1}}{L}\right] \\
\alpha=\left[1-\frac{0.0695}{0.457}\right] \\
\alpha=32.02^{\circ}
\end{gathered}
$$

The value of $\alpha$ gives the angle at which the pendulum is dropped such that the impact energy is equal to $3 \mathrm{~J}$. The value of $\alpha$ remains constant for all the specimens impacted at location $\mathrm{P}_{1}$.

After the impact, due to the transfer of energy, the rebound energy and the absorbed energy can be calculated. This can be done by using the rebound angle, $\theta$ and equation 3.4.

$$
\begin{gathered}
H_{2}=L(1-\cos \cos \theta) \\
H_{2}=0.457 \times(1-\cos \cos (22.20)) \\
H_{2}=0.034 \mathrm{~m}
\end{gathered}
$$

From equation 3.5 , the rebound energy is calculated as, 


$$
\begin{gathered}
E_{R}=m g H_{2} \\
E_{R}=4.4 \times 9.807 \times 0.034 \\
E_{R}=1.462 \mathrm{~J}
\end{gathered}
$$

Finally, the absorbed energy by the coupon can be calculated using equation 3.6,

$$
\begin{gathered}
E_{a b}=E-E_{R} \\
E_{a b}=3-1.462 \\
E_{a b}=1.538 \mathrm{~J}
\end{gathered}
$$

This gives the absorbed energy for a PLA specimen with 25 layers and a laminate thickness of $2.54 \mathrm{~mm}$ impacted with $3 \mathrm{~J}$ impact energy at the centre position as $1.538 \mathrm{~J}$.

The same process is repeated for all the specimens to calculate the absorbed energy for every case and at the end, to calculate the absorbed energy percentage, the average of all three absorbed energies for a single case is taken.

This section is further divided into two subsections to discuss the effect of impact location individually. The first sections describe the effect of layer thickness when the specimen is impacted at location $P_{1}$ and the latter section describes the effect of layer thickness when the specimen is impacted at location $\mathrm{P}_{2}$.

\subsection{Results for Impact Location $P_{1}$}

The first coupons to be tested were the coupons with 25 layers, followed by 21 layers, then 16 and finally 14 layer specimens. 
The 25 layer coupons that were tested at location $\mathrm{P}_{1}$ show a severe crack along the horizontal axis and along the vertical axis. The horizontal and vertical cracks intensify at the upper half of the coupon making a $Z$ formation as shown in the figure 4.1 below.

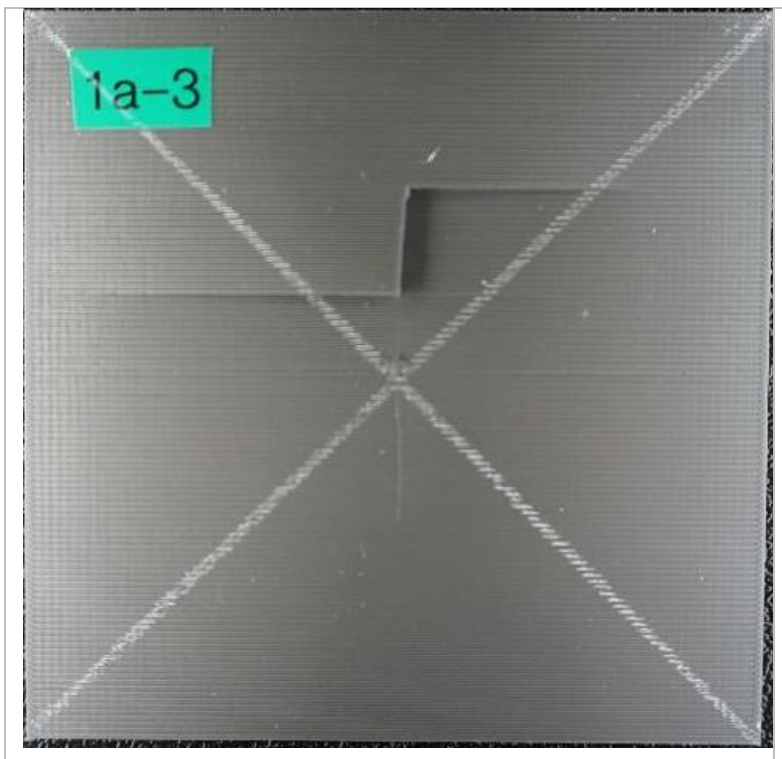

(a)

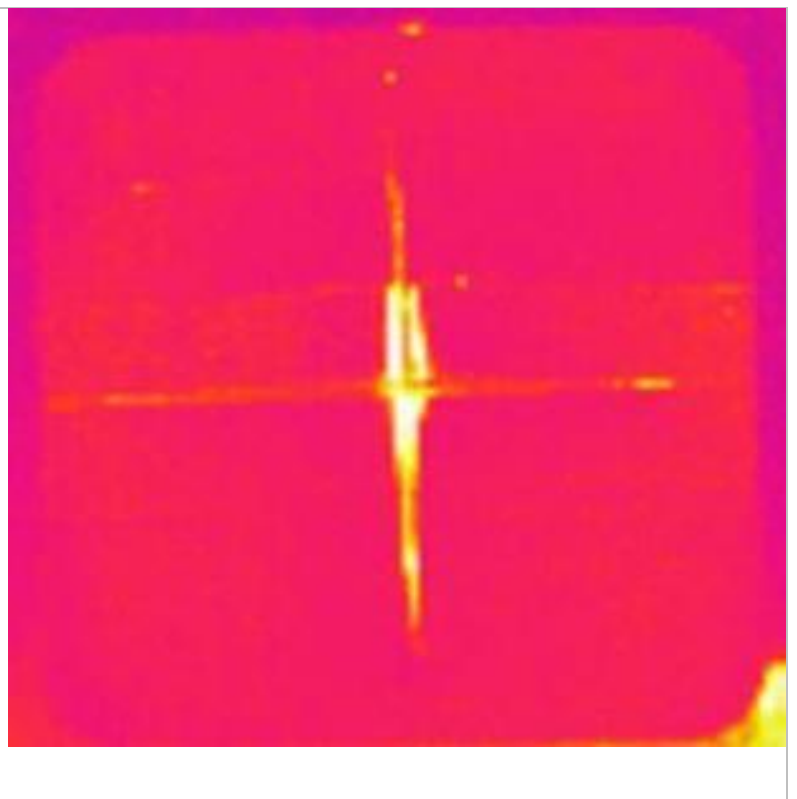

(b)

Figure 4.1: Specimens for location $P_{1}$ with 25 layers: (a) specimen after testing; (b) thermal imaging

When comparing this to the coupons with 21 layers, the cracks are not that severe and showed almost a similar pattern to the coupons with 25 layers with a horizontal and vertical crack originating from the center and an additional horizontal crack near the edge at the upper half section of the coupon. 


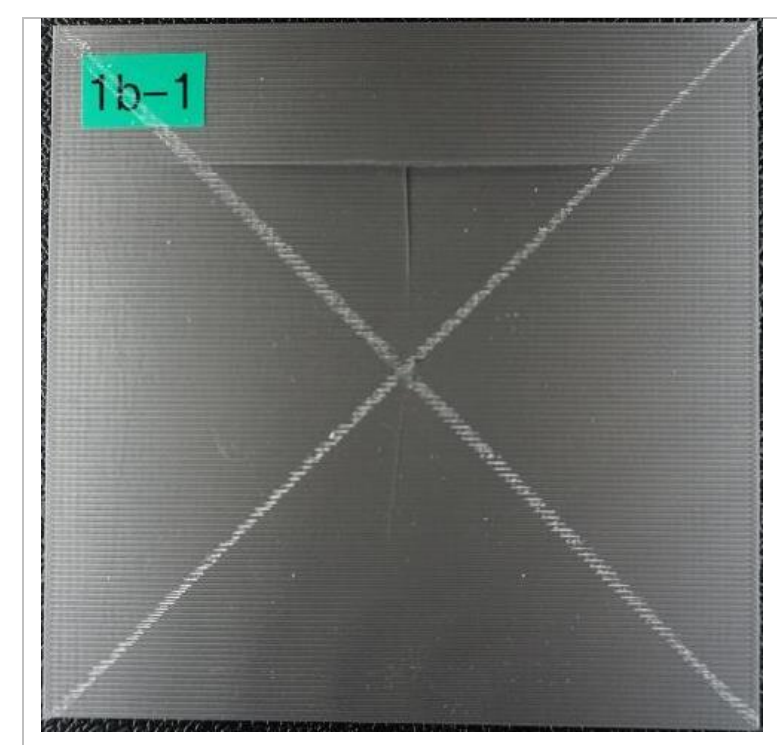

(a)

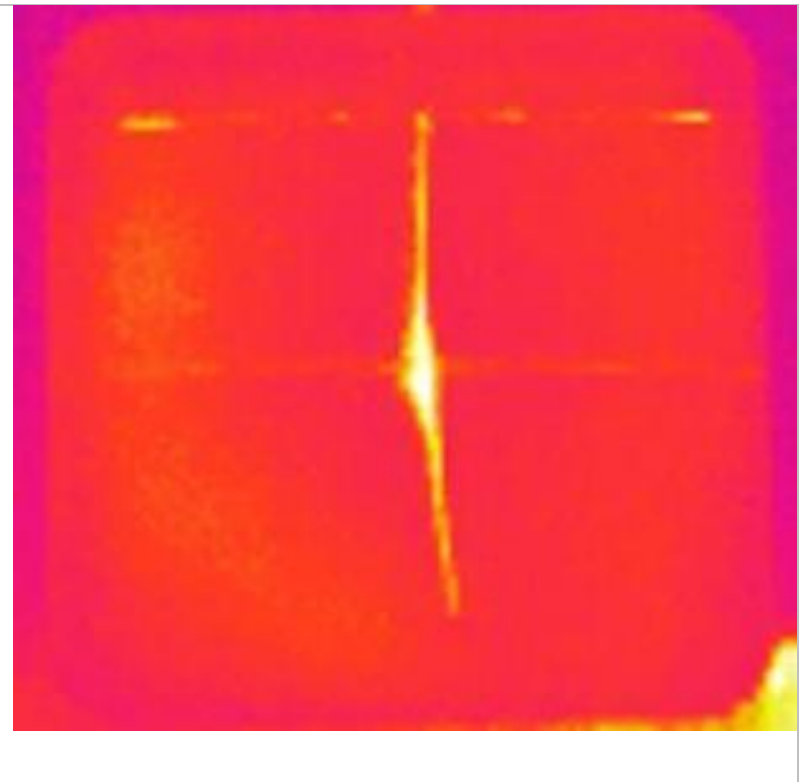

(b)

Figure 4.2: Specimens for location $P_{1}$ with 21 layers: (a) specimen after testing; (b) thermal imaging Analyzing the thermal pictures of the specimens with 16 layers showed that all three coupons tested for this case had different damage patterns. The picture shown below (figure 4.3) is of the specimen with the most critical damage. The thermal and the camera image show severe cracks along the horizontal and vertical direction.

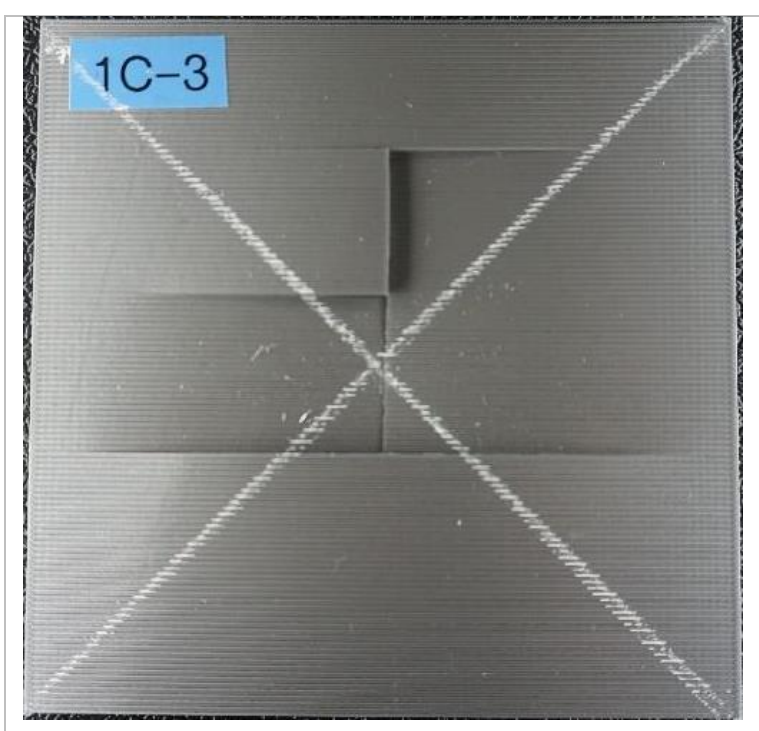

(a)

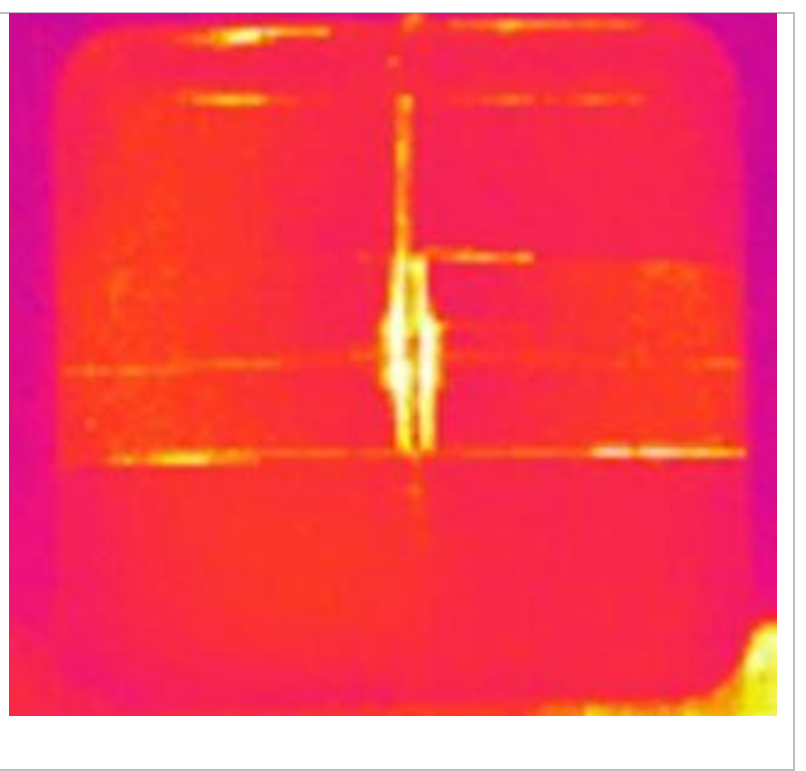

(b)

Figure 4.3: Specimens for location $P_{1}$ with 16 layers: (a) specimen after testing; (b) thermal imaging 
The last set of coupons tested for position $\mathrm{P}_{1}$ had 14 layers. Every sample had a horizontal center crack and a vertical crack that terminated at different horizontal positions for all three tests. For the first sample, there was a horizontal crack at a distance slightly above the centre, for the second sample, the horizontal crack was near the upper edge (Figure 4.4).

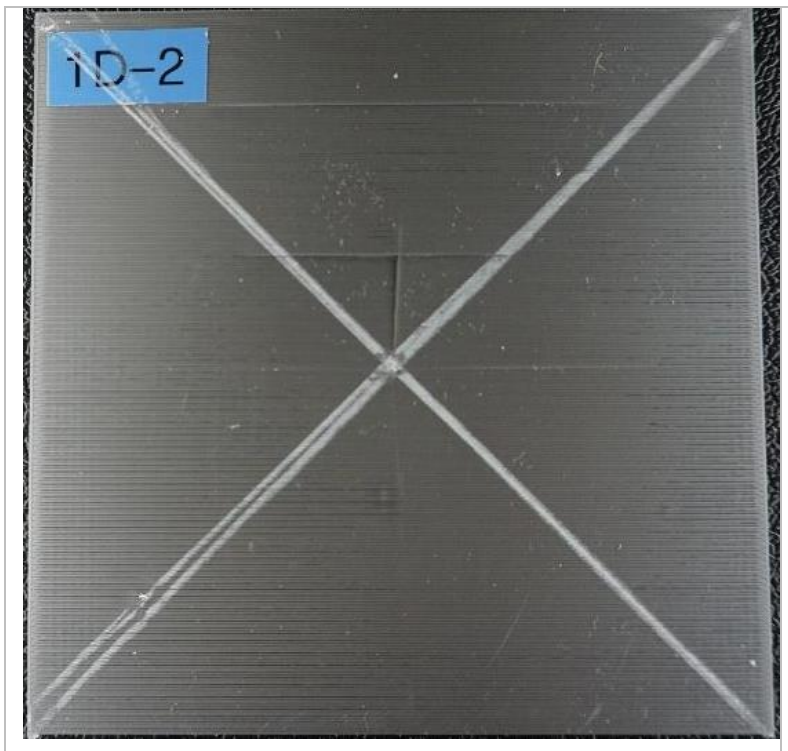

(a)

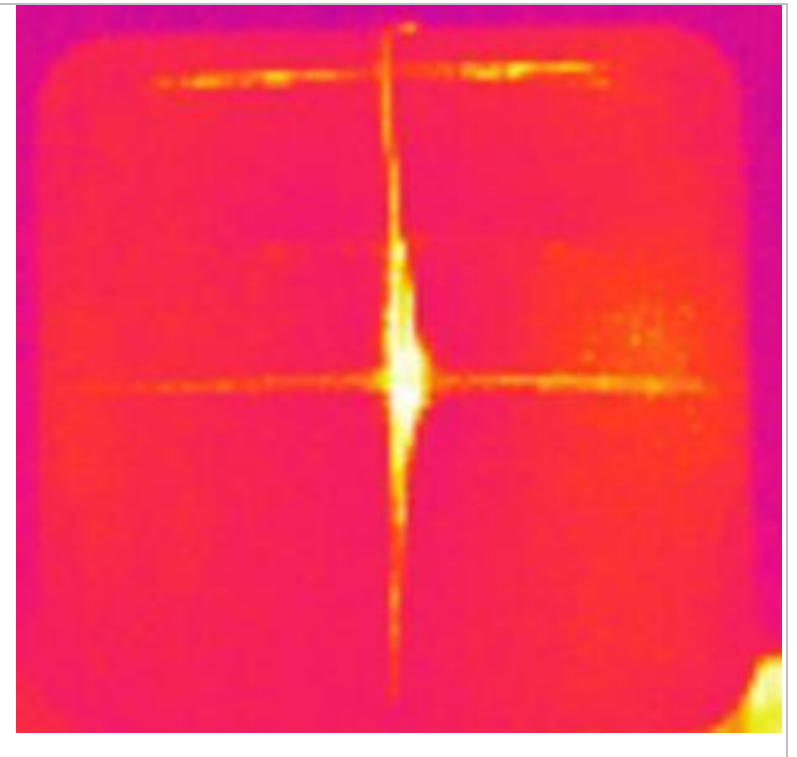

(b)

Figure 4.4: Specimens for location $P_{1}$ with 14 layers: (a) specimen after testing; (b) thermal image

And, as shown in figure 4.5 , in regards to the third sample, the horizontal crack was at a position below the center. 


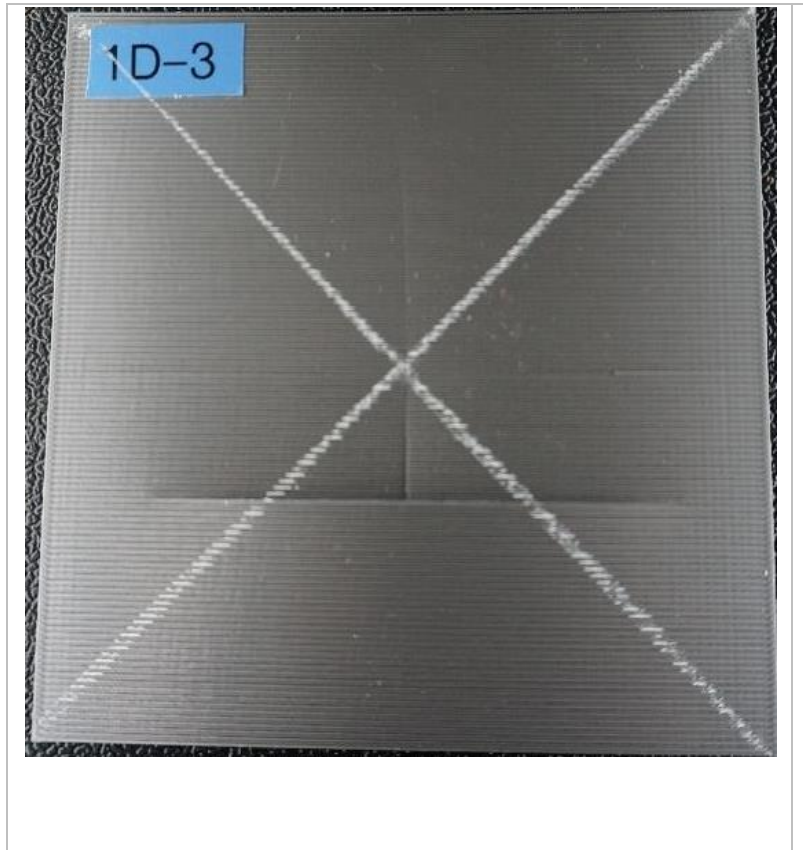

(a)

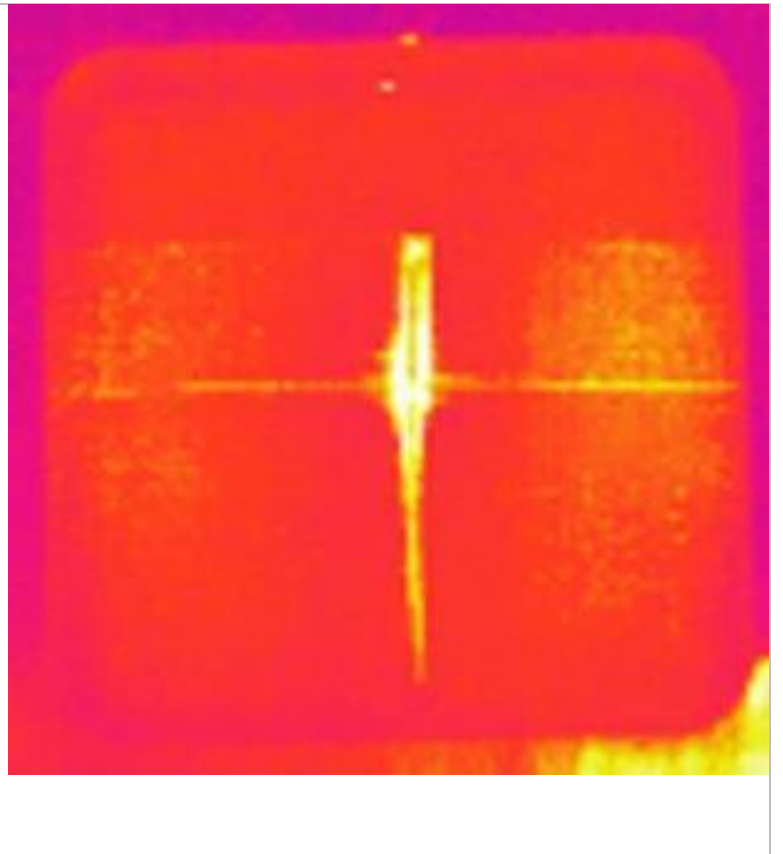

(b)

Figure 4.5: Specimens for location $P_{1}$ with 14 layers: (a) specimen after testing; (b) thermal imaging

The procedure mentioned above is used to calculate the rebound and hence the absorbed energy for every case using Microsoft Excel and a table is created to compare the values of absorbed energy for different specimens. This is done to understand the different damage patterns for coupons with different layer thicknesses and impact locations. The table below (Table 4.1) gives in detail the values of the rebound angle and rebound energy for all three samples tested for a specific case ID.

Table 4.1: Rebound energy calculations for each specimen tested at $\mathbf{P}_{\mathbf{1}}$

\begin{tabular}{|c|c|c|c|c|c|c|c|c|c|}
\hline \multirow{2}{*}{$\begin{array}{c}\text { Test } \\
\text { case } \\
\text { ID }\end{array}$} & \multirow{2}{*}{$\begin{array}{c}\text { Impact } \\
\text { energy } \\
\text { (J) }\end{array}$} & \multirow{2}{*}{$\begin{array}{l}\text { Impact } \\
\text { location }\end{array}$} & \multirow{2}{*}{$\begin{array}{c}\text { Impact } \\
\text { angle } \\
\left(\alpha^{\circ}\right)\end{array}$} & \multicolumn{3}{|c|}{ Rebound angle $\left(\theta^{\circ}\right)$} & \multicolumn{3}{|c|}{ Rebound Energy (J) } \\
\hline & & & & $\begin{array}{c}\text { Sample } \\
\# 1\end{array}$ & $\begin{array}{c}\text { Sample } \\
\# 2\end{array}$ & $\begin{array}{c}\text { Sample } \\
\text { \#3 }\end{array}$ & $\begin{array}{c}\text { Sample } \\
\# 1\end{array}$ & $\begin{array}{c}\text { Sample } \\
\# 2\end{array}$ & $\begin{array}{c}\text { Sample } \\
\# 3\end{array}$ \\
\hline $1 a$ & \multirow{3}{*}{3} & \multirow{3}{*}{$P_{1}$} & \multirow{3}{*}{32.02} & 22.20 & 20.66 & 18.78 & 1.462 & 1.268 & 1.050 \\
\hline $1 b$ & & & & 16.00 & 17.40 & 19.45 & 0.764 & 0.902 & 1.125 \\
\hline 1c & & & & 14.02 & 22.12 & 14.11 & 0.587 & 1.451 & 0.595 \\
\hline
\end{tabular}


Following the calculation of rebound energy, absorbed energy is calculated using equation

3.6. The average of all three values is taken to calculate the absorbed energy percentage.

MNR method was used to find any outliers in the test and the MNR test concluded that the absorbed energy value for sample number 2 in case of test ID 1c results in the MNR value higher than that critical value and hence this sample is ignored when calculating the absorbed energy percentage for case ID 1c. The table below presents the absorbed energy percentage values after implementing all the changes.

Table 4.2: Rebound and absorbed energies for each specimen tested at $P_{1}$

\begin{tabular}{|c|c|c|c|c|c|c|c|c|c|}
\hline \multirow{2}{*}{$\begin{array}{c}\text { Test } \\
\text { case } \\
\text { ID }\end{array}$} & \multicolumn{3}{|c|}{ Rebound Energy $(\mathrm{J})$} & \multirow{2}{*}{$\begin{array}{l}\text { Average } \\
\text { rebound } \\
\text { energy } \\
\text { (J) }\end{array}$} & \multicolumn{3}{|c|}{ Absorbed Energy (J) } & \multirow{2}{*}{$\begin{array}{l}\text { Average } \\
\text { absorbed } \\
\text { energy (J) }\end{array}$} & \multirow{2}{*}{$\begin{array}{l}\text { Absorbed } \\
\text { energy } \\
\text { percentage }\end{array}$} \\
\hline & $\begin{array}{c}\text { Sample } \\
\quad \# 1\end{array}$ & $\begin{array}{c}\text { Sample } \\
\# 2\end{array}$ & $\begin{array}{c}\text { Sample } \\
\# 3\end{array}$ & & $\begin{array}{c}\text { Sample } \\
\# 1\end{array}$ & $\begin{array}{c}\text { Sample } \\
\# 2\end{array}$ & $\begin{array}{c}\text { Sample } \\
\text { \#3 }\end{array}$ & & \\
\hline $1 a$ & 1.462 & 1.268 & 1.050 & 1.260 & 1.538 & 1.732 & 1.950 & 1.740 & 58.00 \\
\hline $1 b$ & 0.764 & 0.902 & 1.125 & 0.930 & 2.236 & 2.098 & 1.875 & 2.070 & 69.00 \\
\hline 1c & 0.587 & 1.451 & 0.595 & 0.877 & 2.413 & 1.549 & 2.405 & 2.409 & 80.30 \\
\hline 1d & 0.776 & 0.893 & 0.693 & 0.787 & 2.224 & 2.107 & 2.307 & 2.213 & 73.76 \\
\hline
\end{tabular}

Standard deviation values were also calculated for each case ID using Microsoft Excel and the results are provided in the table 4.3 .

Table 4.3: Standard deviation for each test at $P_{1}$

\begin{tabular}{|c|c|c|}
\hline Test case ID & $\begin{array}{c}\text { Absorbed energy } \\
\text { percentage }\end{array}$ & $\begin{array}{c}\text { Standard } \\
\text { deviation }\end{array}$ \\
\hline 1a & 58.00 & 0.2061 \\
\hline 1b & 69.00 & 0.1821 \\
\hline
\end{tabular}




\begin{tabular}{|c|c|c|}
\hline 1c & 80.30 & 0.0056 \\
\hline 1d & 73.76 & 0.1004 \\
\hline
\end{tabular}

From the tables it can be concluded that as the number of layer decrease, that is, the layer thickness increases, the absorbed energy percentage first increases and then decreases. And the damage is higher for specimens with higher absorbed energy hence it shows that the highest damage is for specimens with 16 layers when the PLA plates are tested at impact location $\mathrm{P}_{1}$. This is also confirmed by the thermal pictures where figure 4.3 shows the most severe damage among all the cases.

The absorbed energy percentage is plotted against layer thickness in the figure 4.6. The plot gives a description of the standard error as well.

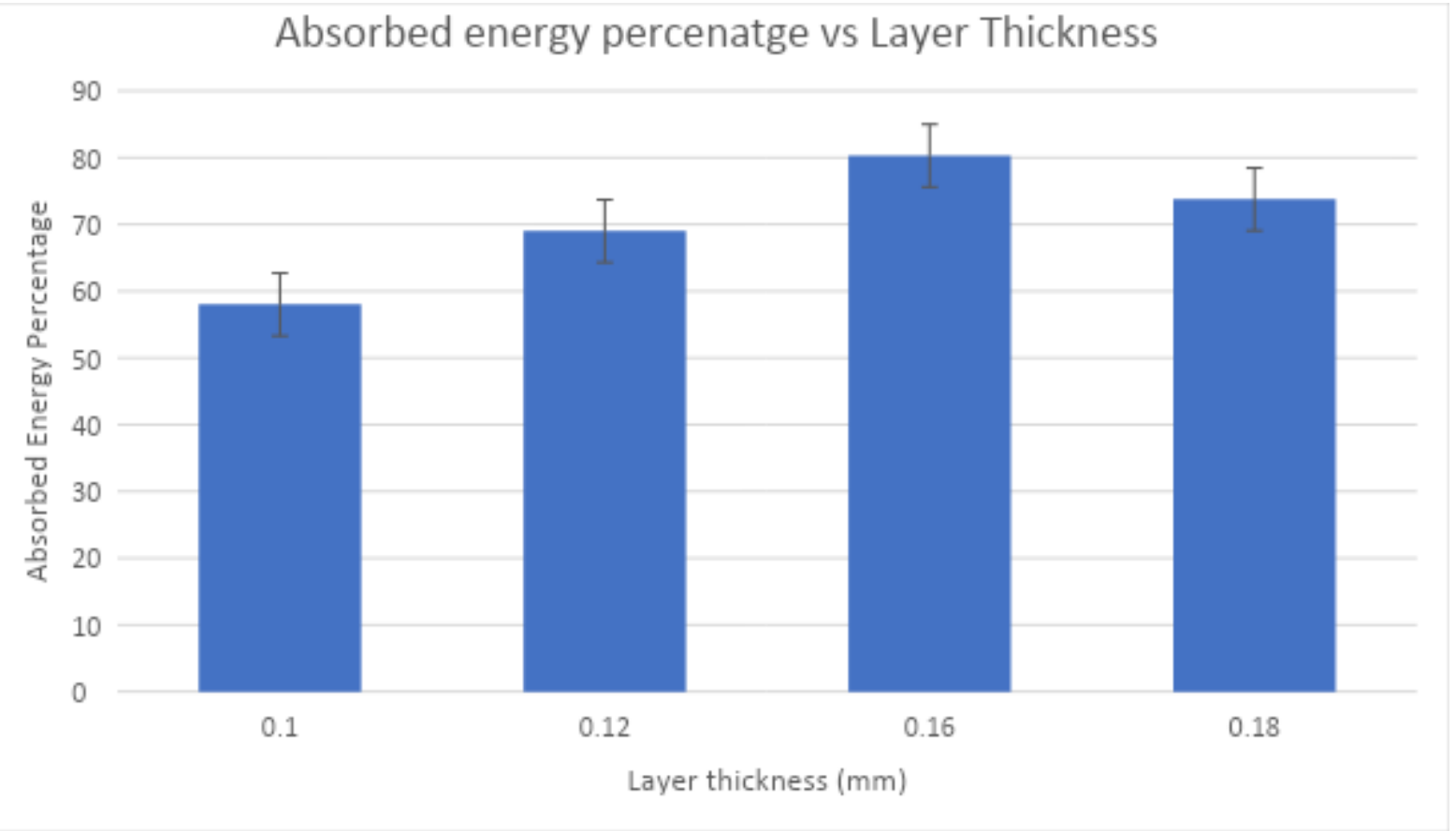

Figure 4.6: Absorbed energy percentage versus layer thickness at $\mathbf{P}_{1}$ location

\subsection{Results for Impact Location $P_{2}$}

The same types of coupons were tested for position $\mathrm{P}_{2}$ and it was observed that the damage for 25, 21 and 16 layers was more severe than in the previous case of $P_{1}$ location. For 25 
layers, all the samples experienced a horizontal fracture along the impact location; however, for one the part of the specimen the coupon broke completely at the impact location (shown in the figure 4.7).

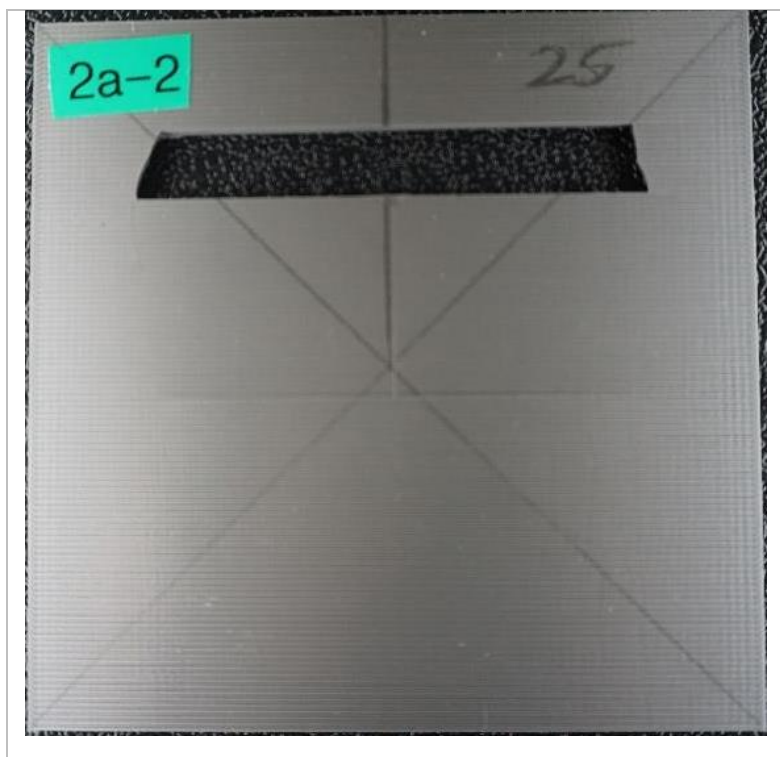

(a)

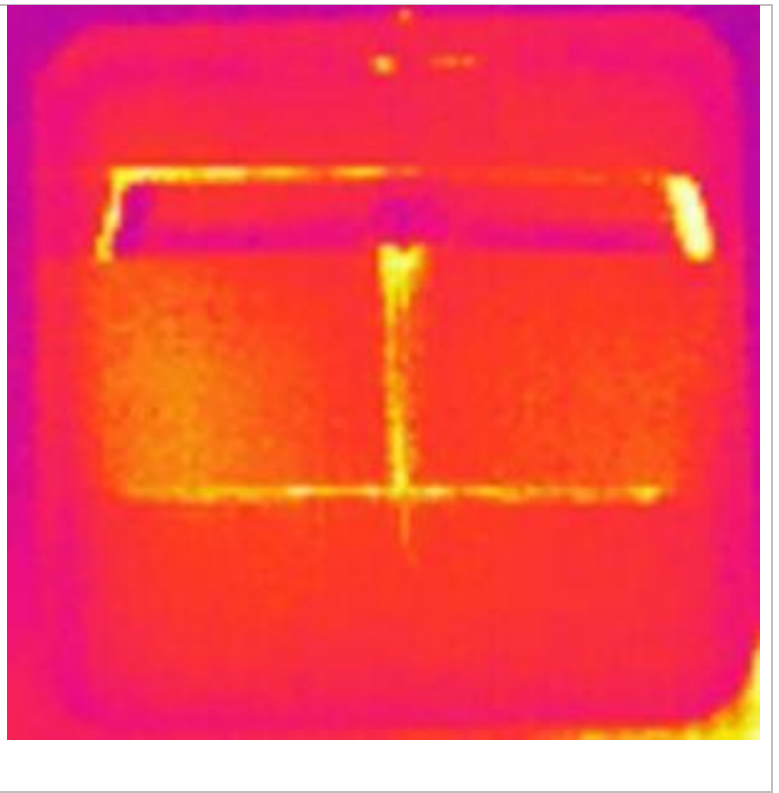

(b)

Figure 4.7: Specimens for location $P_{2}$ with 25 layers: (a) specimen after testing; (b) thermal imaging

When the next set of coupons was tested (21 layers), the pattern for all the samples was different, but if critically observed there could be seen some similarities. For example, for a sample, there was a horizontal crack above the location $\mathrm{P}_{2}$ and a vertical crack travelling downward the vertical crack terminated with a horizontal crack at a location near the centre (figure 4.8). 


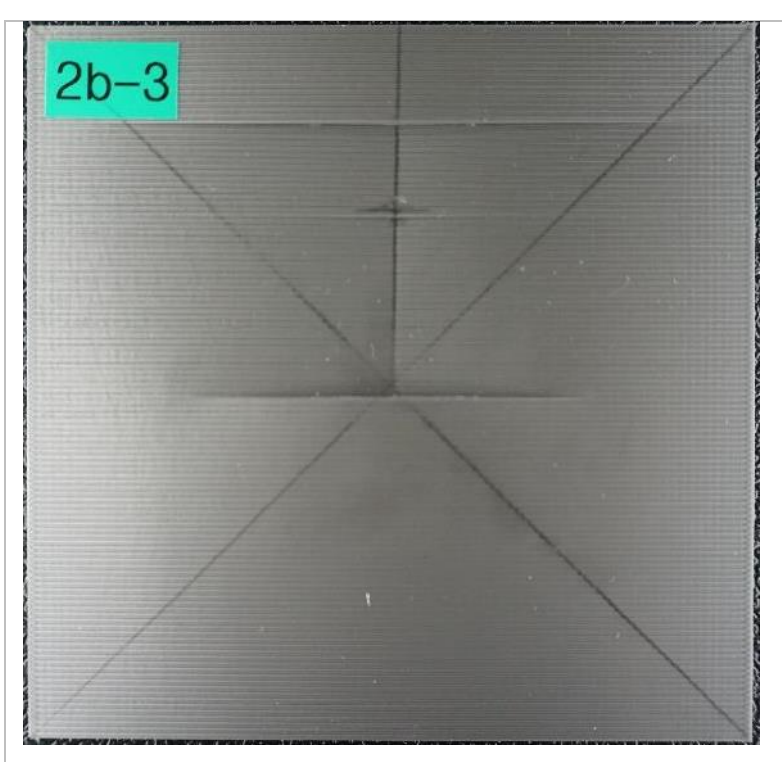

(a)

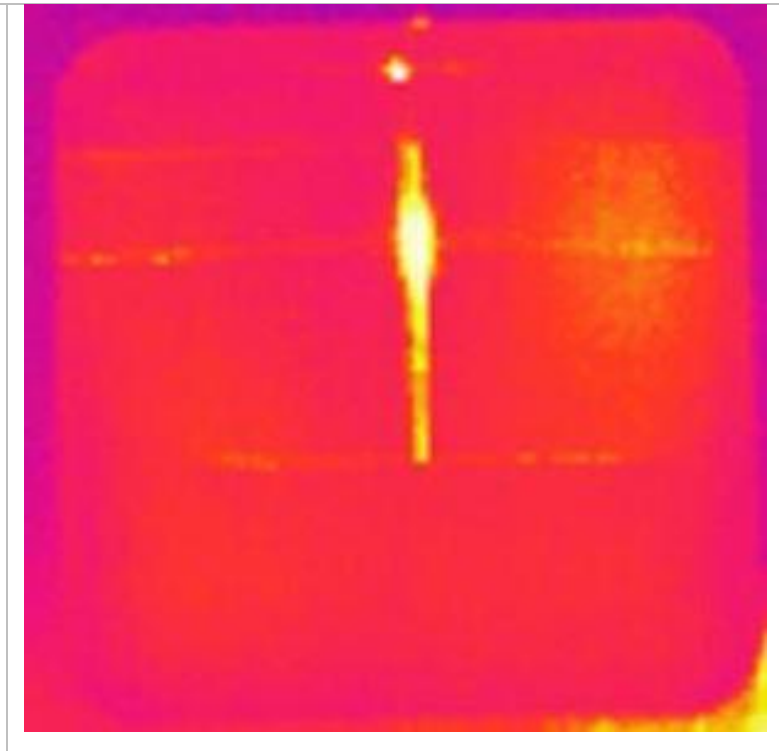

(b)

Figure 4.8: Specimens for location $P_{2}$ with 21 layers: (a) specimen after testing; (b) thermal image

In case of another sample (figure 4.9), along with the crack at $P_{2}$ and a downward vertical crack terminating with a horizontal one, the vertical crack also travelled upward ending at a location near the edge again with a horizontal crack causing a part of the coupon to completely break between these cracks.

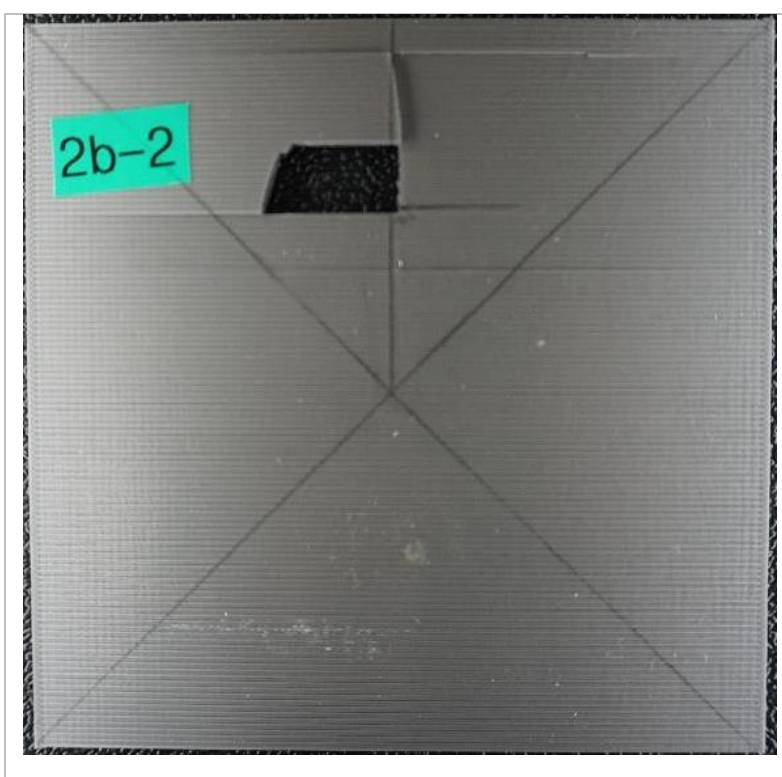

(a)

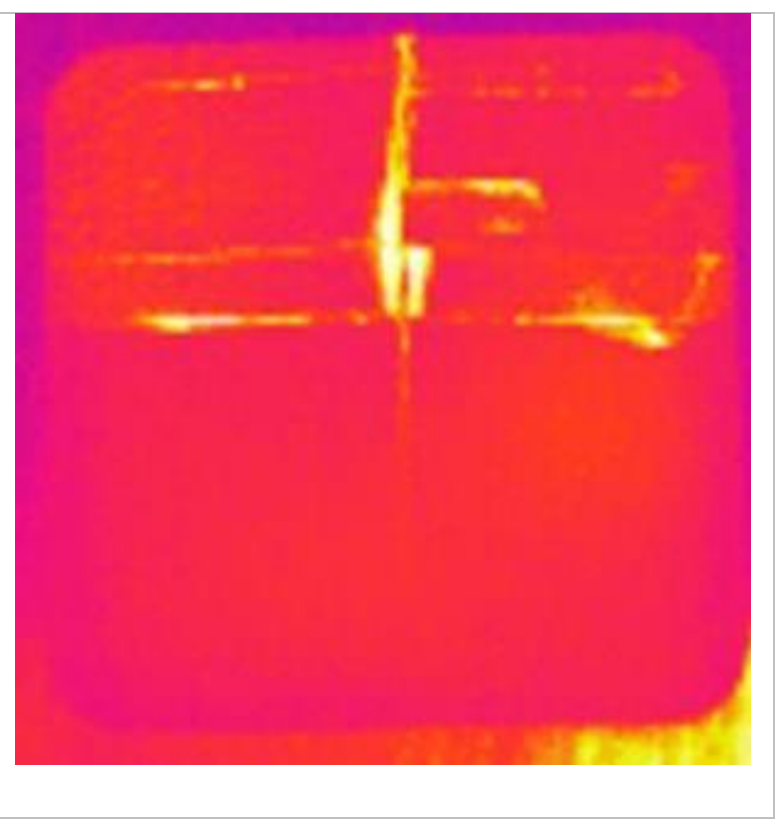

(b)

Figure 4.9: Specimens for location $P_{2}$ with 21 layers: (a) specimen after testing; (b) thermal imaging 
For the coupons with 16 layers, the coupons showed damage with two horizontal cracks at the impact location and near the upper edge, a vertical crack travelling all the way to the lower edge and a broken part between the horizontal cracks.

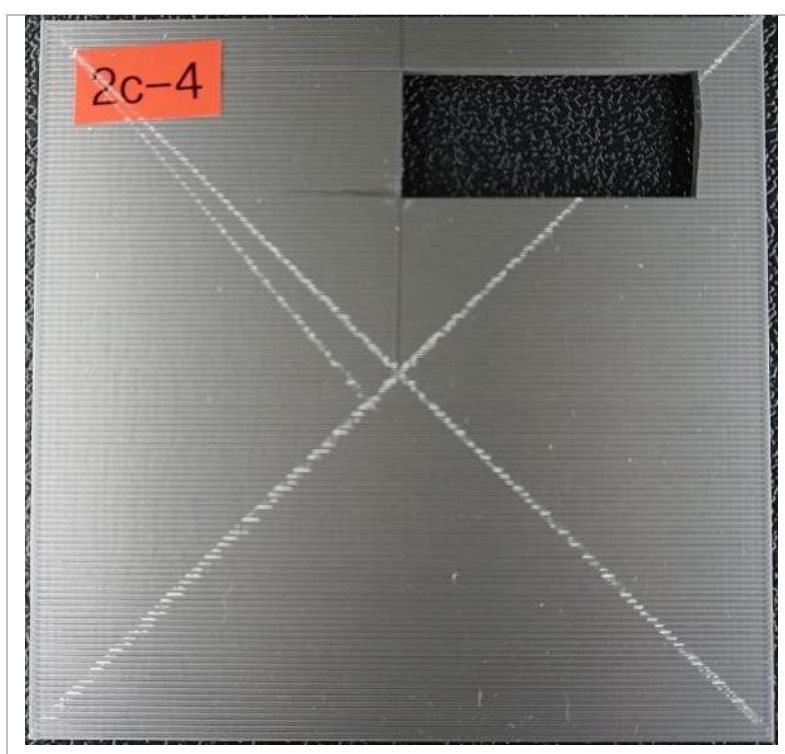

(a)

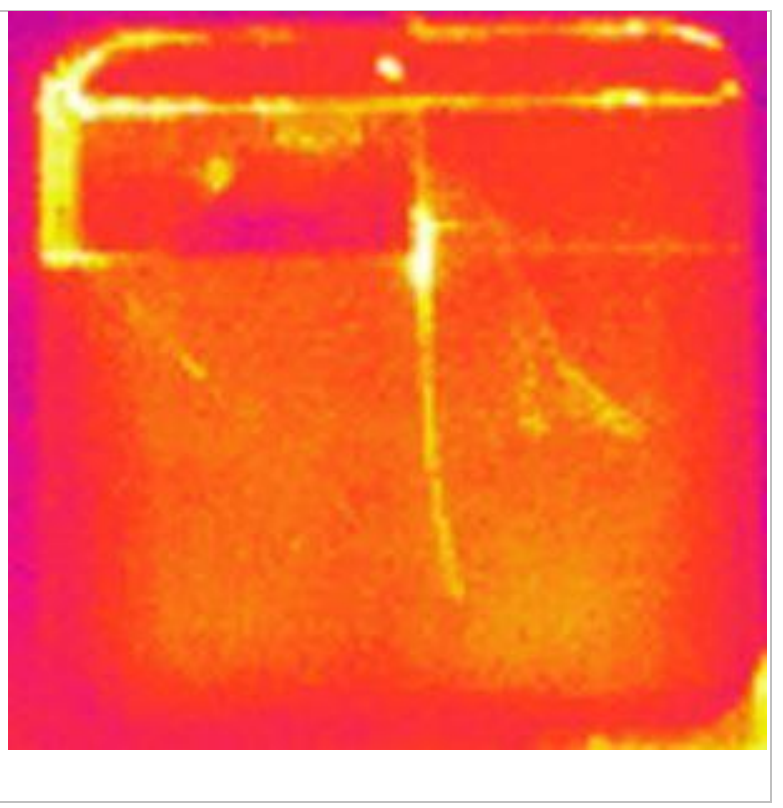

(b)

Figure 4.10: Specimens for location $P_{2}$ with 16 layers: (a) specimen after testing; (b) thermal imaging

At the end, observing the cracks in the specimens with 14 layers for location $P_{2}$, it can be seen that every coupon showed a horizontal crack at the impact location and a vertical crack but in addition to this for the coupon with the most severe damage, there was a horizontal crack near the upper edge and a completely broken part to the left of the impact location in addition to the formerly mentioned cracks (figure 4.11). 


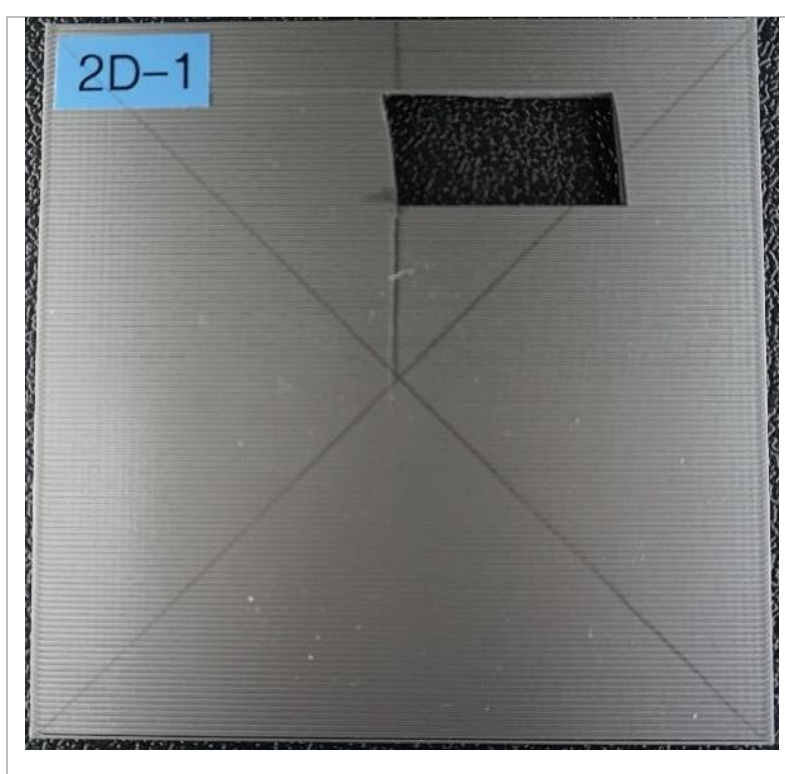

(a)

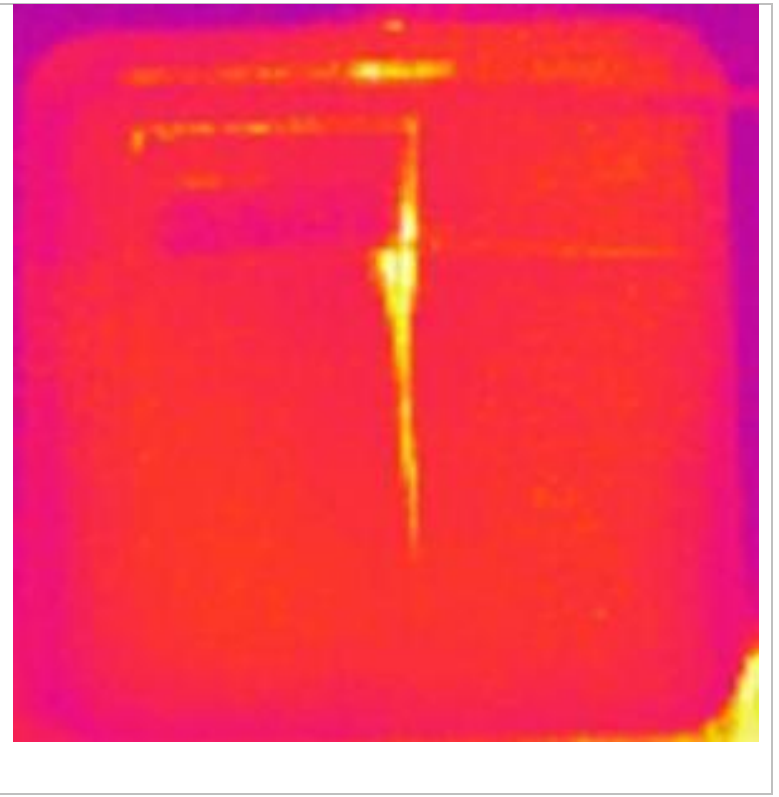

(b)

Figure 4.11: Specimens for location $P_{2}$ with 14 layers: (a) specimen after testing; (b) thermal imaging

In the next section, the results are explained with the help of rebound energy and absorbed energy calculations of each coupon for $\mathrm{P}_{2}$ impact location. Table 4.4 provides in detail the energy values for all three coupons tested for each case ID.

Table 4.4: Rebound energy calculations for each specimen tested at $\mathbf{P}_{\mathbf{2}}$

\begin{tabular}{|c|c|c|c|c|c|c|c|c|c|}
\hline \multirow{2}{*}{$\begin{array}{c}\text { Test } \\
\text { case } \\
\text { ID }\end{array}$} & \multirow{2}{*}{$\begin{array}{c}\text { Impact } \\
\text { energy } \\
\text { (J) }\end{array}$} & \multirow{2}{*}{$\begin{array}{l}\text { Impact } \\
\text { location }\end{array}$} & \multirow{2}{*}{$\begin{array}{c}\text { Impact } \\
\text { angle } \\
\left(\alpha^{\circ}\right)\end{array}$} & \multicolumn{3}{|c|}{ Rebound angle $\left(\theta^{\circ}\right)$} & \multicolumn{3}{|c|}{ Rebound Energy (J) } \\
\hline & & & & $\begin{array}{c}\text { Sample } \\
\# 1\end{array}$ & $\begin{array}{c}\text { Sample } \\
\# 2\end{array}$ & $\begin{array}{c}\text { Sample } \\
\# 3\end{array}$ & $\begin{array}{c}\text { Sample } \\
\# 1\end{array}$ & $\begin{array}{c}\text { Sample } \\
\# 2\end{array}$ & $\begin{array}{c}\text { Sample } \\
\# 3\end{array}$ \\
\hline $2 a$ & & & & 14.95 & 15.32 & 18.95 & 0.625 & 0.656 & 1.001 \\
\hline $2 b$ & 3 & $\mathrm{P}_{2}$ & 33.12 & 13.49 & 12.32 & 12.39 & 0.510 & 0.425 & 0.430 \\
\hline $2 c$ & & & & 18.20 & 19.75 & 14.40 & 0.924 & 1.086 & 0.580 \\
\hline $2 d$ & & & & 13.67 & 18.11 & 19.00 & 0.523 & 0.915 & 1.006 \\
\hline
\end{tabular}

Observing the table mentioned below (table 4.5) for the absorbed energy percentages, it can be concluded that the absorbed energy when the coupons are impacted at location $\mathrm{P}_{2}$ first 
increases with an increase in layer thickness then decreases and again increases. There is an increasing trend when the layer thickness is increased from $0.10 \mathrm{~mm}$ to $0.12 \mathrm{~mm}$ then the absorbed energy decreases with further increase in layer thickness to $0.16 \mathrm{~mm}$ and finally the absorbed energy again increases for $0.18 \mathrm{~mm}$ layer thickness. This uneven trend can be due to the difference in the clamping force for each specimen.

Table 4.5: Rebound and absorbed energies for each specimen tested at $P_{2}$

\begin{tabular}{|c|c|c|c|c|c|c|c|c|c|}
\hline \multirow{2}{*}{$\begin{array}{c}\text { Test } \\
\text { case } \\
\text { ID }\end{array}$} & \multicolumn{3}{|c|}{ Rebound Energy (J) } & \multirow{2}{*}{$\begin{array}{l}\text { Average } \\
\text { rebound } \\
\text { Energy } \\
\text { (J) }\end{array}$} & \multicolumn{3}{|c|}{ Absorbed Energy $(\mathrm{J})$} & \multirow{2}{*}{$\begin{array}{c}\text { Average } \\
\text { absorbed } \\
\text { energy } \\
\text { (J) }\end{array}$} & \multirow{2}{*}{$\begin{array}{c}\text { Absorbed } \\
\text { energy } \\
\text { percentage }\end{array}$} \\
\hline & $\begin{array}{c}\text { Sample } \\
\text { \#1 }\end{array}$ & $\begin{array}{c}\text { Sample } \\
\# 2\end{array}$ & $\begin{array}{c}\text { Sample } \\
\# 3\end{array}$ & & $\begin{array}{c}\text { Sample } \\
\# 1\end{array}$ & $\begin{array}{c}\text { Sample } \\
\# 2\end{array}$ & $\begin{array}{c}\text { Sample } \\
\# 3\end{array}$ & & \\
\hline $2 a$ & 0.625 & 0.656 & 1.001 & 0.760 & 2.375 & 2.344 & 1.999 & 2.240 & 74.66 \\
\hline $2 b$ & 0.510 & 0.425 & 0.430 & 0.455 & 2.490 & 2.575 & 2.570 & 2.545 & 84.83 \\
\hline $2 c$ & 0.924 & 1.086 & 0.580 & 0.863 & 2.076 & 1.914 & 2.420 & 2.137 & 71.23 \\
\hline $2 d$ & 0.523 & 0.915 & 1.006 & 0.814 & 2.477 & 2.085 & 1.994 & 2.186 & 72.86 \\
\hline
\end{tabular}

Similar to the process followed for impact location $\mathrm{P}_{1}$, Standard deviation values were also calculated for each case ID using Microsoft Excel and the results are provided in the table 4.6 for impact location $\mathrm{P}_{2}$.

Table 4.6: Standard deviation for each test at $\mathbf{P}_{2}$

\begin{tabular}{|c|c|c|}
\hline Test case ID & $\begin{array}{c}\text { Absorbed energy } \\
\text { percentage }\end{array}$ & $\begin{array}{c}\text { Standard } \\
\text { deviation }\end{array}$ \\
\hline $\mathbf{2 a}$ & 74.66 & 0.2087 \\
\hline $\mathbf{2 b}$ & 84.83 & 0.0476 \\
\hline $\mathbf{2 c}$ & 71.23 & 0.2583 \\
\hline
\end{tabular}




\begin{tabular}{|l|l|l|}
\hline 2d & 72.86 & 0.2566 \\
\hline
\end{tabular}

The absorbed energy percentage is plotted against layer thickness in the figure 4.12. The plot gives a description of the standard error as well. The graph agrees with the conclusion mentioned above and shows the same trend for absorbed energy percentage with layer thickness.

\section{Absorbed energy percentage vs Layer Thickness}

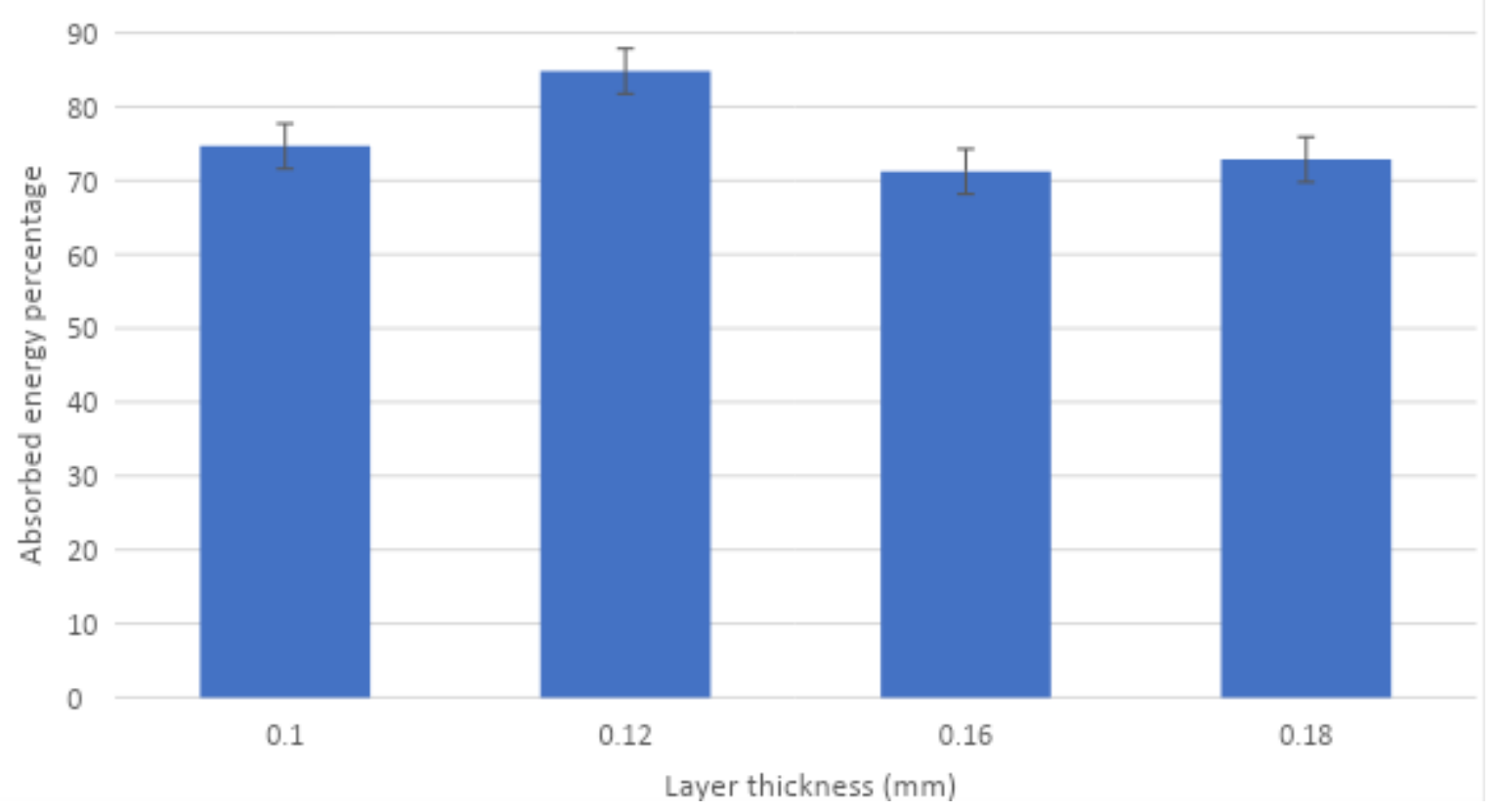

Figure 4.12: Absorbed energy percentage versus layer thickness at $P_{2}$ location

Basic inferences from the tests are as follows: the absorbed energy is directly related to the extent of the damage, that is, the coupon with more absorbed energy shows more damage. It is also observed that if there are only horizontal cracks (crack along extrudates) the absorbed energy is less. If vertical cracks are formed (transverse to extrudates), the absorbed energy increases. Furthermore, the absorbed energy increases with the number of cracks and the crack length also affects the absorbed energy. Higher absorbed energy result in larger cracks. Also, it can be concluded that the coupons which have cracks on both sides of the 
impact location have more absorbed energy than the coupons with damage in either one direction.

In case of $\mathrm{P}_{2}$ impact location, one of every type of samples had a broken part and the absorbed energy for these specimens was highest when compared to the other two. Analysing the results for both locations, it can be observed that the absorbed energy is higher in case of $\mathrm{P}_{2}$ specimens for all the layers except for 14 layers in which case the energy for $\mathrm{P}_{2}$ is slightly lower than that in case of $\mathrm{P}_{1}$ location. Finally, it can be concluded that for the impact at the plate centre $\left(P_{1}\right)$ the absorbed energy percentage increases with an increase in layer thickness (a decrease in total number of layers) with an exception for 0.18 layer thickness. However, at the other impact location $\left(P_{2}\right)$, the absorbed energy percentage increases from 25 layers to 21 layers but then decreases for 16 layers and then again increases slightly for 14 layers hence showing an inconsistent trend.

Table 4.7: Comparison of Absorbed energy percentages between $P_{1}$ and $P_{2}$ impact locations

\begin{tabular}{|c|c|c|}
\hline $\begin{array}{c}\text { Layer thickness } \\
\text { mm (number } \\
\text { of layers) }\end{array}$ & $\begin{array}{c}\text { Absorbed energy } \\
\text { percentage at } \mathbf{P}_{\mathbf{1}}\end{array}$ & $\begin{array}{c}\text { Absorbed energy } \\
\text { percentage at } \mathbf{P}_{\mathbf{2}}\end{array}$ \\
\hline $0.10(25)$ & 58 & 74.66 \\
\hline $0.12(21)$ & 69 & 84.83 \\
\hline $0.16(16)$ & 80.30 & 71.23 \\
\hline $0.18(14)$ & 73.76 & 72.86 \\
\hline
\end{tabular}

$3 \mathrm{D}$ printing is a complex process and the mechanical and physical properties of the final printed parts depend on various process parameters such as layer thickness, raster angle, raster width, orientation, nozzle temperature etc. Even if all the process parameters are same, two different 3D printed parts of the same material might have different properties depending on the use of different 3D printers and different material spools. In the above study, the low velocity impact damage characteristics have high dependence on the clamping 
force, i.e. the force exerted on the plate when it is clamped between the two steel plates on the apparatus before testing. Since the plates were clamped manually without the use of a mechanical tool, the exceptions or the different damage characteristics shown by different coupons having same layer thickness can be explained by the difference in the clamping force in each case. 


\section{Conclusions and Future Work}

In this study, impact testing of 3D printed PLA plates with different layer thicknesses and impact locations was performed. An in house manufactured pendulum test apparatus was used to perform impact tests. A high-speed camera was installed to calculate the absorbed energy by each specimen after impact and an infra-red camera was also used to perform the NDT technique of thermography. Thermography helped in understanding the failure characteristics in each specimen. For all the coupons, the laminate thickness was kept constant and coupons were printed in four different layer thicknesses, that were, $0.10 \mathrm{~mm}$, $0.12 \mathrm{~mm}, 0.16 \mathrm{~mm}, 0.18 \mathrm{~mm}$. All the coupons were impacted with an impact energy of $3 \mathrm{~J}$ at two different locations by the pendulum impact test apparatus and post-processing was done with the help of the high-speed and the infra-red camera.

Some of the major conclusions from the tests can be the following:

1. For impact location $\mathrm{P}_{1}$, as the layer thickness was increased, the absorbed energy first increased and then decreased.

2. For impact location $P_{2}$, with an increase in layer thickness, the absorbed energy first increased and then decreased, with one exception that the absorbed energy value for $0.18 \mathrm{~mm}$ layer thickness was slightly higher (2.28\%) than the absorbed energy value for $0.16 \mathrm{~mm}$.

3. In general, the specimens which were impacted at location $P_{2}$, i.e. near the clamped edge, show more severe damage and have higher absorbed energy.

4. The extent of damage depends directly on the absorbed energy by the coupon, where a specimen with higher value of absorbed energy shows more damage.

5. Specimens with only horizontal or vertical cracks absorb less energy than the coupons with cracks in multiple directions.

6. Specimens with cracks in the direction perpendicular to the orientation absorb more energy, than the specimens with cracks in the direction of extrudates.

7. Coupons with damage on both the sides of the impact location absorb higher amount of energy. 
Due to the complexity of the process of 3D printing, the properties of the printed part are affected by a lot of process parameters, some of which are controllable and some uncontrollable. This makes understanding the low velocity damage characteristics of 3D printed parts just by controlling one process parameter, in this case layer thickness, very difficult. Hence as future work, the effect of various process parameters such as infill percentage, printing speed, nozzle temperature, raster angle, raster width can be studied. The coupons tested in this study are only printed in 0-degree orientation, for future research different orientations as well as different stacking sequences can also be explored. One of the main reasons behind the inconsistent trend in the results is the clamping force, hence a mechanical drill machine can be used and the specimens can be clamped inside the fixture using a constant force. This can be further used to explore the effect of clamping force as well. Further, in this study, thermography was used to understand the different types of failure in the specimens, but other NDT techniques can be used to examine the failure surface and understand the failure mechanisms in detail. 


\section{APPENDIX}

The appendix section includes the camera and thermal pictures for all the tests conducted in this study.

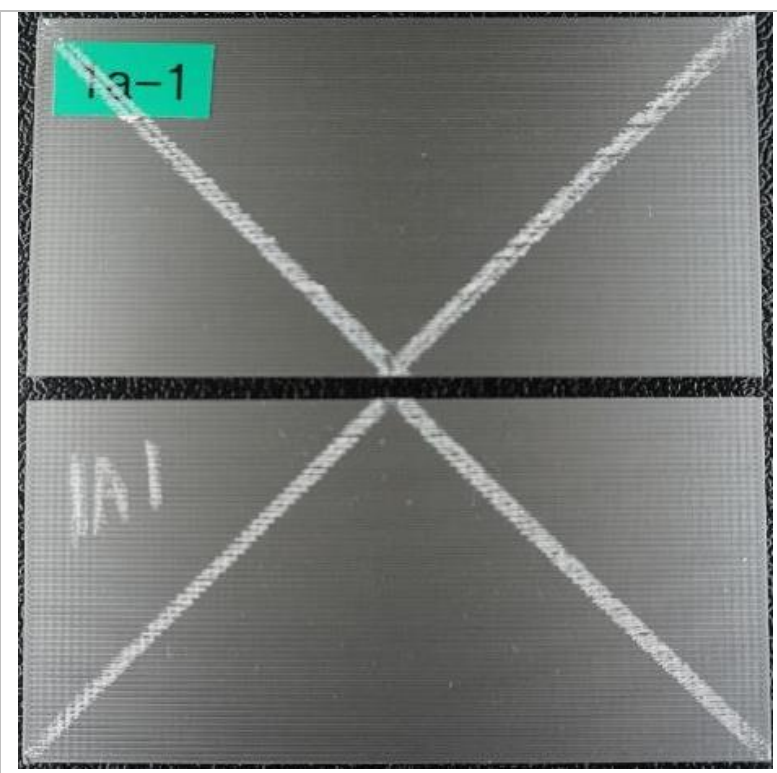

(a)

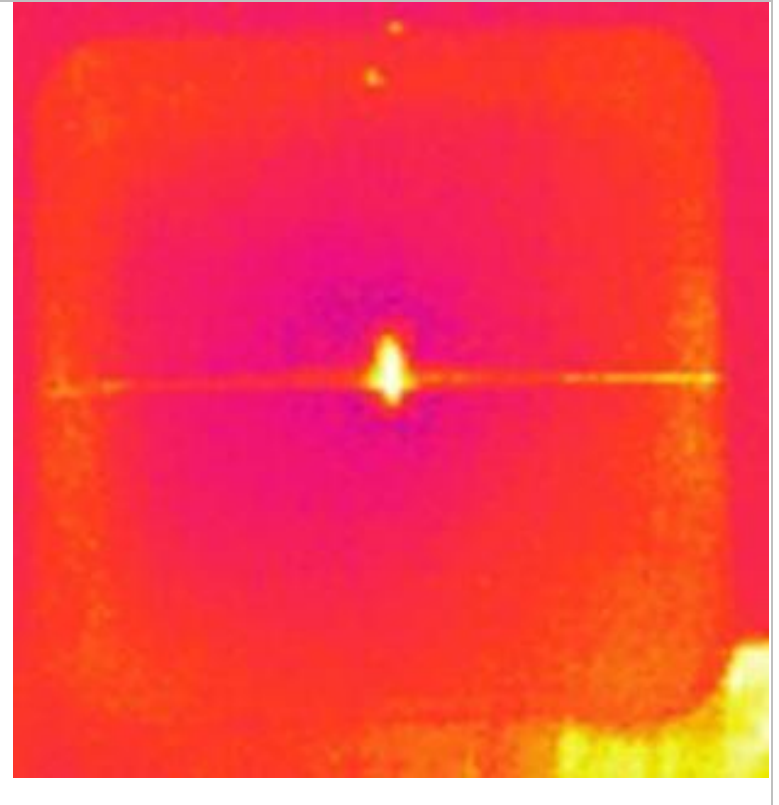

(b)

Figure 7.1: $\mathbf{1}^{\text {st }}$ specimen for case ID 1a: (a) specimen after testing; (b) thermal image

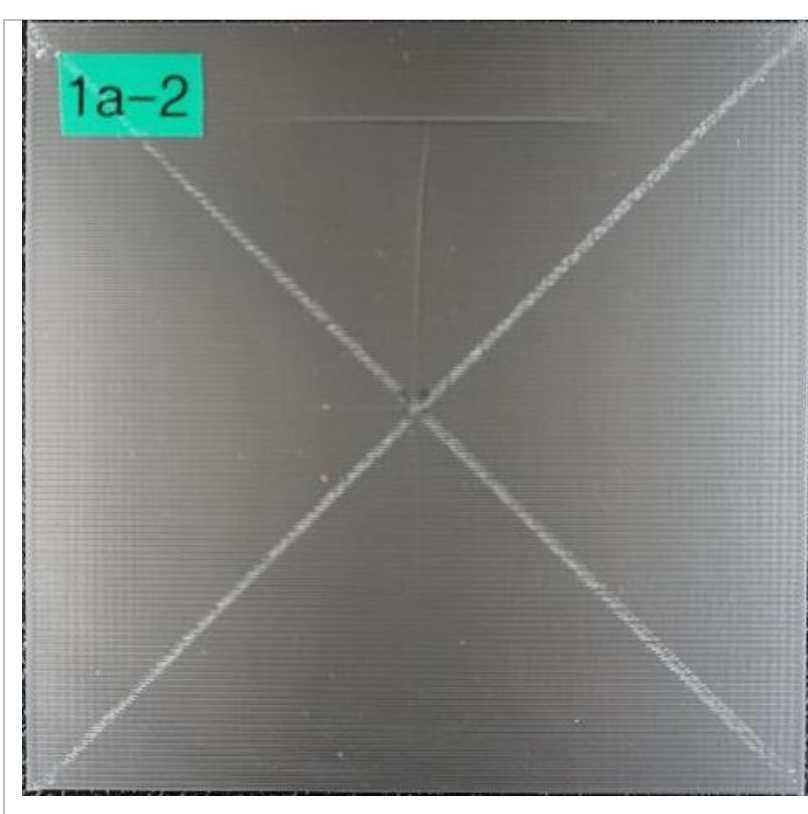

(a)

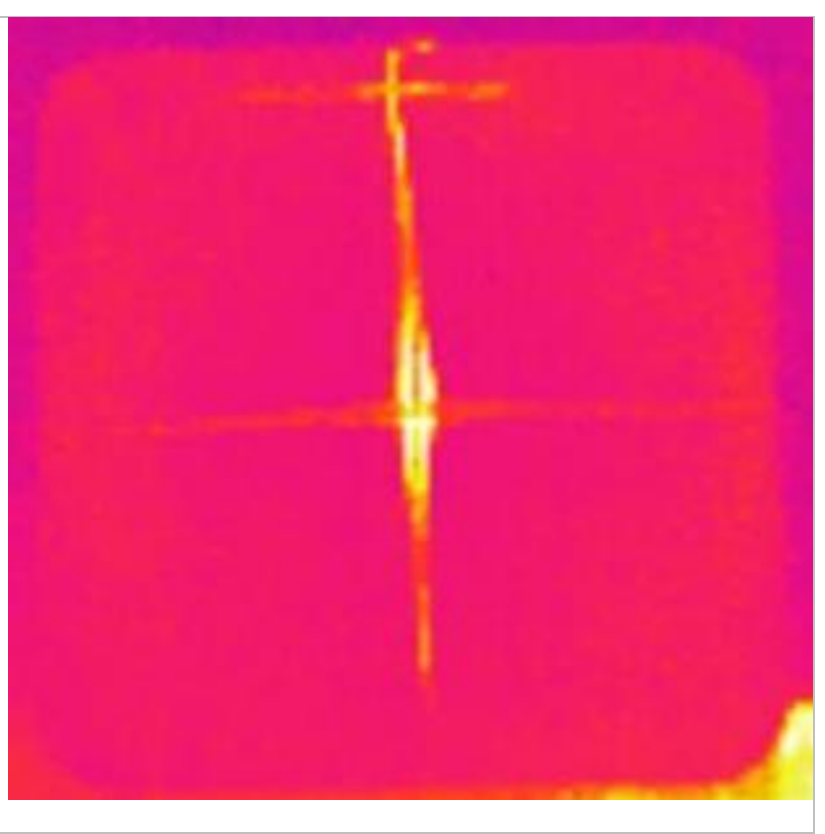

(b)

Figure 7.2: $2^{\text {nd }}$ specimen for case ID 1a: (a) specimen after testing; (b) thermal image 


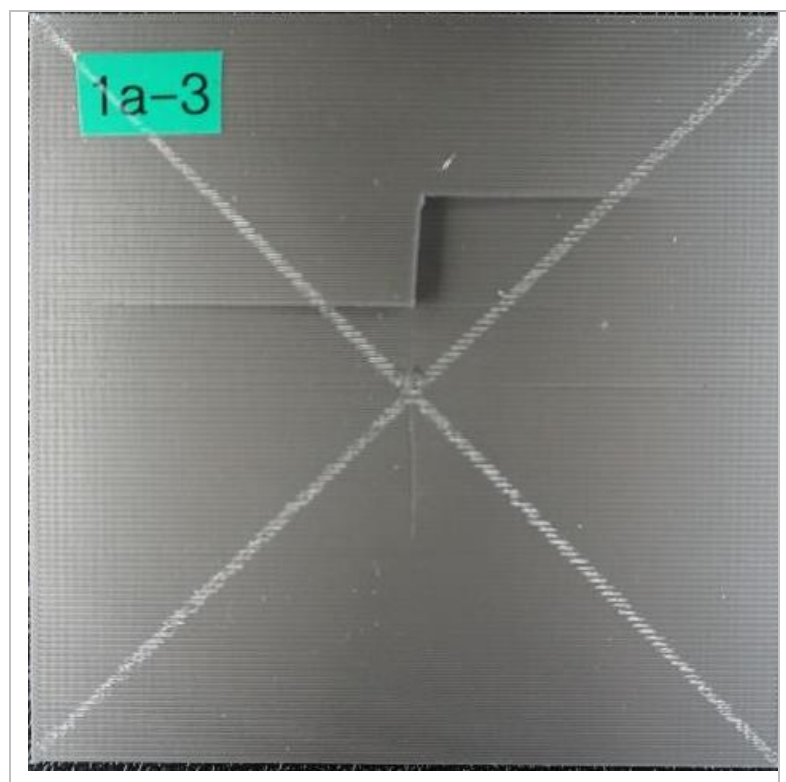

(a)

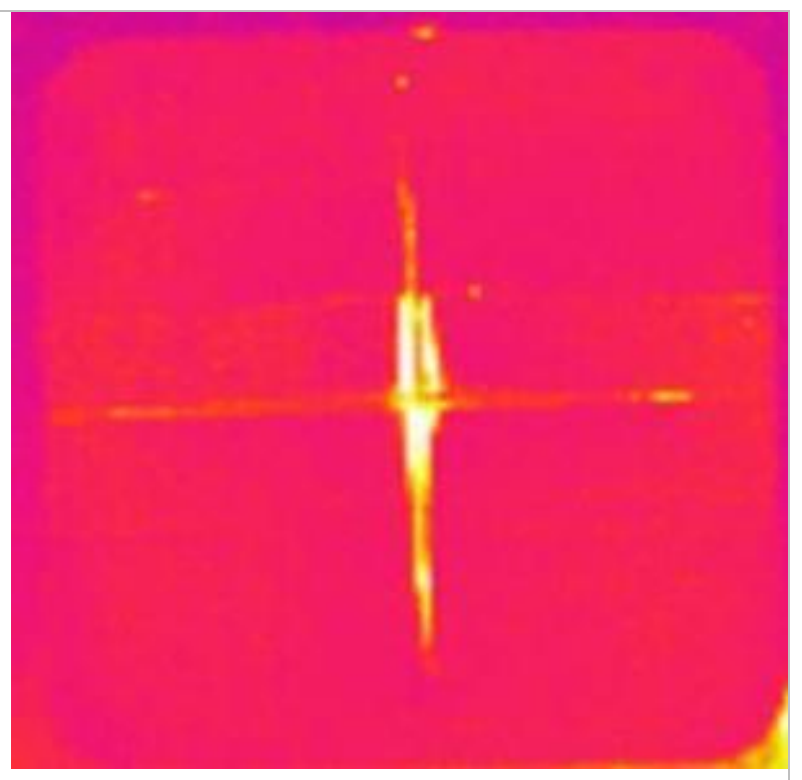

(b)

Figure 7.3: $3^{\text {rd }}$ specimen for case ID 1a: (a) specimen after testing; (b) thermal image

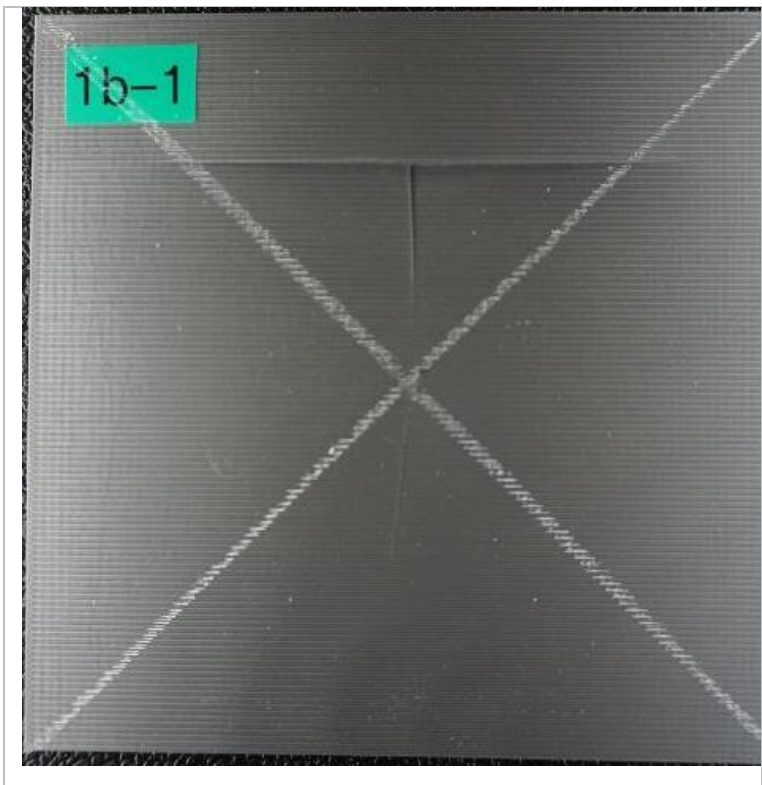

(a)

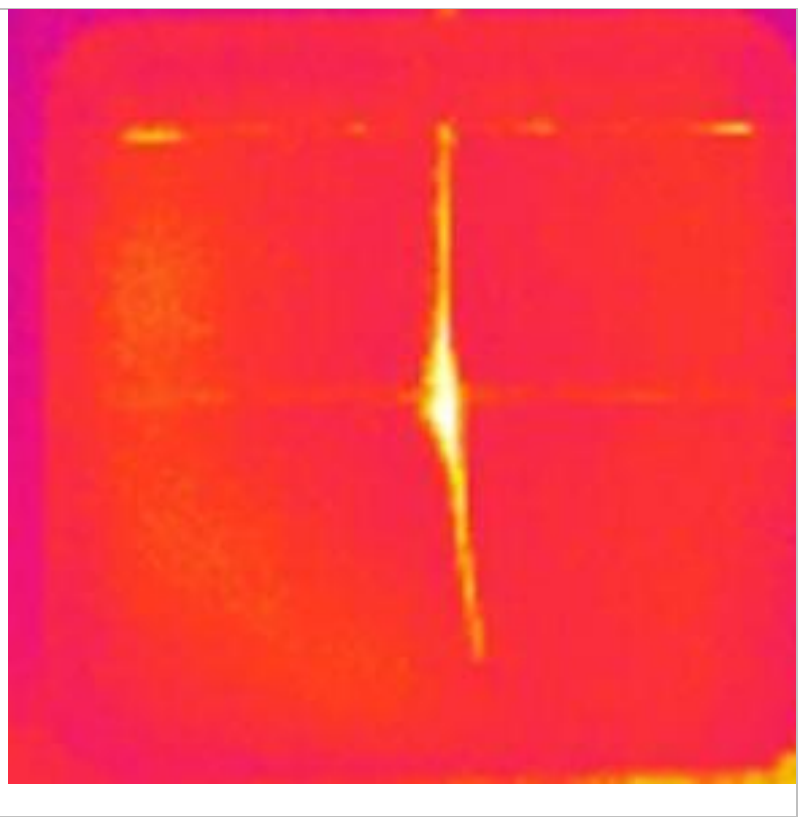

(b)

Figure 7.4: $\mathbf{1}^{\text {st }}$ specimen for case ID 1b: (a) specimen after testing; (b) thermal image 


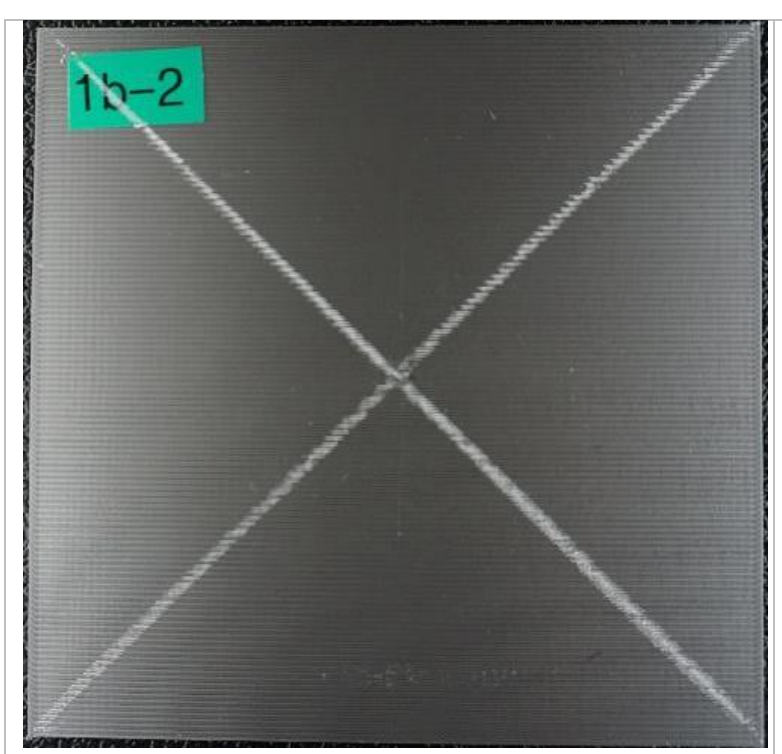

(a)

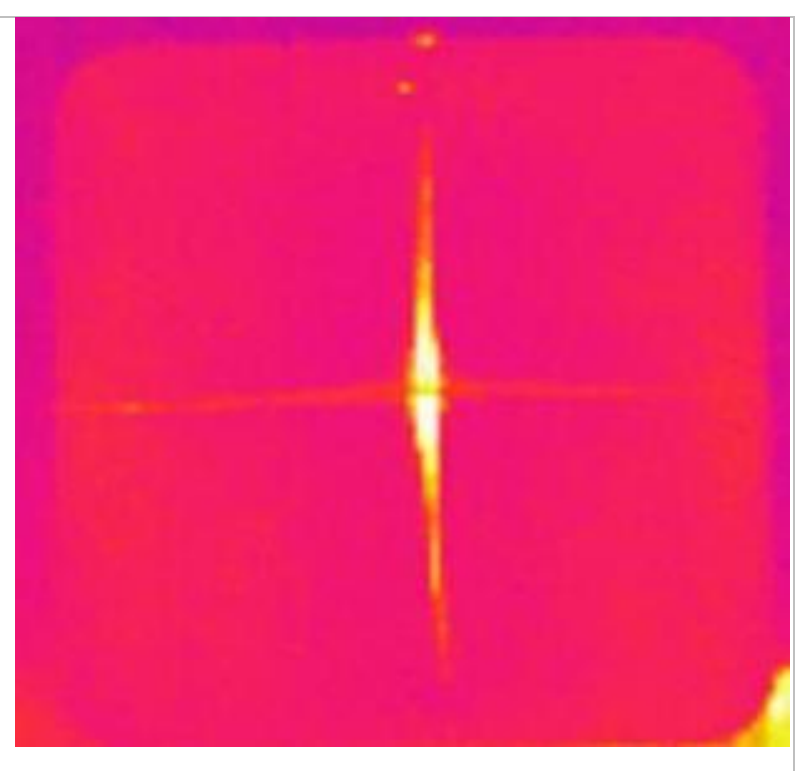

(b)

Figure 7.5: $2^{\text {nd }}$ specimen for case ID $1 \mathrm{~b}$ : (a) specimen after testing; (b) thermal image

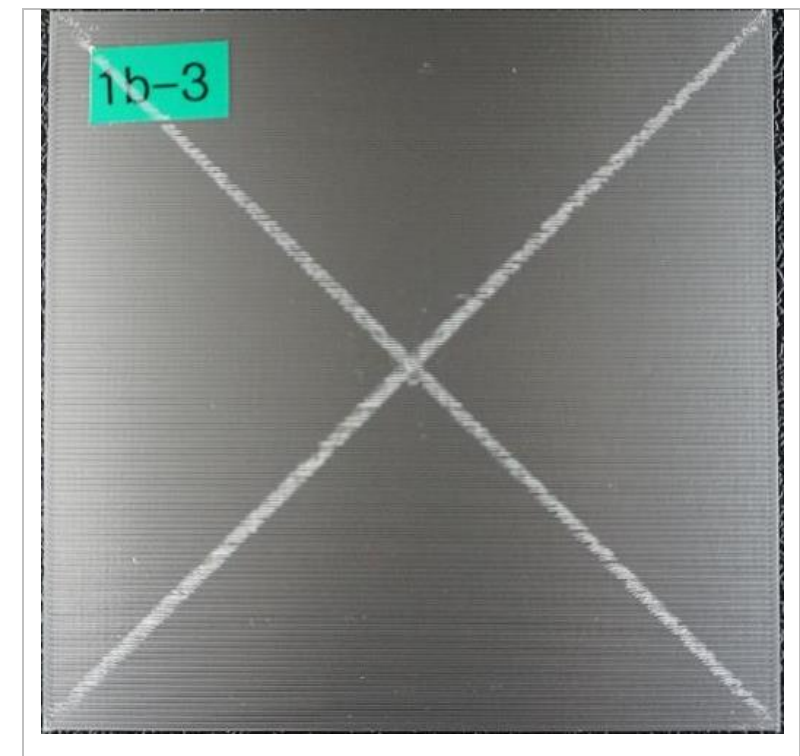

(a)

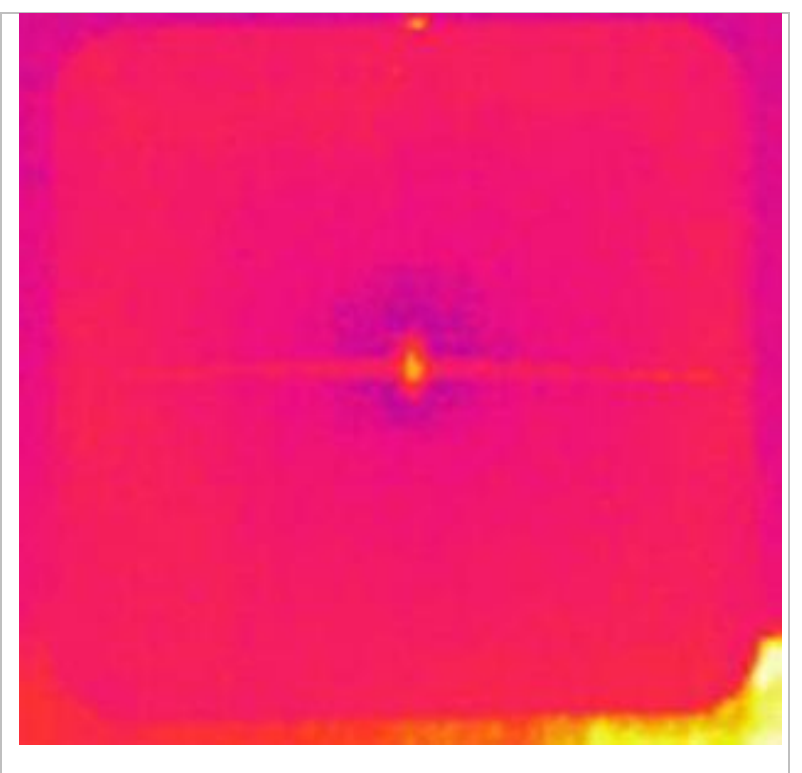

(b)

Figure 7.6: $3^{\text {rd }}$ specimen for case ID 1b: (a) specimen after testing; (b) thermal image 


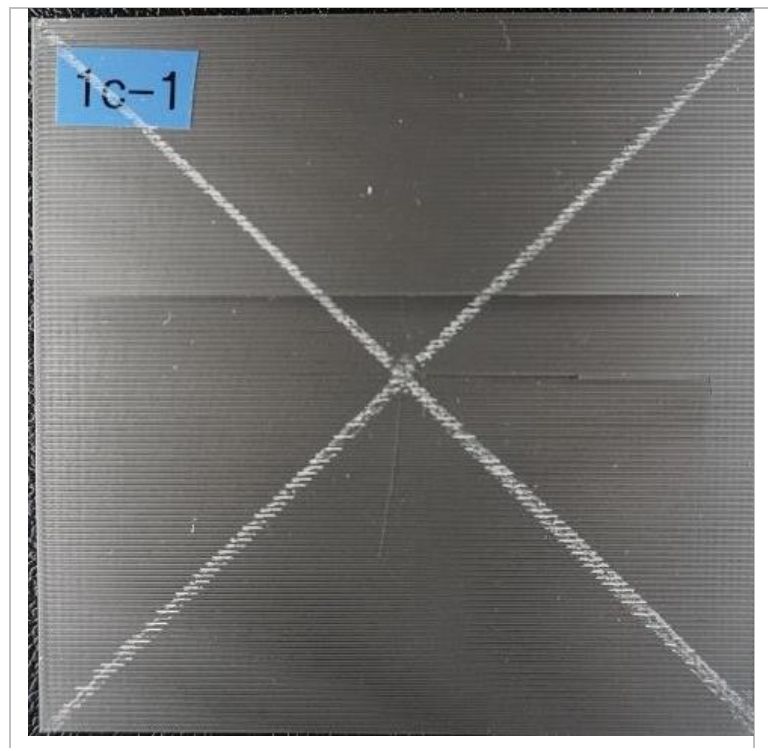

(a)

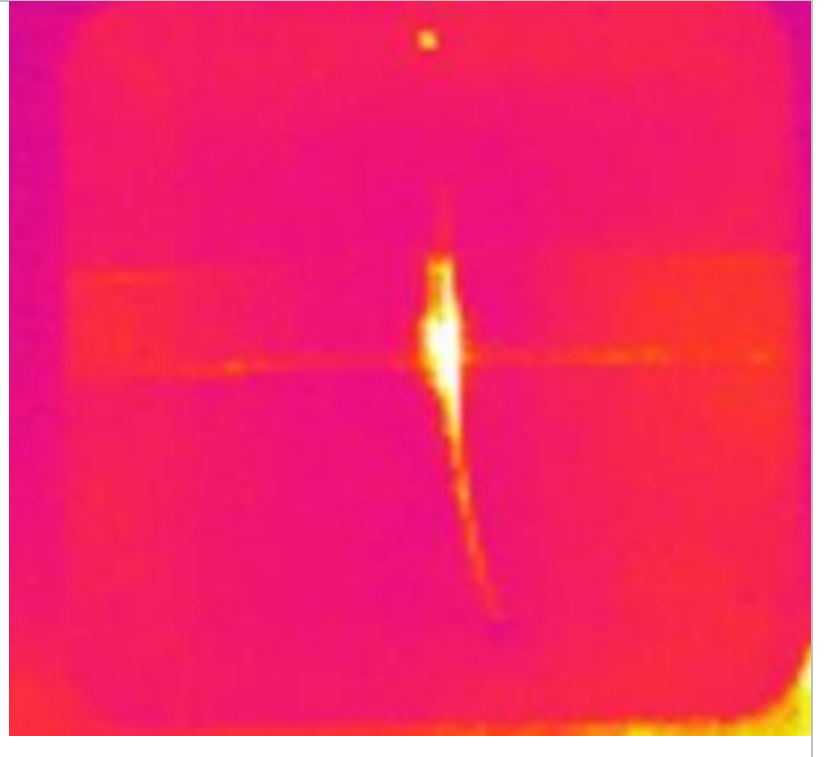

(b)

Figure 7.7: $1^{\text {st }}$ specimen for case ID 1c: (a) specimen after testing; (b) thermal image

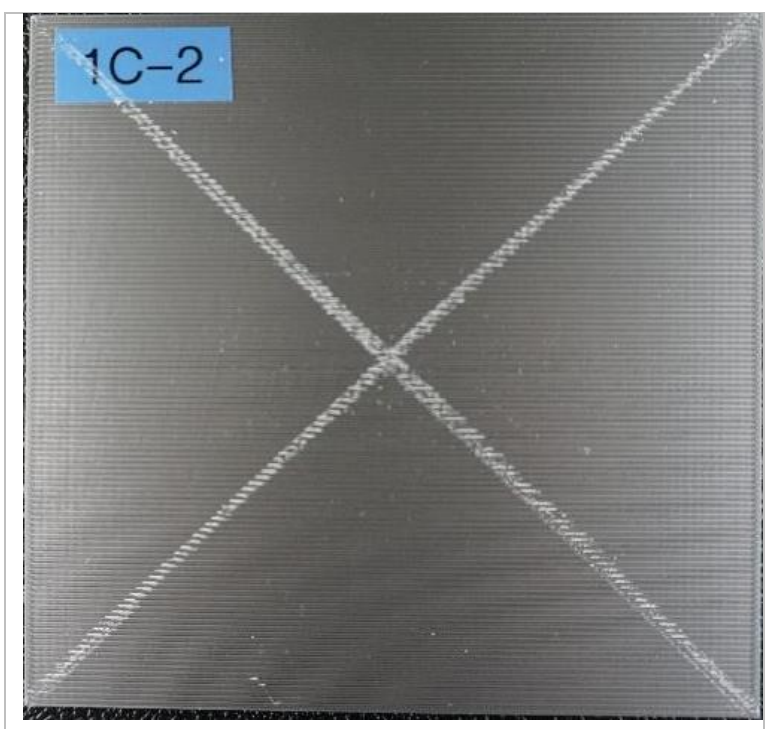

(a)

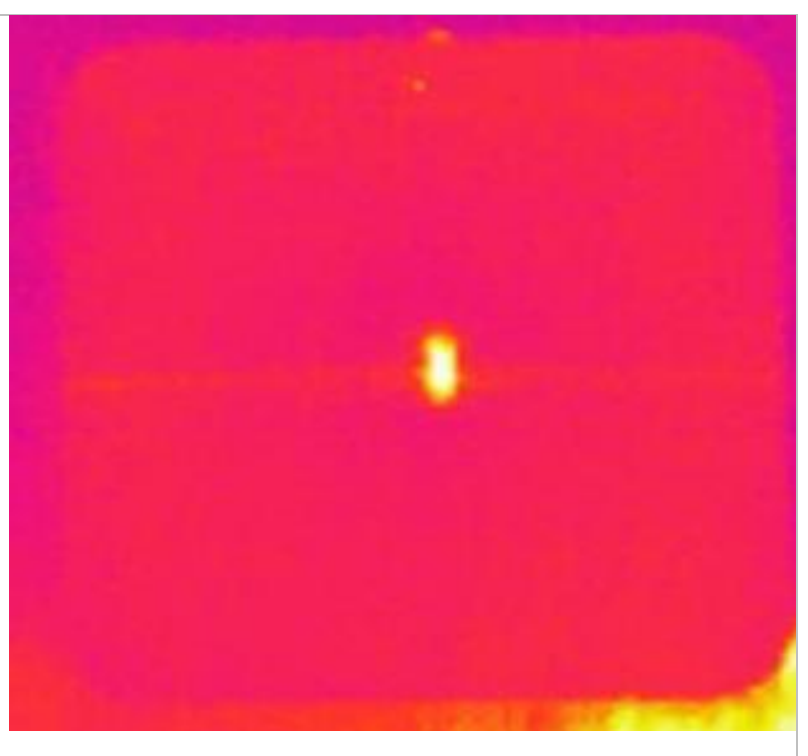

(b)

Figure 7.8: $2^{\text {nd }}$ specimen for case ID 1c: (a) specimen after testing; (b) thermal image 


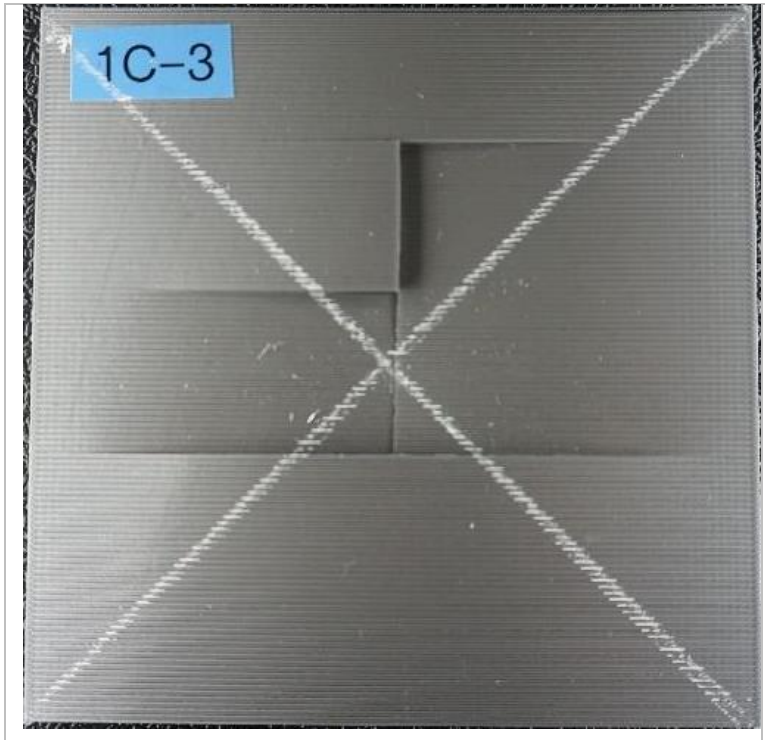

(a)

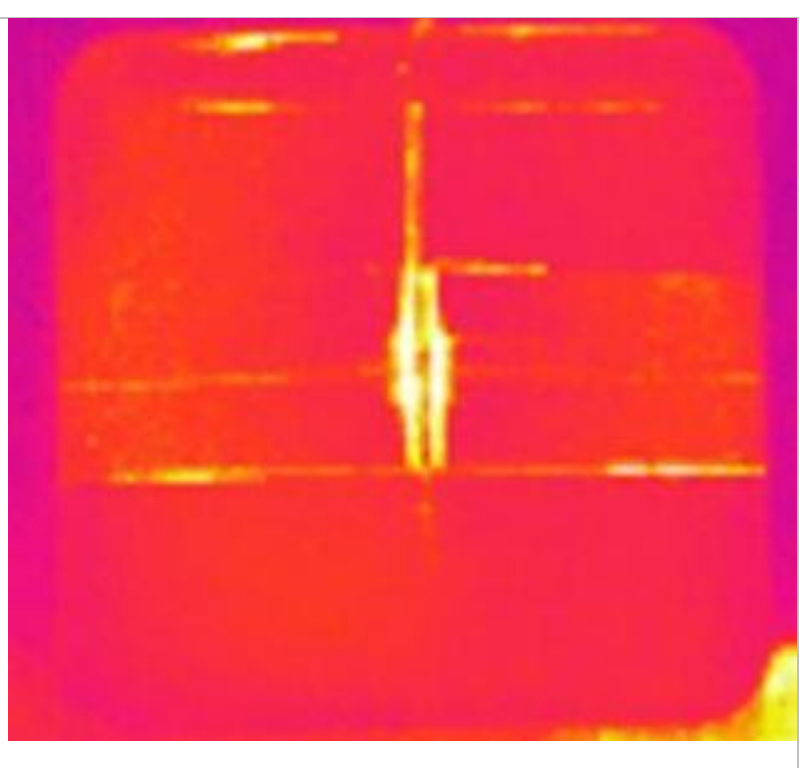

(b)

Figure 7.9: $3^{\text {rd }}$ specimen for case ID 1c: (a) specimen after testing; (b) thermal image

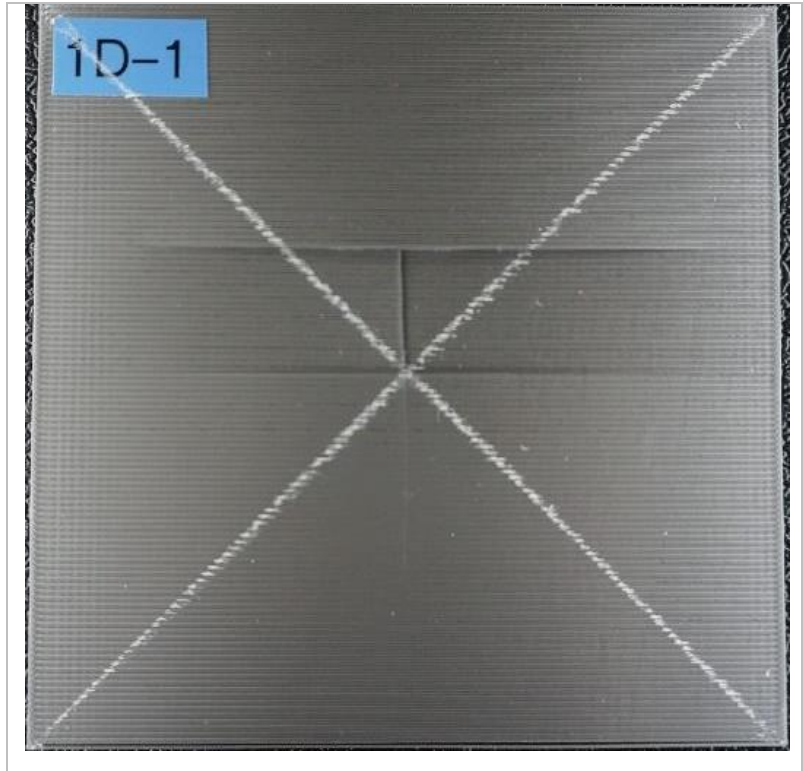

(a)

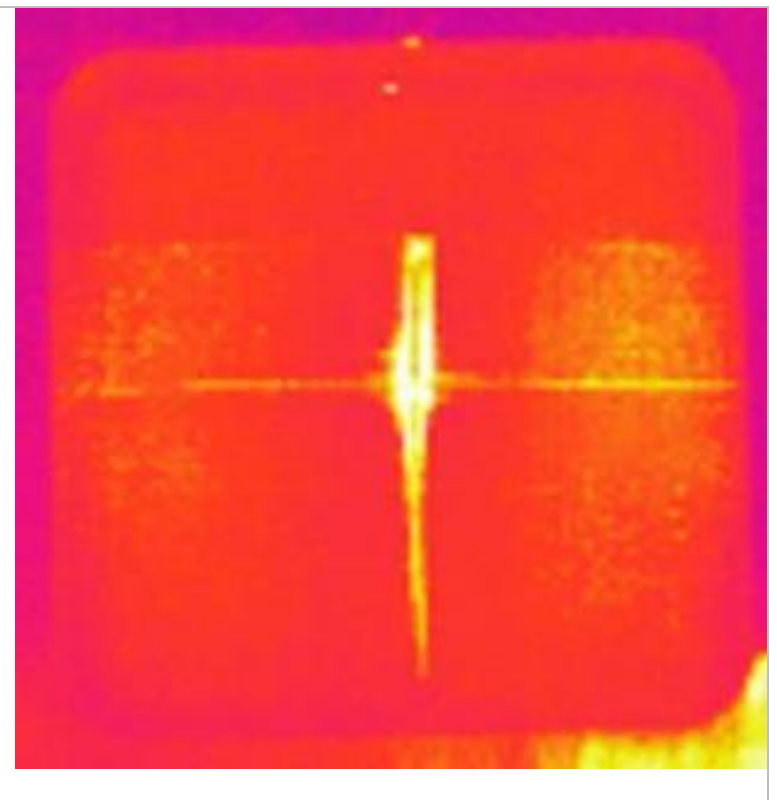

(b)

Figure 7.10: $1^{\text {st }}$ specimen for case ID 1d: (a) specimen after testing; (b) thermal image 


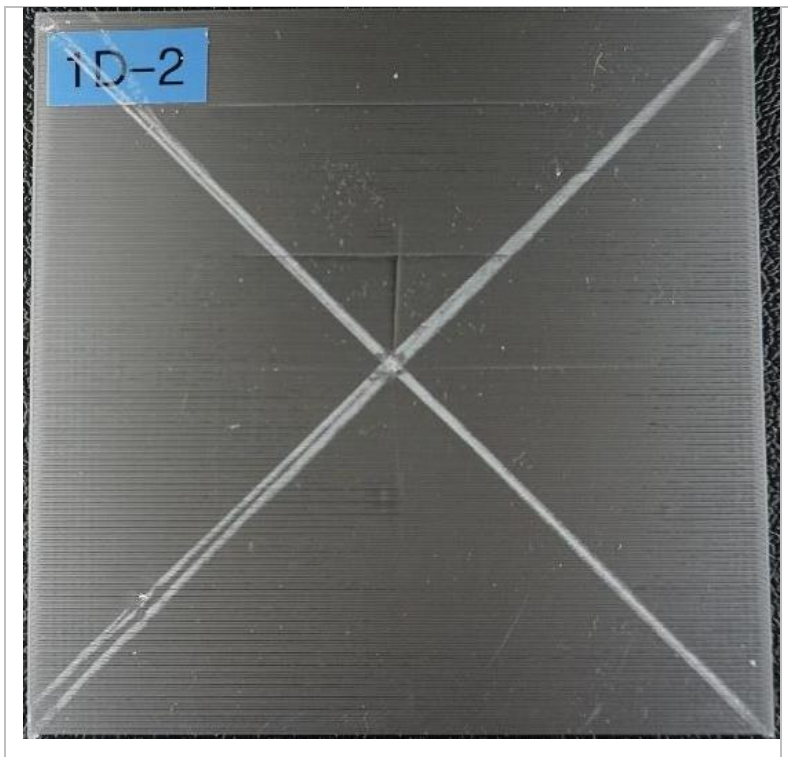

(a)

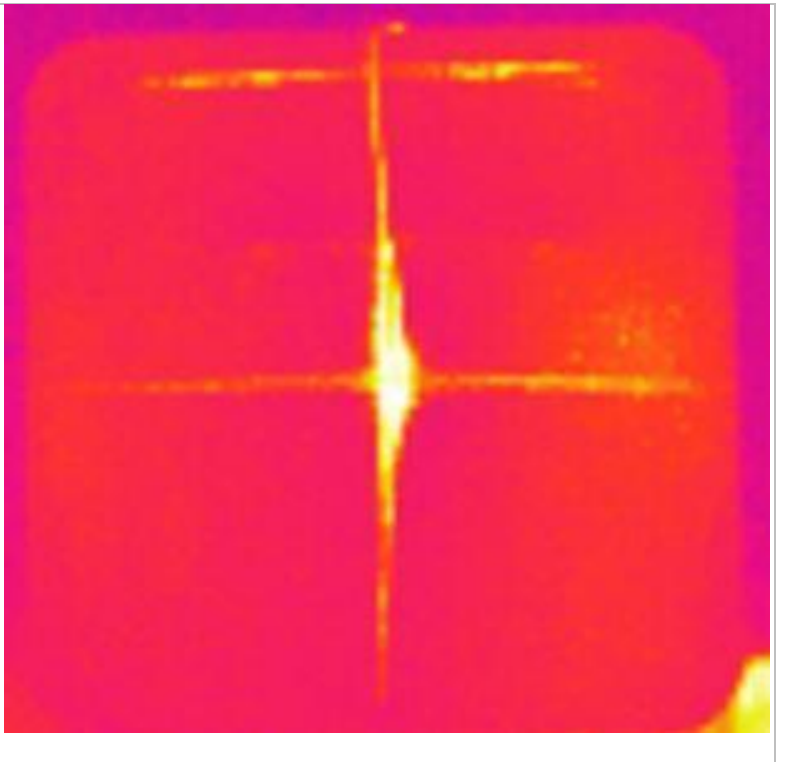

(b)

Figure 7.11: $2^{\text {nd }}$ specimen for case ID 1d: (a) specimen after testing; (b) thermal image

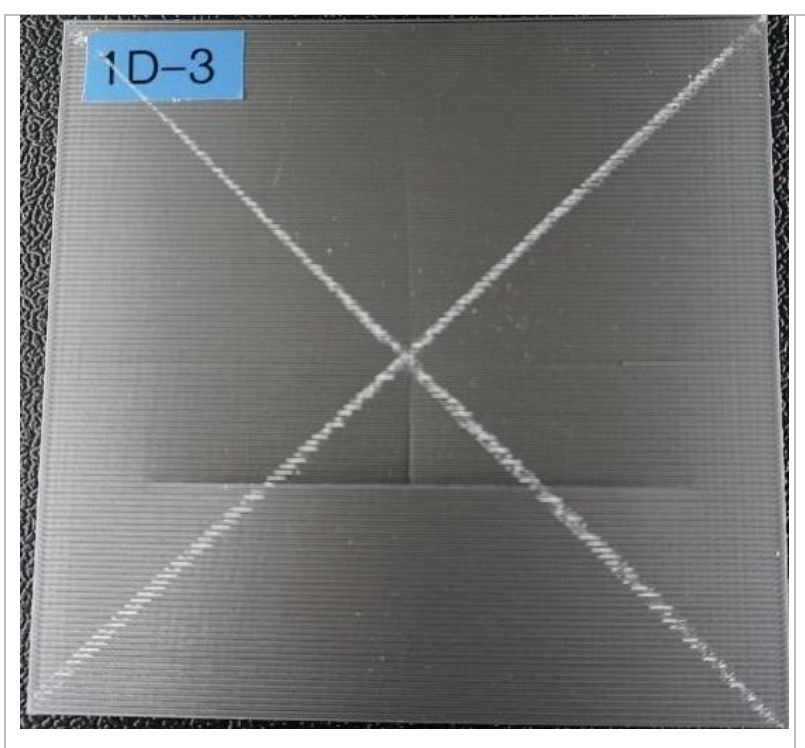

(a)

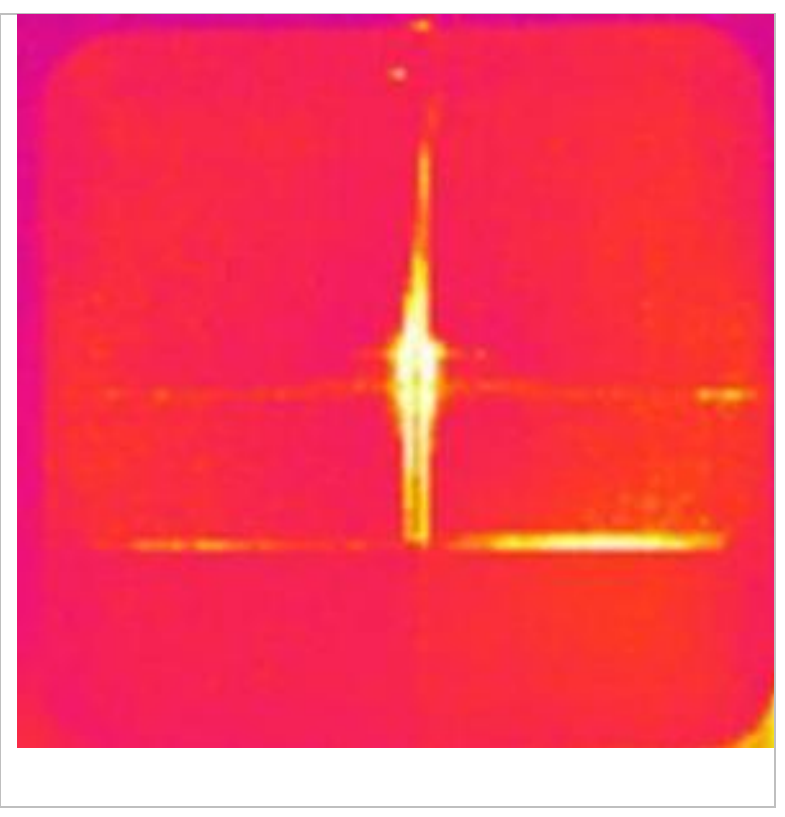

(b)

Figure 7.12: $3^{\text {rd }}$ specimen for case ID $1 \mathrm{~d}$ : (a) specimen after testing; (b) thermal image 


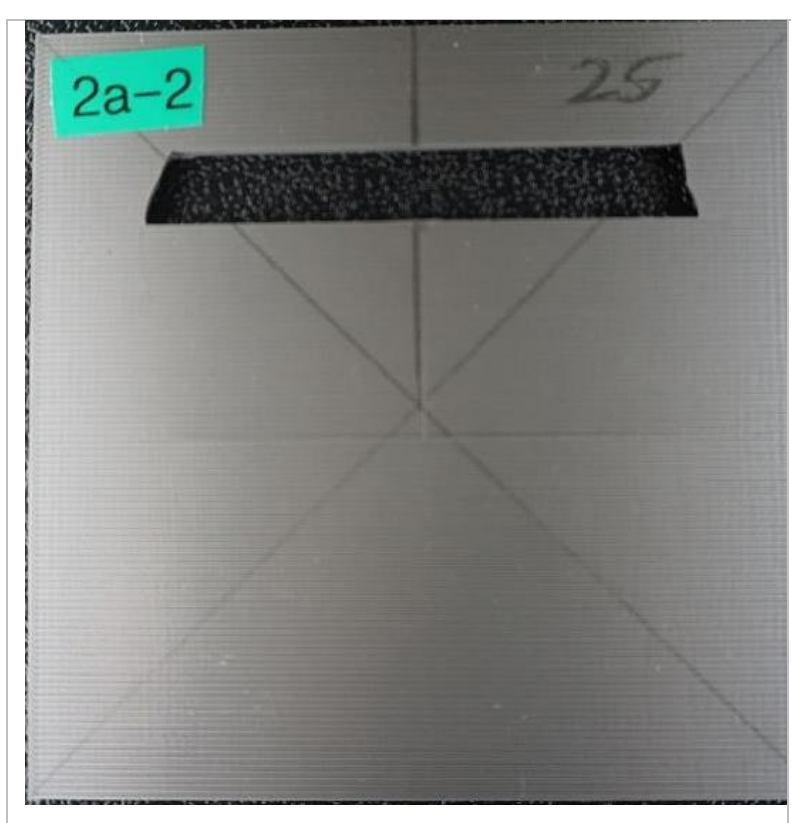

(a)

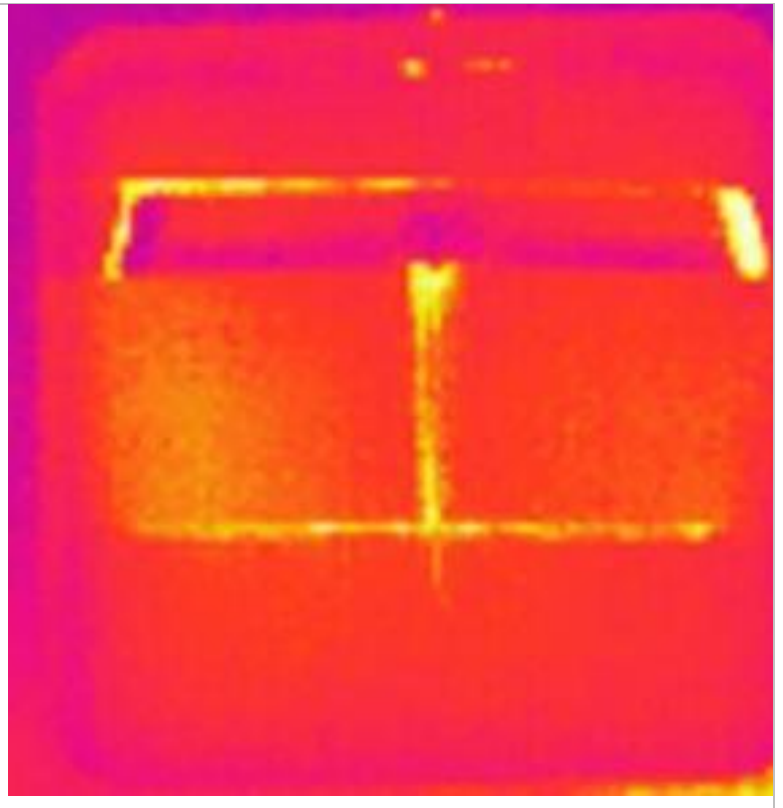

(b)

Figure 7.13: $1^{\text {st }}$ specimen for case ID 2a: (a) specimen after testing; (b) thermal image

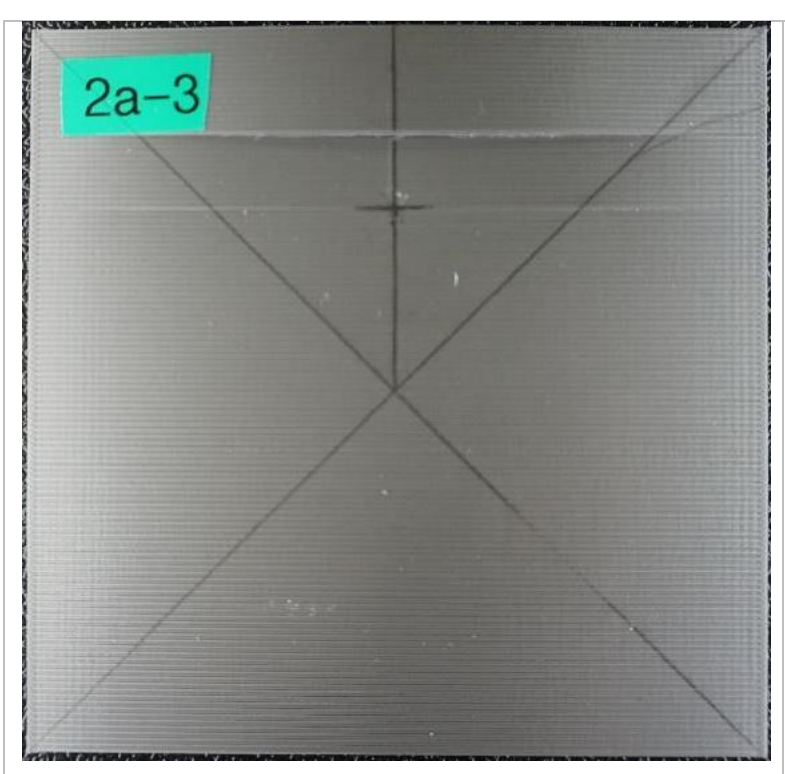

(a)

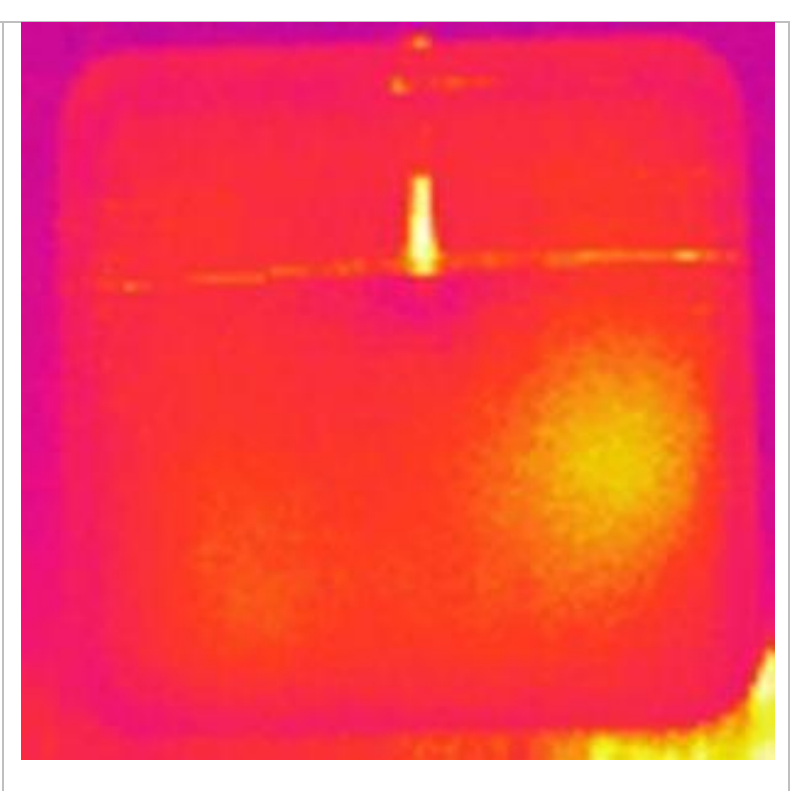

(b)

Figure 7.14: $2^{\text {nd }}$ specimen for case ID 2a: (a) specimen after testing; (b) thermal image 


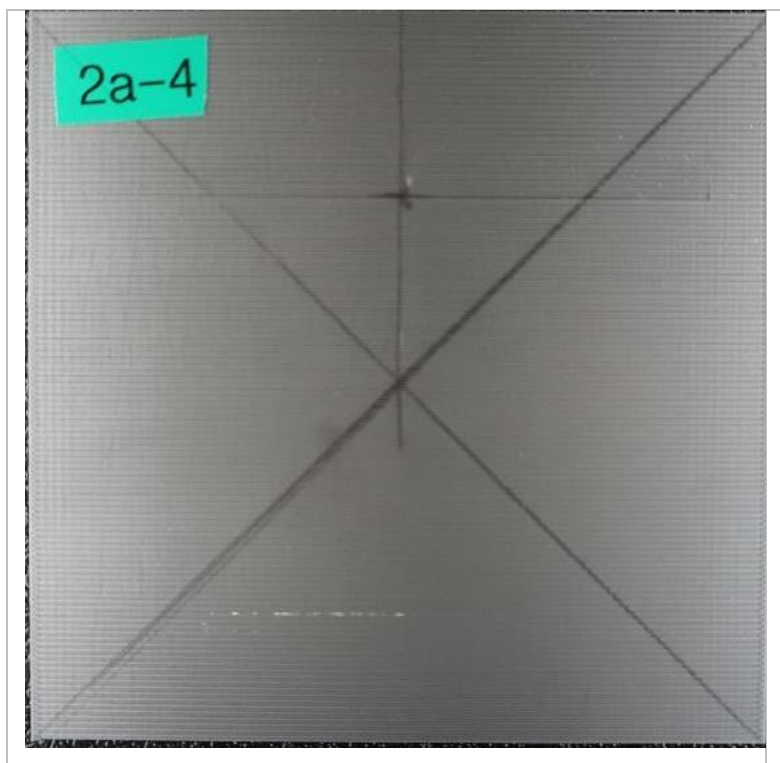

(a)

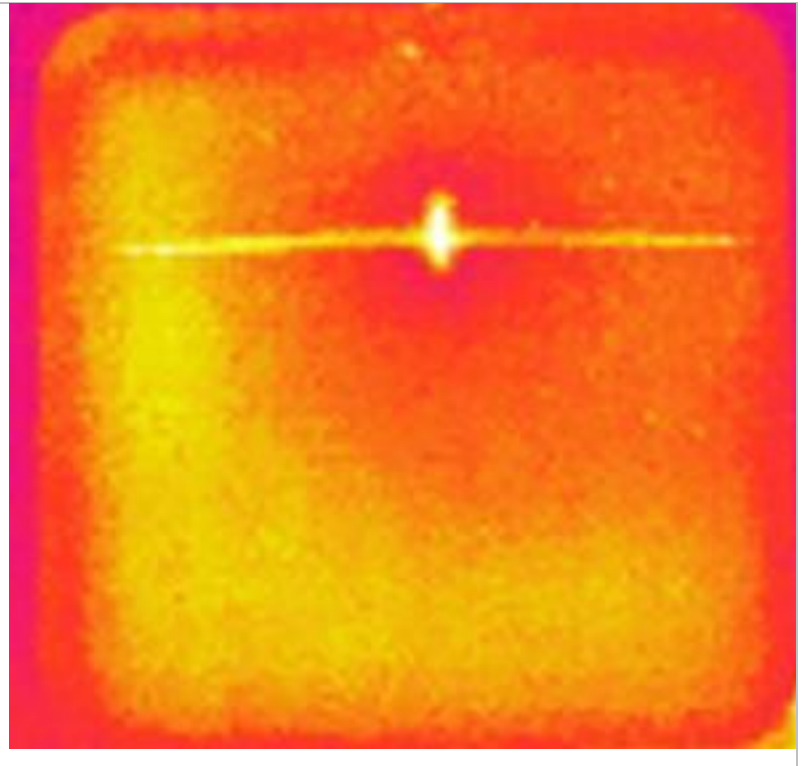

(b)

Figure 7.15: $3^{\text {rd }}$ specimen for case ID 2a: (a) specimen after testing; (b) thermal image

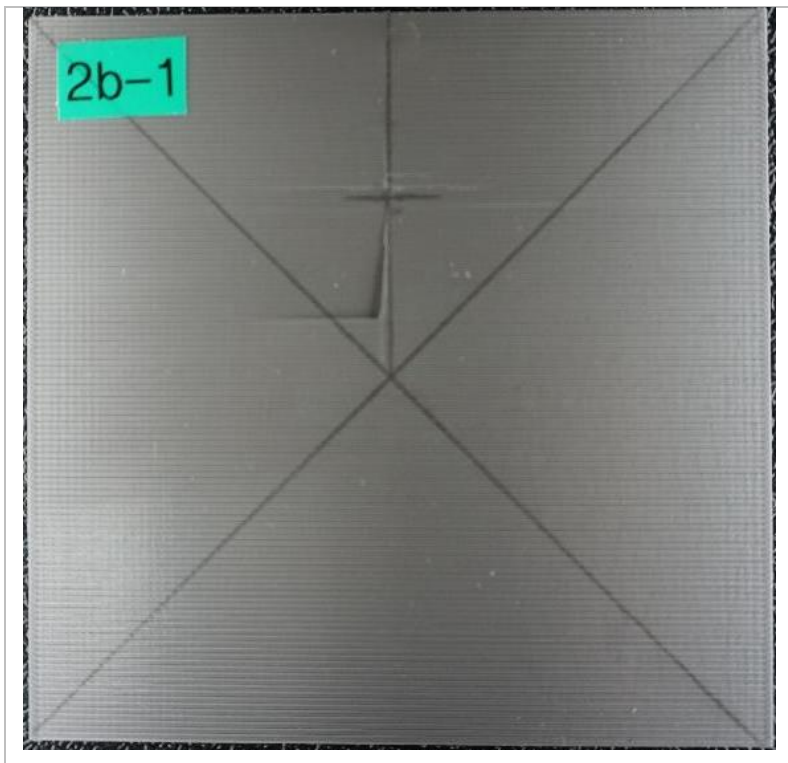

(a)

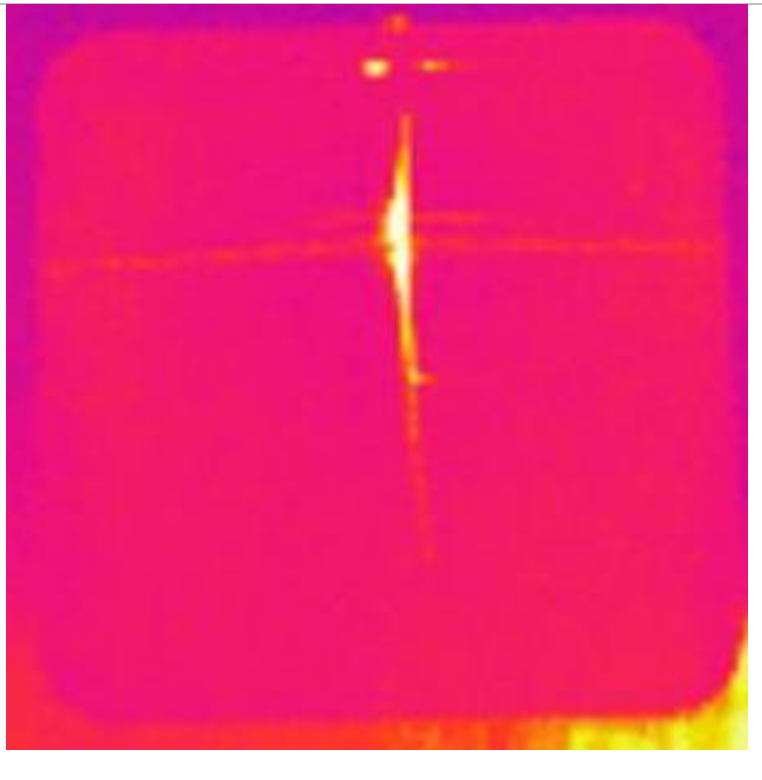

(b)

Figure 7.16: $1^{\text {st }}$ specimen for case ID 2b: (a) specimen after testing; (b) thermal image 


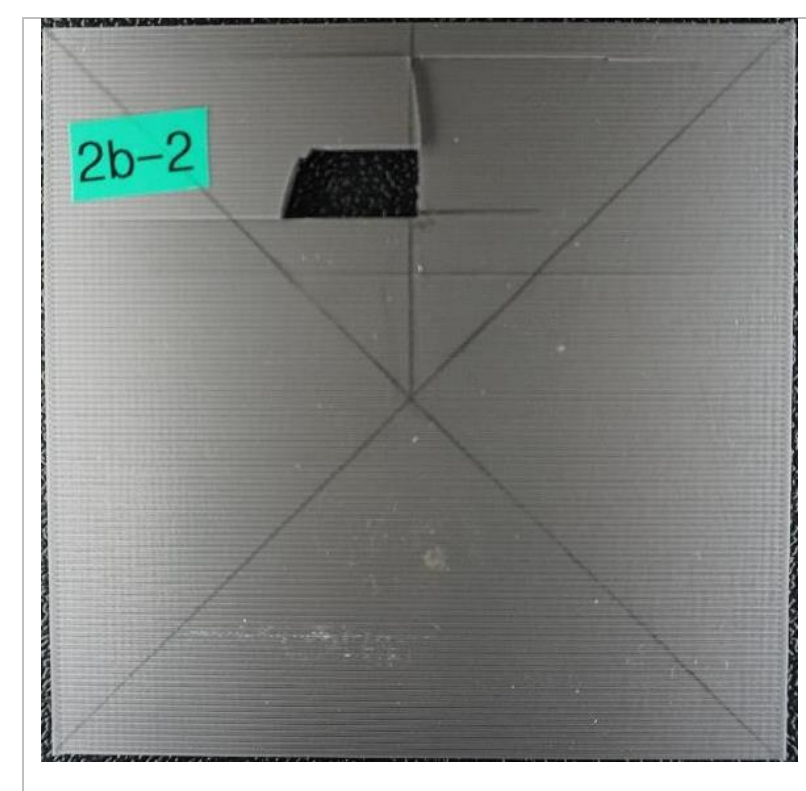

(a)

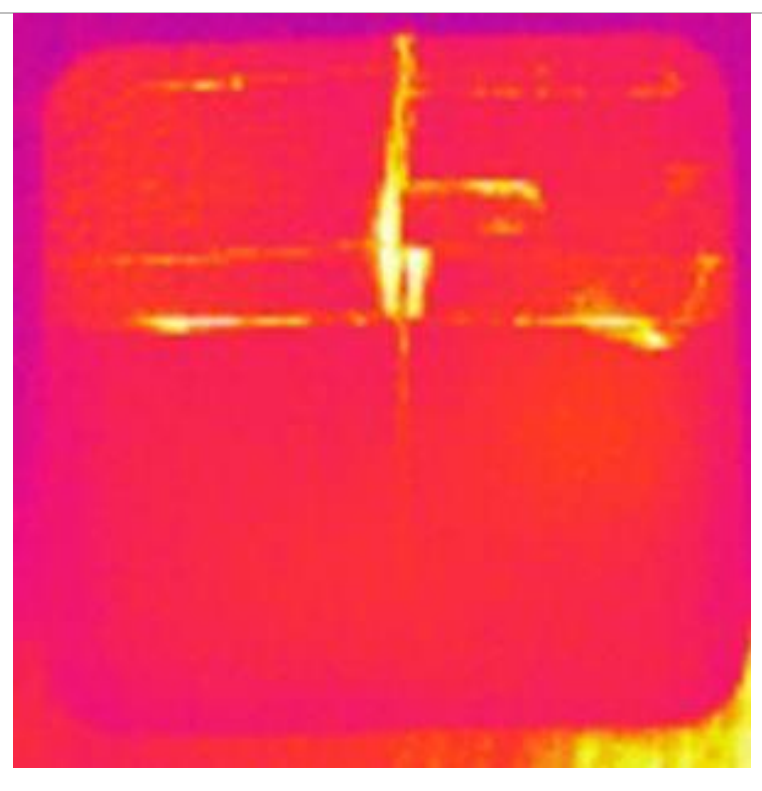

(b)

Figure 7.17: $2^{\text {nd }}$ specimen for case ID 2b: (a) specimen after testing; (b) thermal image

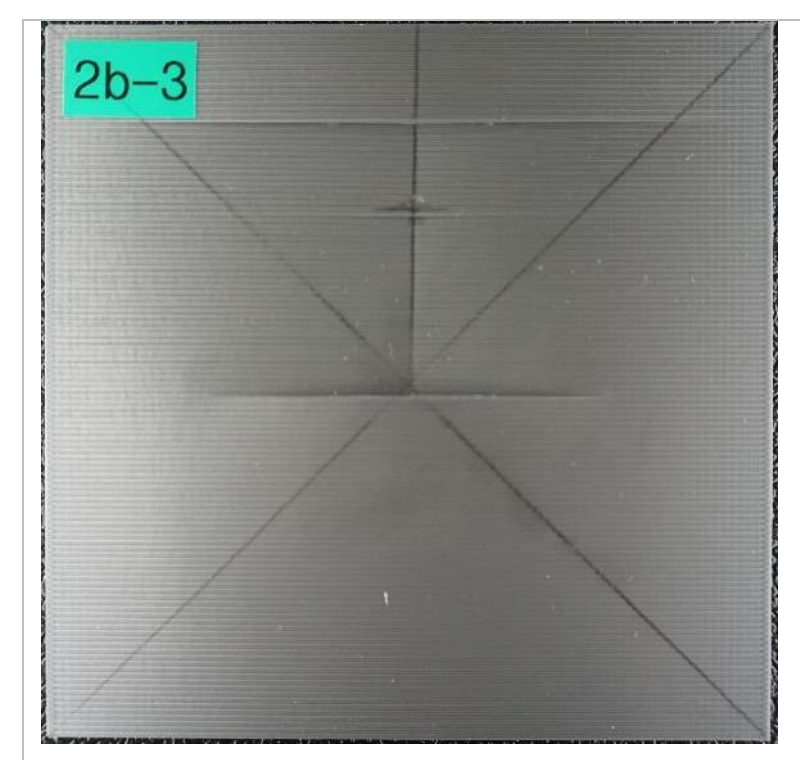

(a)

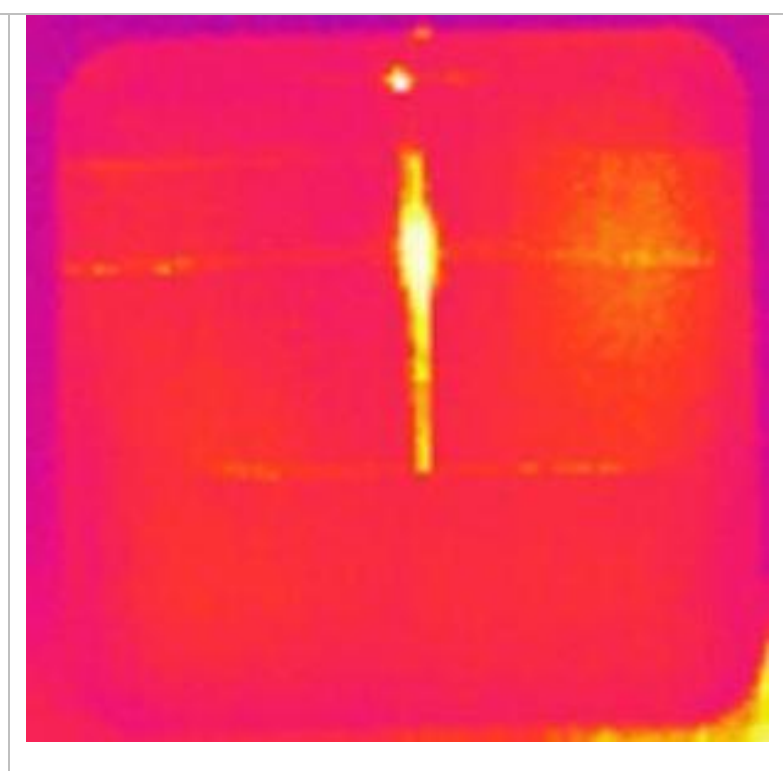

(b)

Figure 7.18: $3^{\text {rd }}$ specimen for case ID $2 \mathrm{~b}$ : (a) specimen after testing; (b) thermal image 


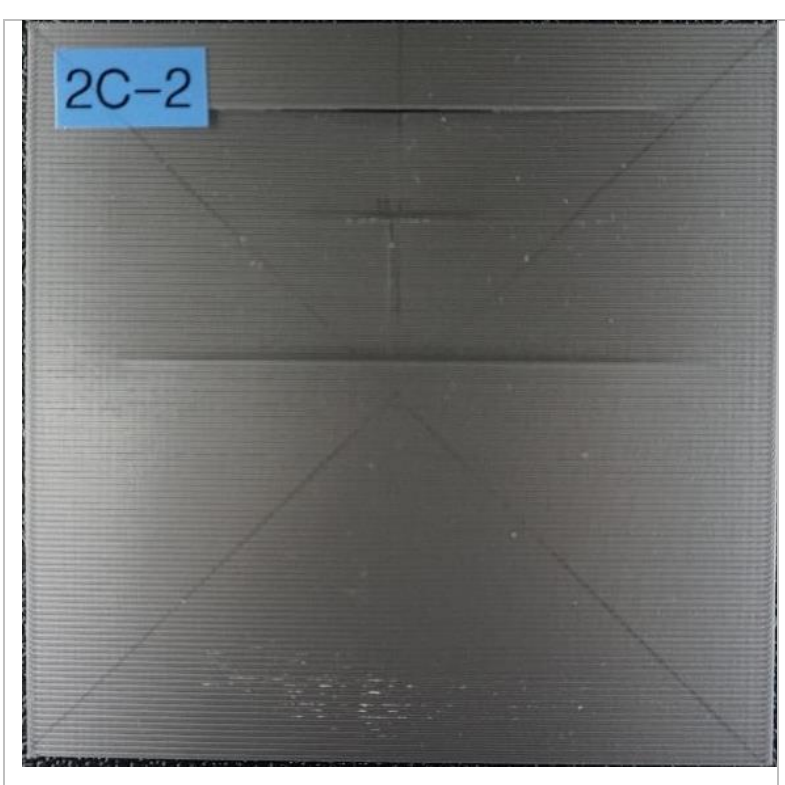

(a)

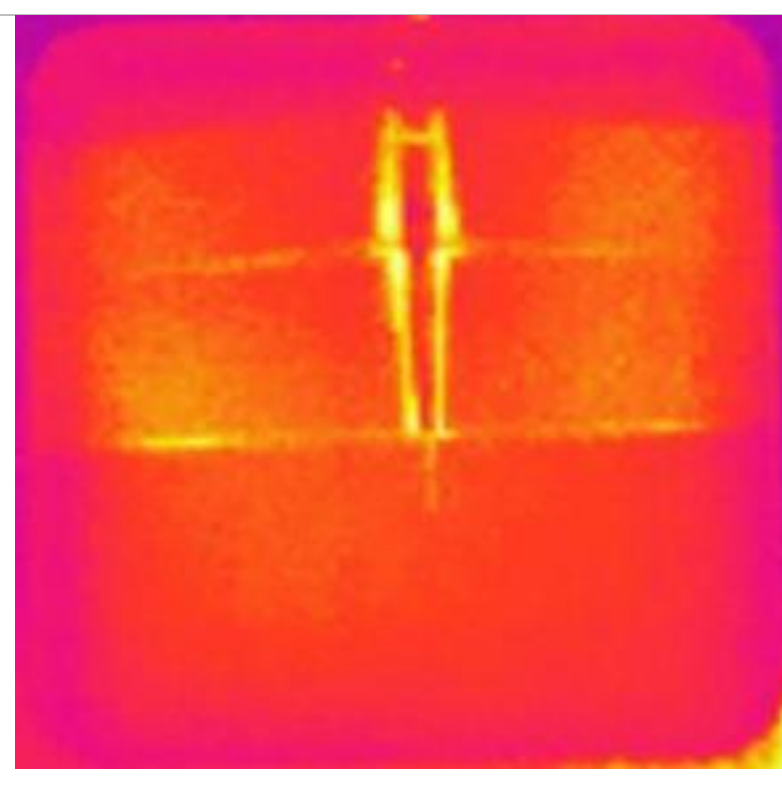

(b)

Figure 7.19: $1^{\text {st }}$ specimen for case ID 2c: (a) specimen after testing; (b) thermal image

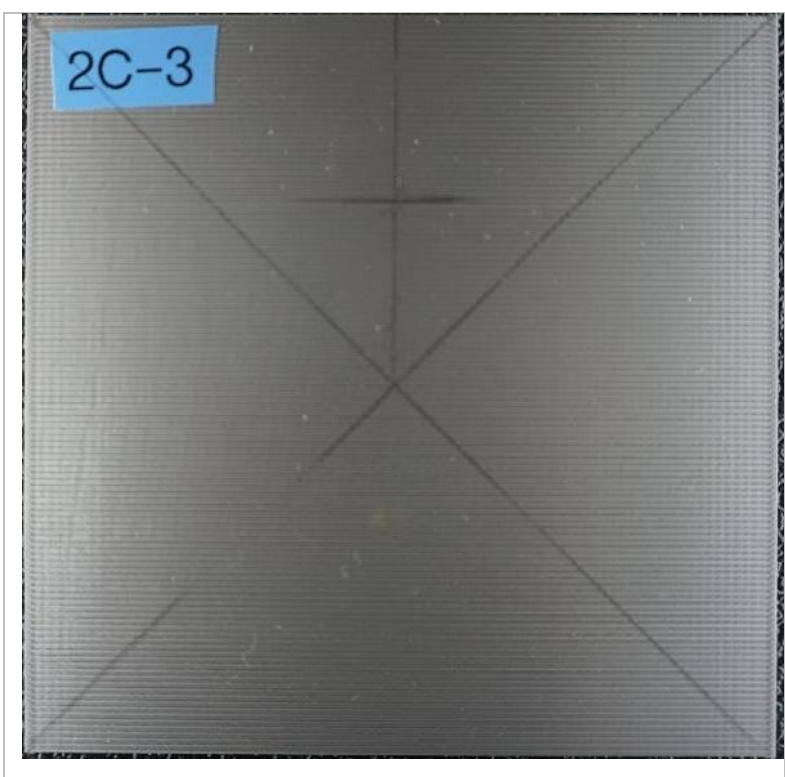

(a)

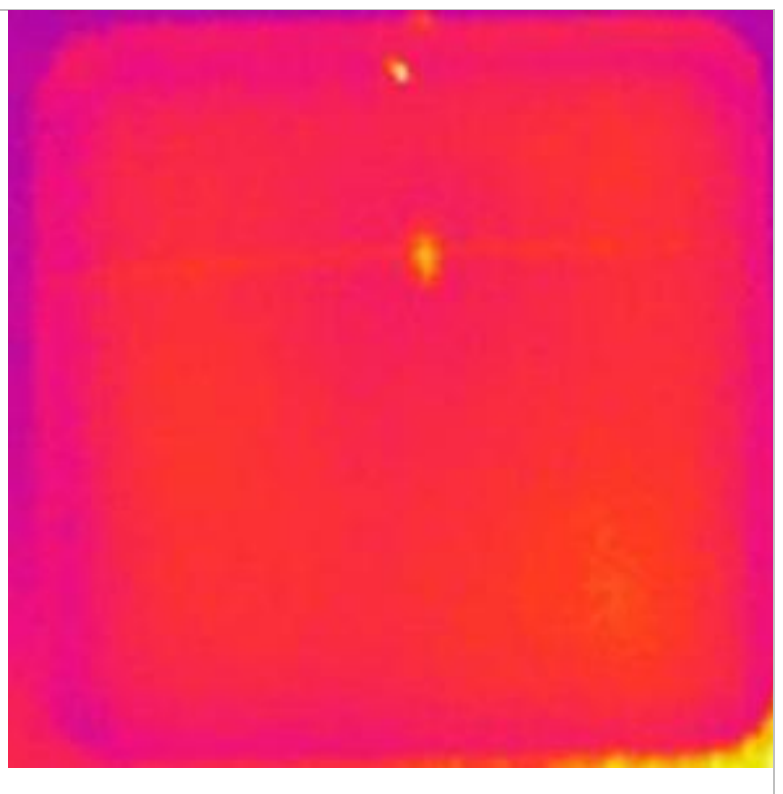

(b)

Figure 7.20: $2^{\text {nd }}$ specimen for case ID 2c: (a) specimen after testing; (b) thermal image 


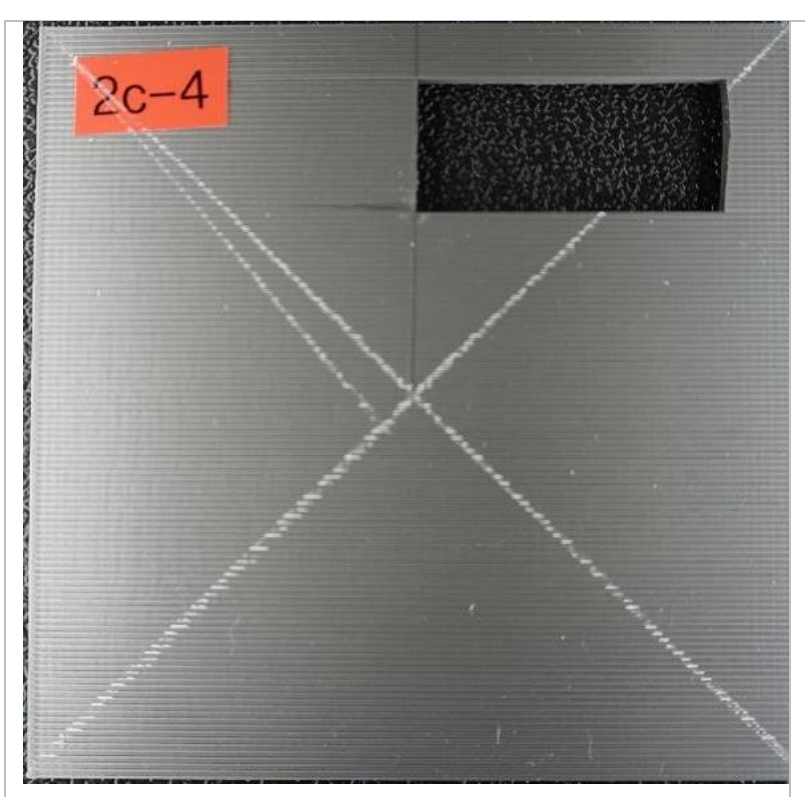

(a)

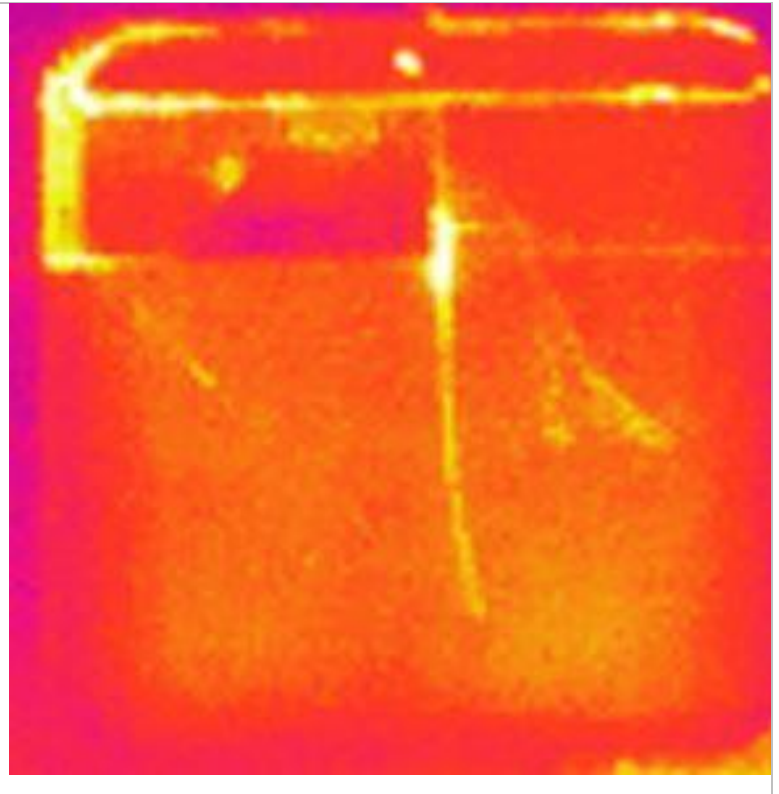

(b)

Figure 7.21: $3^{\text {rd }}$ specimen for case ID 2c: (a) specimen after testing; (b) thermal image

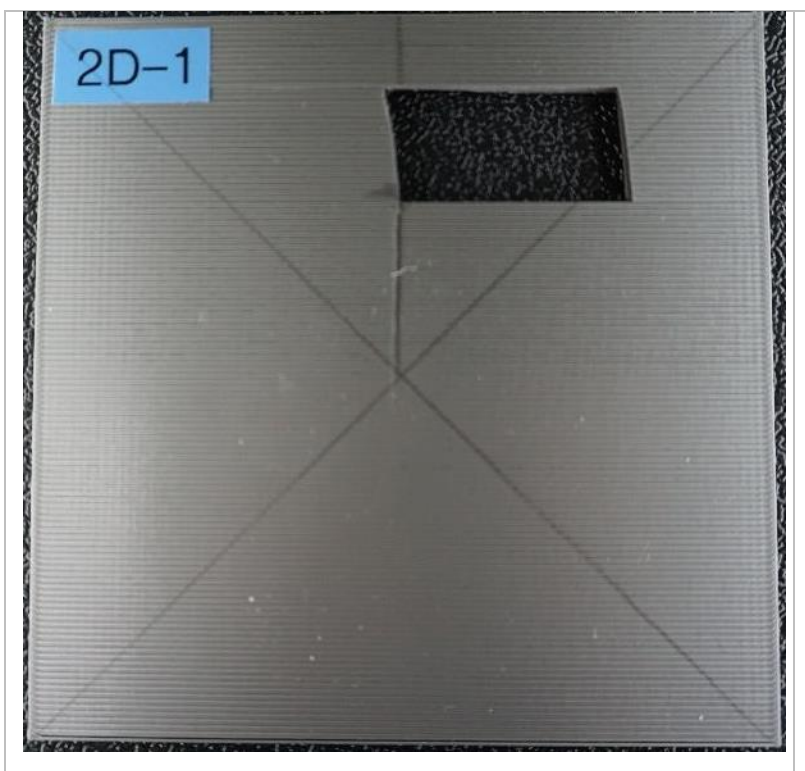

(a)

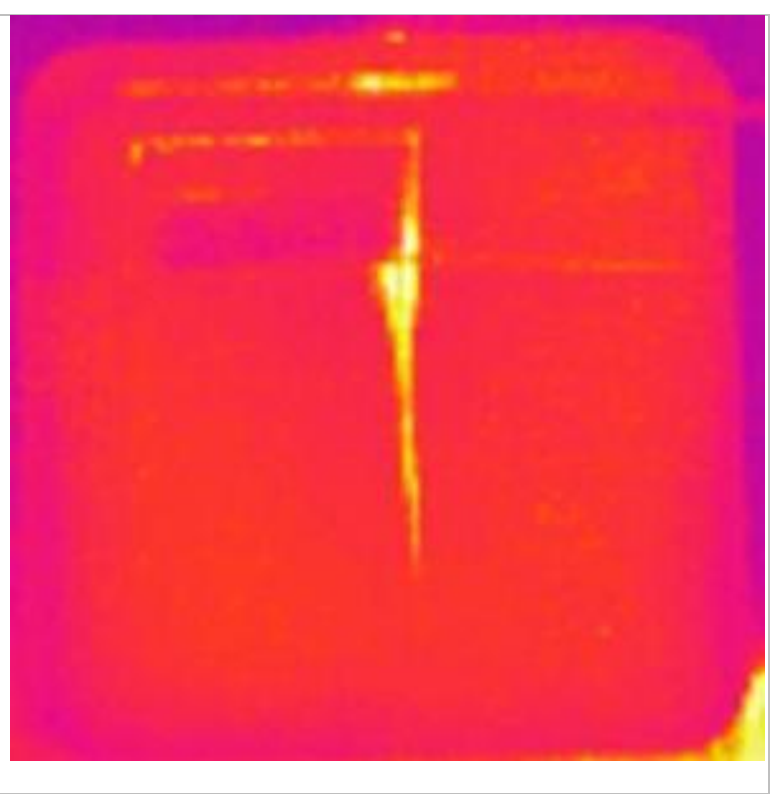

(b)

Figure 7.22: $\mathbf{1}^{\text {st }}$ specimen for case ID 2d: (a) specimen after testing; (b) thermal image 


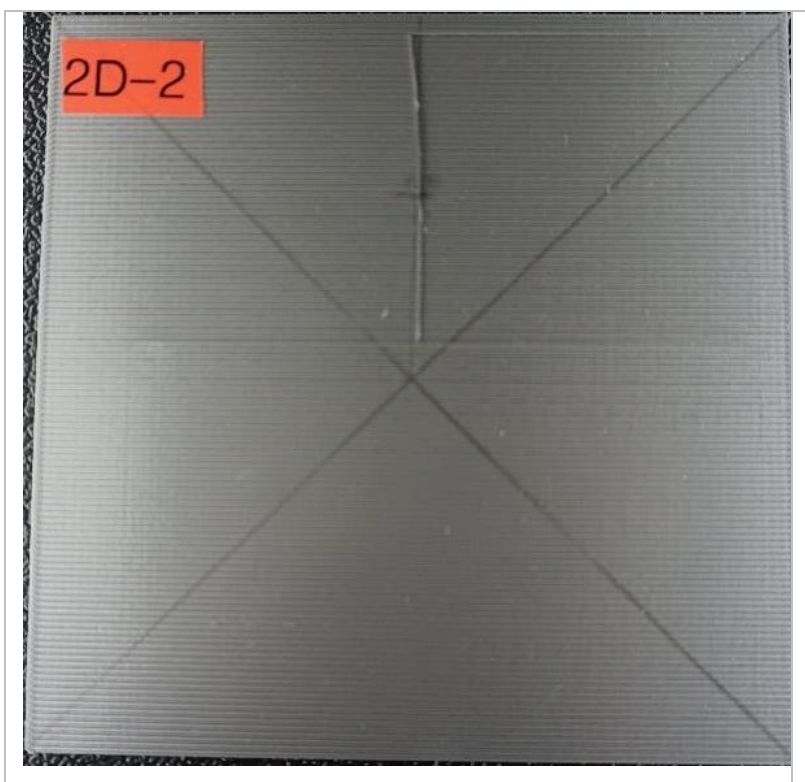

(a)

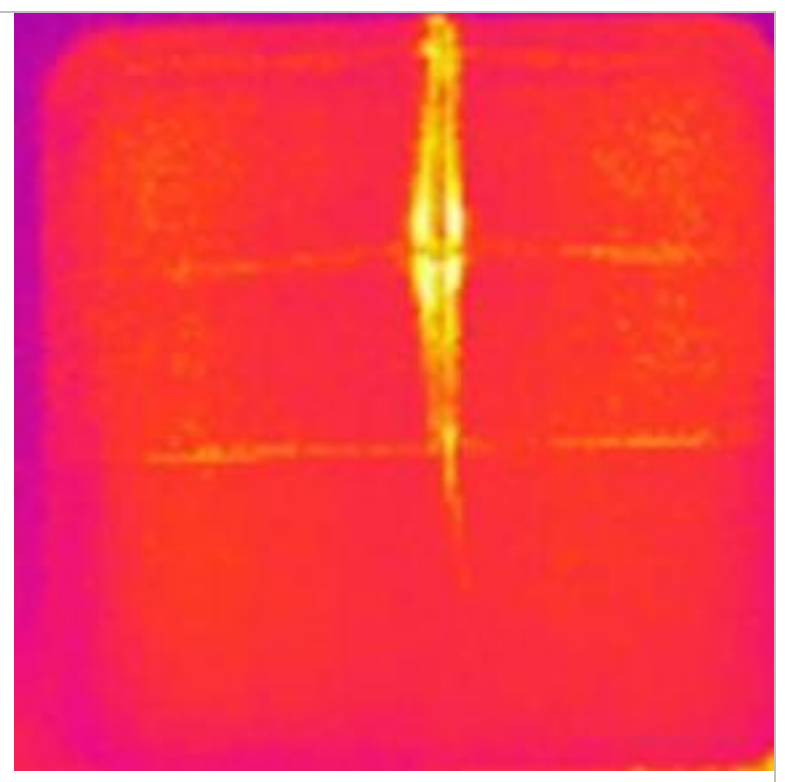

(b)

Figure 7.23: $2^{\text {nd }}$ specimen for case ID $2 \mathrm{~d}$ : (a) specimen after testing; (b) thermal image

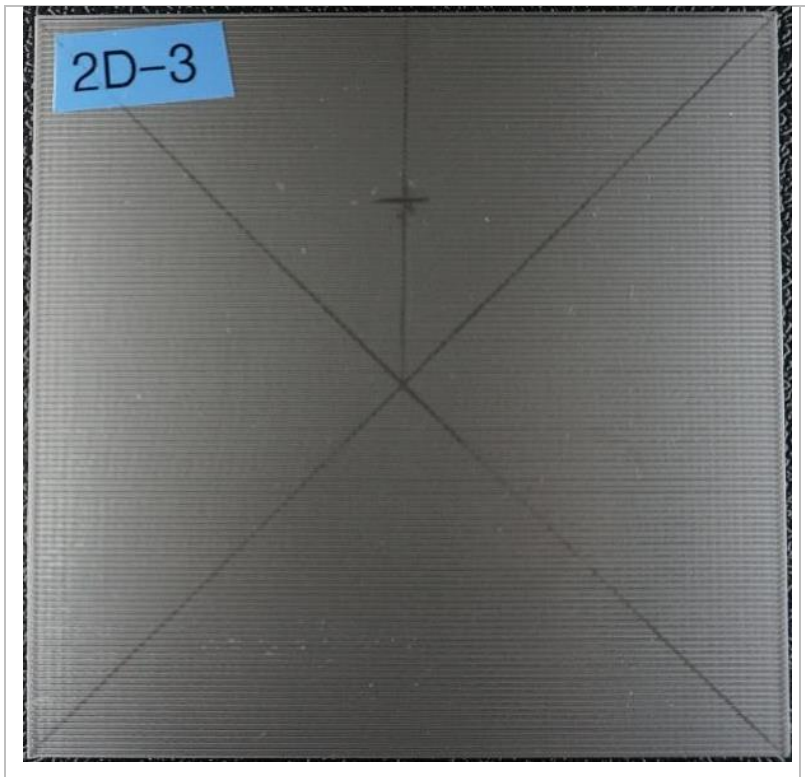

(a)

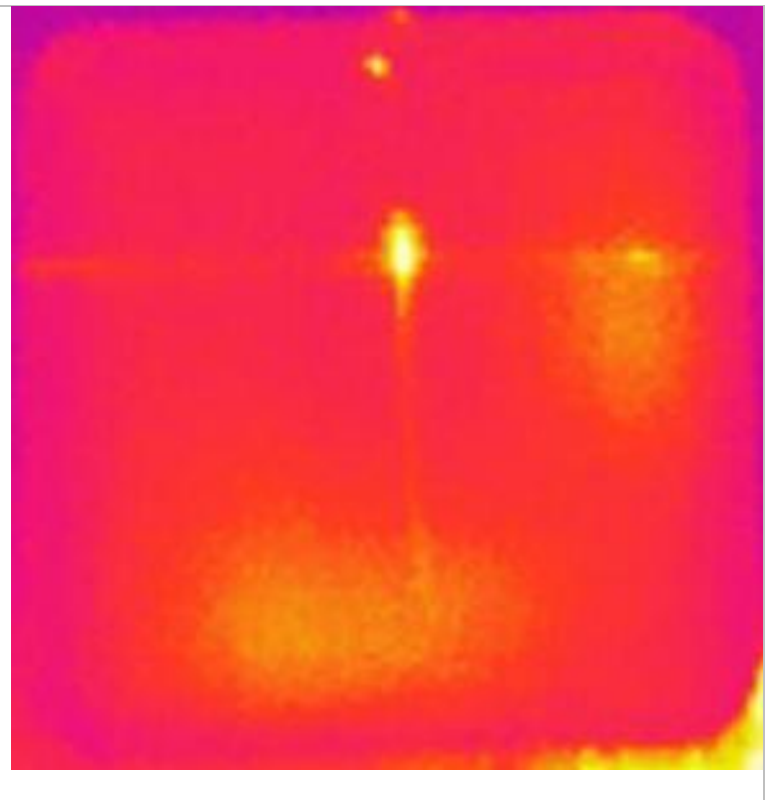

(b)

Figure 7.24: $3^{\text {rd }}$ specimen for case ID $2 \mathrm{~d}$ : (a) specimen after testing; (b) thermal image 


\section{REFERENCES}

1. Yeh, C. Trend analysis for the market and application development of 3D printing. auSMT, Vol. 4, No. 1, 2014.

2. Joshi, S. C.; Sheikh, A. A. 3D printing in aerospace and its long term sustainability, Virtual and physical prototyping, Vol. 10, No. 4 pp 175 - 185, 2015.

3. Ning, F.; Cong, W.; Qiu, J.; Wei, J.; Wang, S. Additive manufacturing of carbon fibre reinforced thermoplastic composites using fused deposition modelling. Composites Part B, 2015.

4. Blok, L. G.; Longana, M. L.; Yu, H.; Woods, B. K. An investigation into 3D printing of fibre reinforced thermoplastic composites. Additive Manufacturing, Vol. 22, pp 176 186, August 2018.

5. Rajpurohit, S. R.; Dave, H. K. Effect of process parameters on tensile strength of FDM printed PLA part. Rapid Prototyping Journal, Vol. 24, Issue 8, pp 1317 - 1324, 2018.

6. Sood, A.K.; Ohdar, R.K.; Mahapatra, S.S. Parametric appraisal of mechanical property of fused deposition modelling processed parts. Materials \& Design, pp 287 - 295, 2010.

7. Chockalingam, K.; Jawahar, N.; Praveen, J. Enhancement of anisotropic strength of fused deposited ABS parts by genetic algorithm. Materials and Manufacturing Processes, pp 2001 - 2010, 2016.

8. Dizon, J. R.; Espera Jr., A. H. Mechanical characterization of 3D-printed polymers. Additive Manufacturing 20, pp $44-67,2018$.

9. Ning, F. Additive manufacturing of carbon fiber-reinforced plastic composites using fused deposition modeling: Effects of process parameters on tensile properties. Journal of Composite Materials, p. 451-462, 2016.

10. Vidakis, N.; et al., Fused deposition modelling parts tensile strength characterisation. Academic Journal of Manufacturing Engineering, 2016.

11. Garg, A.; Bhattacharya, A. An insight to the failure of FDM parts under tensile loading: finite element analysis and experimental study. International Journal of Mechanical Sciences, pp 225 - 236, 2017.

12. Carneiro, O.S.; Silva, A.F.; Gomes, R. Fused deposition modeling with polypropylene. Materials \& Design, pp 768 - 776, 2015. 
13. Afrose, M. S.; Masood, S.H.; Nikzad, M.; lovenitti, P. Effects of Build Orientations on Tensile Properties of PLA Material Processed by FDM. Advanced Materials Research 1662-8985, Vol. 1044 - 1045, pp 31 - 34, 2014.

14. Dawoud, M.; Taha, I.; Ebeid, S.J. Mechanical behaviour of ABS: An experimental study using FDM and injection moulding techniques. Journal of Manufacturing Processes, pp $39-45,2016$.

15. Gomez-Gras, G.; Jerez-Mesa, R. Fatigue performance of fused filament fabrication PLA specimens. Materials and Design, 2018.

16. Beniak, J.; Križan, P.; Matúš, M. Experimental testing of PLA biodegradable thermoplastic in the frame of $3 D$ printing FDM technology. MATEC Web of Conferences 157, 06001, 2018.

17. Fischer, M.; Schöppner, V. Fatigue Behavior of FDM Parts Manufactured with Ultem 9085. Jom, pp $563-568.2016$.

18. Zaldivar, R.J.; Influence of processing and orientation print effects on the mechanical and thermal behavior of 3D-Printed ULTEM ${ }^{\circledR} 9085$ Material. Additive Manufacturing, pp $71-80,2017$.

19. Uddin, M.S.; Evaluating Mechanical Properties and Failure Mechanisms of Fused Deposition Modeling Acrylonitrile Butadiene Styrene Parts. Journal of Manufacturing Science and Engineering, 2017.

20. Chacón, J.M.; Additive manufacturing of PLA structures using fused deposition modelling: Effect of process parameters on mechanical properties and their optimal selection. Materials \& Design, pp $143-157,2017$.

21. Caminero, M.A.; Garcia-Moreno, I.; Rodriguez, G.P.; Chacon, J.M. 'Internal damage evaluation of composite structures using phased array ultrasonic technique: Impact damage assessment in CFRP and 3D printed reinforced composites.' Composites Part B: Engineering, v 165, p 131-142, 15 May 2019.

22. Caminero, M.A.; Garcia-Moreno, I.; Rodriguez, G.P.; Chacon, J.M. 'Impact damage resistance of 3D printed continuous fibre reinforced thermoplastic composites using fused deposition modelling.' Composites Part B: Engineering, v 148, p 93-103, 1 September 2018. 
23. Kao, Y.T.; Amin, A.R.; Payne, N.; Wang, J.T. 'Low-velocity impact response of 3D-printed lattice structure with foam reinforcement.' Composite Structures, v 192, p 93-100, 15 May 2018.

24. Mizera, A.; Bednarik, M.; Mizera, M.; Tomanova, K.; Mohorko, M. 'Tensile impact behavior of 3D printed parts on FFF/FDM printer Zortrax M200.' MATEC Web of Conferences, v 210, p 04049, 2018.

25. Tsouknidas, A.; Pantazopoulos, M. Impact absorption capacity of 3D-printed components fabricated by fused deposition modelling. Materials and Design, 2016.

26. Álvarez, K.; Lagos, R.F.; Aizpun, M. Investigating the influence of infill percentage on the mechanical properties of fused deposition modelled ABS parts. Ingeniería e Investigación, 2016.

27. Sugun, B.S.; Raso, R.M.V.G.K. 'Low-velocity impact characterization of glass, carbon and Kevlar composites using repeated drop tests.' Journal of Reinforced Plastics and Composites, v 23, n 15, p 1583-99, 2004.

28. Ismail, M. F.; Sultan, M. T. H.; Hamdan, A.; Shah, A. U. Md. 'A study on the low velocity impact response of hybrid kenaf-kevlar composite laminates through drop test rig technique.' BioResources, v 13, n 2, p 3045-3960, 2018.

29. Buang, Z. B.; Kashif, S. M. 'Simulation of low velocity impact test on carbon/epoxy composite plates.' Advanced Materials Research, v 1115, p 523-6, 2015.

30. Freeman, B.; Schwingler, E.; Mahinfalah, M.; Kellogg, K. 'The effect of low velocity impact on the fatigue life of sandwich composites.' Composite Structures, v 70, n 3, p 374-81, September 2005.

31. Es-Said, O. Effect of layer orientation on mechanical properties of rapid prototyped samples. Materials and Manufacturing Processes, pp 107 - 122, 2000.

32. https://www.mcanac.co.jp/en/service/detail/6a002.html?c1n=by+Property\&c1s=fun ction\&c2n=Mechanical+Property\&c2s=01

33. Sy, Benedict; Low Energy Pendulum Impact Testing Apparatus, Ryerson University 2016.

34. Sy, B.; Bougherara, H.; Fawaz, Z.; and Sarwar, A.; Low Velocity Impact Assessment of Kevlar/Flax- Epoxy Composite Using IR Thermography, CANCON 2017; May 2017. 